Portland State University

PDXScholar

Spring 6-3-2019

\title{
Learning From Culturally Specific Programs and Their Impact on Latino Parent Engagement
}

Analucia Lopezrevoredo

Portland State University

Follow this and additional works at: https://pdxscholar.library.pdx.edu/open_access_etds

Part of the Education Commons

Let us know how access to this document benefits you.

\section{Recommended Citation}

Lopezrevoredo, Analucia, "Learning From Culturally Specific Programs and Their Impact on Latino Parent Engagement" (2019). Dissertations and Theses. Paper 4997.

https://doi.org/10.15760/etd.6873

This Dissertation is brought to you for free and open access. It has been accepted for inclusion in Dissertations and Theses by an authorized administrator of PDXScholar. Please contact us if we can make this document more accessible: pdxscholar@pdx.edu. 
Learning From Culturally Specific Programs and Their Impact on Latino Parent

\section{Engagement}

by

Analucía Lopezrevoredo

A dissertation submitted in partial fulfillment of the requirements for the degree of

Doctor of Philosophy

in

Social Work and Social Research

Dissertation Committee:

Dr. Roberto Orellana, Chair

Dr. Ann Curry-Stevens

Dr. Alma Trinidad

Dr. Esperanza De La Vega

Portland State University

2019 
(C) 2019 Analucía Lopezrevoredo 


\begin{abstract}
Latinos are the largest and fastest growing ethnic minority group in the United States. Academically, they are significantly trailing their non-Latino peers in graduation and overall educational attainment. Among many socioeconomic factors, parent engagement has been identified as being a defining indicator of student success. Reflective of racial and class disparities, this study explored with the use of critical race and intersectionality theory, that low Latino parent engagement is a result of the historical devaluing and omission of Latino culture, history and language from formal academic settings, and compounding social factors that make engagement complex for Latino immigrants in America today.

In search of programmatic designs that better engage Latino families, this study explored a culturally specific program in San Francisco and its impact on engaging Latino immigrant parents. Using ethnographic methodologies, this study found via direct observation, a parent focus group, nine parent interviews and seven school personnel interviews that culturally specific programs can successfully build relationships, create inclusive spaces, counter ideas of deficit thinking, interrupt systems of oppression, and strengthen community engagement. Implications of this study on social work education, practice, and policy will be discussed.
\end{abstract}




\section{DEDICATION}

Esta disertación está dedicada a mi familia, la comunidad Latina, educadores que dedican su vida a empoderar a otros, y a todo los inmigrantes con un sueño. Nunca olvidemos que nuestro poder reside en nuestra cultura, historia y diversidad. Adelante y presente... si se puede! 


\section{ACKNOWLEDGEMENTS}

This journey would not have been possible without the endless encouragement, help and love from my advisor Roberto Orellana, dissertation committee members Ann Curry-Stevens, Esperanza De La Vega, and Alma Trinidad, and the School of Social Work's administration angel, Thet-Mar Win. Thank you for believing in this study and me.

I would also like to acknowledge my friends and family that have loved and supported me along the way. In particular, my PDX chosen family... you all make Portland home for me. This journey would have been impossible without all of you walking by my side. 


\section{TABLE OF CONTENTS}

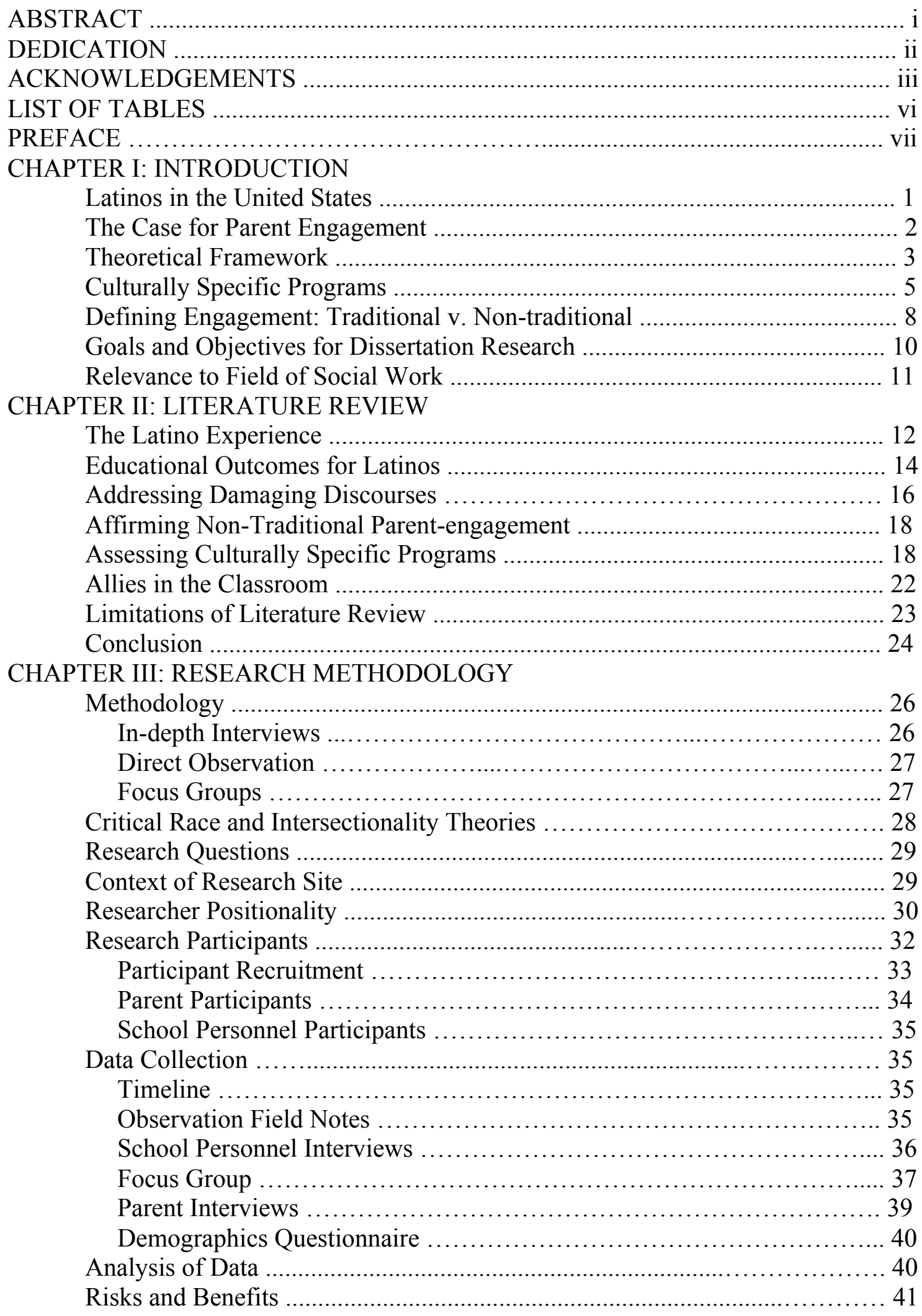


Limitations and Reflection on Data Collection ........................... 42

CHAPTER IV: RESULTS

Introduction ........................................................ 45

Themes of Parent Focus Group and Interview ............................ 45

Findings: Parent Stories ............................................ 47

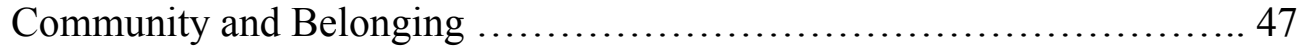

The Power of a Culturally Specific Program ........................... 54

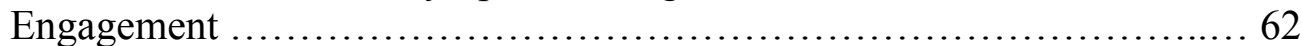

Resiliency ................................................... 81

Findings: Demographics Questionnaire .................................. 87

Themes of School Personnel Interviews ................................ 88

Findings: School Personnel Interviews ................................. 88

Institutional Culture of a Culturally Specific Program ................. 89

Engagement ........................................................ 98

Parent Resiliency ............................................... 103

CHAPTER V: DISCUSSION

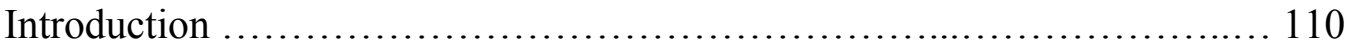

The Power of a Culturally Specific Program ............................... 111

Application of Critical Race and Intersectionality Theory $\ldots \ldots \ldots \ldots \ldots \ldots \ldots 117$

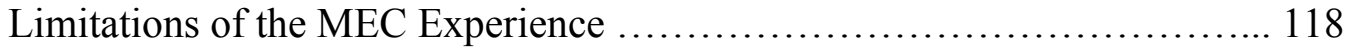

Critiques of Culturally Specific Programs ............................... 120

Study Limitations and Directions for Future Research .................... 121

Implications for Field of Social Work and Education .................... 122

Implications for Policy .......................................... 124

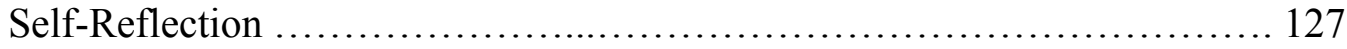

Conclusion ........................................................... 129

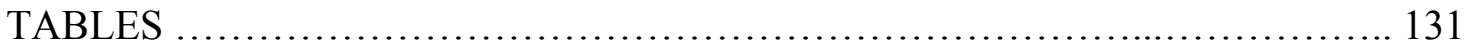

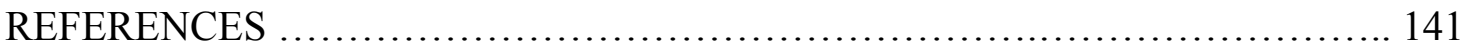

APPENDIX

A. Informed Consent Form (English) .................................. 153

B. Informed Consent Form (Spanish) .................................... 156

C. Demographics Questionnaire (English) ................................. 160

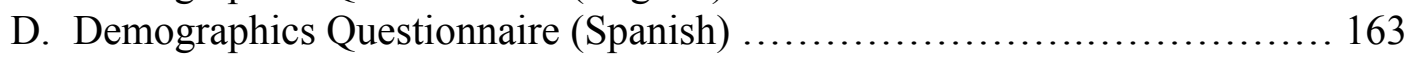

E. Recruitment Flyer ............................................. 166 


\section{LIST OF TABLES}

Table 1. Parent Participant Data

Table 2. School Personnel Participant Data .................................... 132

Table 3. Themes of Parent Focus Group and Interviews ....................... 133

Table 4. Questionnaire Findings (Part One) ................................. 134

Table 5. Questionnaire Findings (Part Two) ................................... 135

Table 6. Themes of School Personnel Interviews ................................ 136

Table 7. Parent Focus Group Guide x Research Questions ........................ 137

Table 8. Parent Interview Guide x Research Questions .......................... 139

Table 9. School Personnel Interview Guide x Research Questions .................. 140 


\section{PREFACE}

Since the 1980s, parent engagement in schools has been linked to various levels of student achievement (Eccles and Harold, 1996; Epstein and Dauber, 1991; Griffith, 1998; Henderson, 1987; Jimerson, Egeland, Sroufe, and Carlson, 2000; Mattingly et al., 2002; Shuang Ji and Koblinsky, 2009). As a result of numerous studies indicating that a positive correlation exists between the two, academic institutions across the United States have focused on increasing parent engagement in public schools. In spite of strong efforts, immigrant parent engagement — especially among Latinos — is still reported to be amongst the lowest. In evaluating past studies, however, I found that only certain parent behaviors were primarily being measured: On-site volunteering, parent-teacher conferences, parent-led initiatives, parent fundraising — all of which generally take place during school hours and in more affluent communities. While the aforementioned techniques are valid and proven to work in a number of situations, I believe from personal experience that these behaviors may not always be the most realistic for English-language learning, immigrant parents. Additionally, I believe that there are a number of other behaviors of engagement not being evaluated: Student-parent relationships, moral support, storytelling — most of which take place in Latino homes and communities. Due to this gap in the literature, I believe there is an opportunity for us to widen our understanding of how immigrant Latino parents engage with their children and their academic institutions.

As an immigrant to this country I can attest that my family's engagement was not always recognized or validated. My parents were English language learners, undocumented, and held multiple jobs. While efforts were made to engage and include 
them, these aspects of their identity made it difficult for them to engage in traditional parent programming that required for them to be on campus during typical work hours. Their lack of traditional participation, however, did not mean they did not engage with my educational experience.

I distinctly remember sitting around the dinner table with my parents, every night, discussing what I had learned in school. I remember my father teaching me his tips for memorizing math and science formulas, and my mother sitting with me to discuss world history and geography. I remember them continuously asking me what I wanted to do when I grew up, where I wanted to go to school, and I remember the tears in their eyes when they dropped me off for my first day of college. Just as vividly, I remember my teachers asking me why my parents didn't come to more school functions and why they didn't volunteer more often in the classroom. I remember feeling ashamed and I remember resenting both my parents for what I considered to be disengagement. It has been almost 15 years since I graduated high school and looking back I realize that my parents were not only engaged, they were deeply invested in my success. As a high school student, however, I didn't understand that their support at home was just as worthy as their support in the classroom. Looking back, my relationship with my school and my family were both great, but they were mutually exclusive. My family didn't interact with my school, and my school didn't interact with my family. And I do not think this needed to be the case. I believe that my elementary, middle, and high school institutions could have made a more conscious effort to understand my family's journey, but in all sincerity, I do not think my teachers and school administrators even knew where to begin. As a result of this realization, I have decided to dedicate this 
dissertation to better understanding what it takes to make the relationship between home life and school life—specifically for immigrant, Spanish speaking families—intersect. This exploratory study aims to explore how an existing parent engagement initiative at Mission Education Center (MEC) in San Francisco, CA operates, and the relationships between parents and school personnel that ensue as a result of their program. MEC's institutional mission is to transition new arrival students and their families into the American public-school system by carrying out a full Spanish instruction curriculum that gradually integrates English over two years. In addition to instruction, MEC looks to identify non-traditional ways in which to engage parents in their children's education so that when they transition to English schools, they have tools for success. Innovative, unique and always adapting, I plan to share my dissertation findings with MEC and the San Francisco Unified School District (SFUSD), so that they have as much information as possible moving forward. Lastly, I hope that this dissertation also helps inform advocates, educators, institutions and policy makers across the United States-but in particular on the west coast where Interstate 5 serves as a corridor for immigrants and connects them to California, Oregon and Washington-about different ways in which to collaborate with Latino families in and out of the classroom 


\section{CHAPTER I: INTRODUCTION}

Latinos in the United States

Making up $18 \%$ of the total population, Latinos are the largest ethnic and racial minority group in the United States (U.S. Census, 2015). According to the American Community Survey (ACS), most immigrants from Mexico settle in California (37\%), Texas (21\%), and Illinois (6\%), and more than half (56\%) of South American immigrants settle in Florida (24\%), New York (21\%), and New Jersey (11\%) (Migration Policy Institute, 2016). Of those that enter through California, many immigrants continue on to Oregon and Washington via to Interstate 5, making the Pacific Northwest one of the United States region's experiencing the most immigrant growth (Ruffenach, Worcel, Keyes \& Franco, 2016). Additional data from the Department of Homeland Security's (DHS) Yearbook of Immigration Statistics (2015), and the World Bank's annual remittance data (2015) indicates that like Oregon and Washington, other western statesdue to their work industries and natural immigration routes - are steadily becoming popular amongst Latino immigrants (Zong \& Batalova, 2016).

Latinos have had a presence in Oregon and Washington since the early 1800s when a large number of Mexican migrant workers moved north to pursue work as vaqueros, or cowboys, and gold miners (Ruffenach et al., 2016). In the early 1900s, a growing need for workers in the agriculture and railroad sectors brought several more waves of Latino migrants, and in 1980s, the United States' Latino population more than

doubled with the arrival of many Central and South American immigrants escaping civil war (We The American Hispanics, 1993). While Oregon and Washington were not 
amongst the most popular states for Latino immigrants in the $20^{\text {th }}$ century, the last 17 years have proven that more and more Latinos are making the Pacific Northwest their home (Parks, 2016; Rivera, 2017; Ruffenach et al., 2016). Today, Latinos are largest minority group in both Oregon and Washington, and Oregon's Latino population is reported to be growing faster than the nationwide average (Parks, 2016).

According to Latinos in Oregon, a report from the Oregon Community Foundation, the Latino population in Oregon increased by $72 \%$ between $2000-2016$, compared to only 50\% nationwide (Ruffenach et al., 2016, p. 2). At the time of the report, nearly 474,000 Latinos lived in 36 counties across Oregon, up from 275,000 in 2000. Of this number, 23\% were K-12 students, and the majority reported speaking Spanish at home, with half identifying as bilingual (p. 5-8). Looking towards the future, the U.S. Census Bureau predicts that Latino students will make up one-third of the nation's child population by 2036 .

The Case for Parent Engagement

Numerous studies demonstrate that parent engagement is highly correlated to student achievement, overall attendance and engagement, and increased positive attitudes toward learning (Eccles and Harold, 1996; Epstein and Dauber, 1991; Griffith, 1998; Henderson, 1987; Jimerson, Egeland, Sroufe, and Carlson, 2000; Mattingly et al., 2002; Shuang Ji and Koblinsky, 2009). More specifically, it is positively correlated to a student's mathematical achievement (Crane, 1996; Muller, 1998; Senechal and LeFevre, 2002), reading attainment (Jeynes, 2001; Shaver and Walls, 1998) and other subject 
matter success (Jasis and Ordonez- Jasis, 2012; Jeynes, 2001; Zdzinski, 1996). Plainly stated, a parent's involvement in their child's educational experience plays a role in their student's academic success (Epstein, 2009; Garcia and Jensen, 2009; Ordoñez-Jasis and Jasis, 2004). Given the US Census Bureau's estimate that one-third of the nation's child population will be Latino by 2036, it is imperative that we continue to learn how weeducators and school workers — can best serve this population (Arvizu, 1992; Bermudez and Marquez, 1996). In order for us to do this, it is imperative to widen our understanding and definition of what it means to be engaged, and invite Latino parents to be a part of this reimagining process

Theoretical Framework

Critical race theory explains that communities of color in the United States have been historically disenfranchised, devalued, "othered," and excluded from opportunities to evoke systemic change or contribute to mainstream culture, as opposed to Whites (Crenshaw, 1998; Leonardo, 2013). Intersectionality theory complements that thinking by adding that social constructs such as race, class, language and immigrant status also add to the level of oppression people of color experience, often leading to hierarchies that place community members against one another (De Gaetano, Williams and Volk, 1998; Inger, 1992; Ladson-Billings and Tate, 1995; Nicolau and Ramos, 1990).

As it currently stands, Latino parent engagement in traditional programs remains low (DeGaetano, 2007), but there is no single reason why. Instead, researchers have recognized a number of factors that often compound together and make it difficult for 
parents to engage in traditional behaviors. Some factors include 1) language, 2) immigration status, 3) past histories with authority, 4) fear of discrimination, 5) work schedules, 6) gender roles and 7) mental health (De Gaetano, Williams \& Volk, 1998; Inger, 1992; Ladson-Billings \& Tate, 1995; Nicolau \& Ramos, 1990). These compounding factors support the theory of intersectionality, which recognizes that social problems experienced by a group of people, is generally the result of numerous discriminations and disadvantages compounding (Crenshaw, 1998; Leonardo, 2013).

From a critical race perspective, the U.S. education system was not created with communities of color in mind. The historic curriculum and class experience was reflective of a community with access, freedom, influence and voice. Though times have changed, racism, classism, sexism remains prevalent in the education system. Ethnocentric studies have gained popularity, but still those studies are seen as elective to mainstream culture and are not offered in many communities.

While it is important to recognize the many barriers Latino immigrants face, it is imperative that we understand that these barriers do not equate to deficit thinking. Aware of the disparaging narratives that exist about Latinos, this study aimed to counter deficit thinking narratives by giving immigrant parents an opportunity to share their story, and by giving school personnel the chance to share what educational and political structures they think continue to oppress immigrant parents. These voices, collected via interviews and focus groups, are an important addition to our fight for educational and racial equity, and are an invitation to other researchers to continue exploring more narratives. 
Paulo Freire's critical race framing in Pedagogy of the Oppressed (1968) was a study designed to elevate voices from a community that was historically silenced and unheard (Smith-Maddox \& Solórzano, 2002). Inspired by Freire's work, this dissertation sought to also give historically oppressed people the opportunity to share their story and have their voice heard. With the use of ethnographic methodologies, that included a focus group and one-on-one interviews, this study was designed to elevate immigrant Latino voices, its cultural values, and disrupt damaging discourses that emerge as a result of social and systemic inequities. Furthermore, by studying a culturally specific program, this study aimed to shed light on the power these programs can have in interrupting Anglonormativity in education (Crenshaw, 1998; Leonardo, 2013).

\section{Culturally Specific Programs}

Culturally specific programs are defined by their intended design to serve a particular community of color's experience (Curry-Stevens, Deloney \& Morton, 2018). Also referred to as "culturally focused," these interventions are primarily staffed by professionals with a personal tie to the community being served, and have a record of successful community engagement (Lawson \& Alameda-Lawson, 2011). When created to support immigrant communities, these programs are designed to be bilingual, and pay close attention to the social complexities that can make integration difficult for immigrants— such as linguicism, classism, racism and uncertainty around immigration status (De Gaetano, Williams \& Volk, 1998; Dragnea \& Erling, 2008). Furthermore, by being bilingual, culturally specific programs demonstrate and model that a community's 
native language is one of knowing and of value (Dei \& Asante, 2013; Gulson \& Webb, 2012). In comparison to programs that are created with dominant culture in mind, culturally specific programs have a deeper impact on the communities they serve.

Birthed in response to the failure of mainstream organizations' ability to effectively serve communities of color, culturally specific design in education has resulted in numerous ethnocentric movements that address the levels of racial disparities in the education system (Dei \& Asante, 2013; Gulson \& Webb, 2012; Guo \& Guo 2011). More specifically, they aim to solve the disproportionate achievement, discipline, engagement, graduation, and higher education attainment gap between communities of color and White students (Dei, 2006; Farthcloth \& Tippeconnic, 2010; Fryberg, Covarrubias \& Burack, 2013; Pedroni, 2007; Shockley, 2007; Shockley \& Frederick, 2010; Dragnea \& Erling, 2008 as cited in Curry, Deloney \& Morton, 2018).

Today, scholars that study culturally specific programs have identified a set of key elements that ground this type of work. The first component is inclusivity, by means of designing a program that eliminates community members' "outsider" status (Curry, Deloney \& Morton, 2018; Gulson \& Webb, 2012; Guo \& Guo 2011). As critical race theory describes, communities of color have been subjected to ongoing racism as a result of the U.S. education system's subjective Anglonormativity (Ladson-Billings, 2008; Leonardo, 2013; Smith-Maddox \& Solórzano, 2002). Since White culture has informed the design of many systems - placing Whites as the primary beneficiaries and "insiders" of these systems (Ladson-Billings, 2010) — culturally specific programs aim to disrupt this reality by granting the community members being served access to "insider" status 
(Dei, 1996, Dei \& Asante, 2013; Dragnea \& Erling, 2008). This, however, can only be achieved if the program's leadership team shares ties to the community being served, as this tie to shared culture and history, allows for deeper relationships to be built among service providers and community members (Beresford, 2000; Butcher, 2008).

Other key characteristics that define culturally specific programs are their inclination towards advocacy, their holistic response to need, their focus on relationship building, their emphasis on mutual respect, and their commitment to affirming and recognizing community members and their accomplishments (Curry-Stevens, Deloney \& Morton, 2018; Dei, 2006; Fryberg, Covarrubias \& Burack, 2013; Pedroni, 2007; Pon, 2009; Shockley, 2007; Shockley \& Frederick, 2010). Centered around social action, these programs also actively work to eliminate barriers that have historically oppressed the community being served. This key element also leads to the thoughtful exploration of a community's culture, experience, identity and history independently and within dominant culture (Dei \& Asante, 2013; Guo \& Guo, 2011; Gulson \& Webb, 2012). In short, culturally specific programs are an anti-oppressive, critical approach to the failed concept of cultural competency (Fryberg, Covarrubias \& Burack, 2013; Sakamoto, 2007; Utall, 2006).

Designed to address the historical omission of non-White culture, culturally specific programs have proven to "meet the needs of communities of color, both in terms of improving individual health and well-being outcomes and also in terms of improving social capital by engaging in community development and systemic advocacy" (Hohman \& Gait, 2001; Takeuchi, Sue \& Yeh, 1995; Yeh, Takeuchi \& Sue, 1994). More 
specifically, culturally specific services have been found to "improve client retention, affirm racial identity and pride" and "help clients avoid sticking out as 'other' and thus provides a culture of inclusion for clients of color" (Scheppers, van Dongen, Dekker, Geertzen \& Dekker, 2006; Takeuchi, Sue \& Yeh, 1995; Uttal, 2006 as cited in Curry, Deloney \& Morton, 2018). Though informed by numerous literary works, this study also sought to identify additional key elements that would help the field of social work further define characteristics of culturally specific programs.

\section{Defining Engagement: Traditional v. Non-traditional}

Parent engagement is an umbrella term used to describe the numerous ways in which parents support their children's education. While "the term is a multidimensional construct that encompasses parents' activities at home, at school, and in the community" (Epstein, 1995), this dissertation will define engagement with two terms: Traditional and non-traditional engagement. Traditional engagement refers to formal school-based behaviors like parent-teacher conferences, in-class and off-site volunteering, and participation in parent leadership initiatives like parent teacher associations (PTAs). The term non-traditional engagement will refer to informal school and home-based behaviors that provide children and their families creative, culturally sensitive solutions to engagement.

Traditional parent engagement programs have long been a staple of the U.S. education system, yet compounding factors like language barriers, educational background, immigration status and work schedules have all contributed to lower 
engagement rates by Latino parents (Auerbach, 2004; Behnke \& Kelly, 2011; Leonardo, 2013). In a 2011 study conducted by Behnke \& Kelly, Latino parents revealed that their inability to volunteer during school hours and their insecurity to communicate in the English language prevented them from forming significant relationships with school personnel and other parents. This led to them feeling unwelcomed at school and incapable of contributing to their child's school culture and environment (p.10). Zeus Leonardo critically points out that these feelings are a result of a system that was not set up for immigrant parents to succeed (2013). Anglo-normative in nature, meaning that they were designed by and for White people (Solórzano \& Delgado, 2001), traditional engagement initiatives leave many minoritized people struggling or failing within a system. Our failure as educators and social workers to address a community's culturally specific needs leads to deficit thinking — the idea that children and families from “immigrant groups don't have the 'right culture' to succeed in school—and further isolates a community from educators (Abdi, 2016).

In order to interrupt notions of deficit thinking and strengthen the relationship between the immigrant Latino community and U.S. educators, we must begin by understanding the social, political, and economic constraints that have historically prevented immigrant parents from traditionally engaging in their children's physical school environment (Crenshaw, 1998; Leonardo, 2013; Solórzano \& Delgado, 2001). We must then explore if and how culturally specific initiatives - designed by and for Latinos - can bridge the relational gap between parents and school personnel and result in educators better supporting culturally specific engagement. By taking a step back to 
apply a more critical review of the experience of Latino immigrants in the United States, school personnel can begin to reform damaging programmatic designs that were not made with all community experiences in mind.

Goals and Objectives for Dissertation Research

The goal of this study is to explore the function and results of a culturally specific school program that uses non-traditional strategies to strengthen parent engagement. Designed to address the specific needs of newcomer Latino immigrant families in the San Francisco Bay Area, Mission Education Center (MEC), is also staffed by an entirely bilingual team with personal ties to Latino culture. Seeing as the value of culture and cultural capital is at the root of this dissertation, this study will also assess the impact that bilingual educators and educators of color have on 1) building relationships with parents 2) helping identify, affirm, and support non-traditional forms of parent engagement at home, and 3) affecting overall parent engagement on and off campus. The second, but probably more important goal was to give MEC parents as much opportunity to share their stories of fear, resiliency and success. Fully aware of the limited opportunities immigrant people have to freely express their feelings, thoughts and their experience, this study aimed to be give as many parents as possible the chance to be heard in an academic setting. 


\section{Relevance to Field of Social Work}

Education social workers are crucial to maintaining the integrity of schools and communities. "They are often called on to help students, families, and teachers address problems such as truancy, social withdrawal, overaggressive behaviors, rebelliousness, and the effects of special physical, emotional, or economic problems" (Barker, 2003). At schools with high immigrant populations like Mission Education Center (MEC), social workers are called on to help newcomer families navigate various struggles associated with immigration, like trauma, homesickness and loneliness. Given the economic and social constraints many immigrant families have, education social workers often become the only mental health professional a student or parent comes in contact with for years. Due to these reasons - and the predicted growth of immigration to the United States - it is important that the field of social work gain more insight on how to best serve diverse newcomer populations. With this in mind, this study aims to widen the field's understanding of how education social workers can complement the work educators are doing with culturally specific programs, and hopes to encourage schools of social work to development more specialized tracks for graduate students interested in serving in culturally specific educational programs. 


\section{CHAPTER II: LITERATURE REVIEW}

The Latino Experience

Latin America is a large geographical area that stretches from Mexico to Chile, includes parts of the Caribbean, represents 20 Spanish-speaking countries, and an innumerable amount of cultures and traditions (Martinez \& Castillo, 2013). Due to its size, Latinos — people who are from, or are descendants of this region—represent a wide range of stories, ideals, traits and dreams (Lopez, Gonzales-Barrera, López, 2017; Vega, 2016). From people's physical appearance, to a particular region's cuisine and jargon, there are many factors that contribute to the Latino community's diversity. Even within each Latin American country, there are a wide number of lived experiences prior to immigrating to the United States that will contribute to their experience of integration or segregation (Martinez \& Castillo, 2013). Once in the United States, many immigrants from Mexico, the Caribbean, and Central and South America may find themselves bonding over entertainment and language — but this does not mean their experience and identity are equal, or that they will form relationships with one another. To add another level of complexity, there is growing number of Latino migrant laborers whose first language is a native/indigenous language, and therefore may never build bonds with other Latino immigrants whose first language is Spanish (Lo Wang, 2014; Semple 2014). All of this is important to note, as being labeled Latino does not mean one stands or connects with Latino struggles or identity.

Immigrant status is another factor that contributes to the diversity of Latino experiences in the United States. It can also be a point of tension amongst Latinos who 
feel another Latino group's immigration status misrepresents their own community (Lawson \& Alameda-Lawson, 2011; López, 2010; McCarthy, 2015). Between 1930 and 1980, Latinos from places other than Mexico nearly doubled their population in the United States, growing from $22.4 \%$ to $40.6 \%$ overall. Puerto Ricans started rapidly migrating to the United States' northeast after they were granted U.S. citizenship by President Woodrow Wilson in 1917, and Cubans primarily arrived to the United States in the years following the 1958 Cuban Revolution, growing from 79,000 to 439,000 in a decade (Batalova \& Zong, 2017). Civil wars and political instability also led many Central Americans to migrate north beginning in the 1980s. By 2015, the "Central American immigrant population grew nearly tenfold," with many being granted protection from deportation (Lesser \& Batalova, 2017).

It is important to understand the complexities that affect relationships within the Latino community. Latino immigrants who arrived in the early $20^{\text {th }}$ century, or were granted asylum from communist oppression or civil war, gained legal status much faster than other immigrant groups who could not prove special humanitarian provisions (Batalova \& Zong, 2017). Many immigrants who experienced a speedy immigration process feel a false sense of "seniority" and superiority towards undocumented immigrants and their needs, and this continues to be divisive at an institutional and government level (Lawson \& Alameda-Lawson, 2011; Martinez \& Castillo, 2013, McCarthy, 2013). Today, more than 15 million undocumented immigrants who illegally crossed the border, or overstayed a tourist visa to come to the United States, are in a state of influx regarding their ability to stay in the United States (Glass, 2012; Gonzalez- 
Barrera, 2017; Krogstad, Passel \& Cohn, 2017). This sense of instability leads many undocumented people to fear and mistrust institutions and their representatives, resulting in refusal to interact with people outside of their direct community in order to ensure survival (Kang, 2017; Keierleber, 2017).

Only after understanding the complexities of the Latino experience in the United States can we begin to build ties with specific Latino communities. In order to do this, community leaders, educators, school personnel and policy makers need to stretch their identity as "knowers" and "experts" and become "learners" and "listeners" (Taylor, Lopez, Martinez \& Velasco, 2012; Quiocho, 2016). Described by Ray Chow (1993) as having an uncanny source of knowledge and subjectivity, immigrants have significant insight to share regarding their community's culture, identity and needs (Leonardo, 2013, p. 134). If we want to truly build bridges and reach more Latino families, we must begin by inviting them to the design-thinking table, listen to what they have to say, and move forward as a unit. Only then can we break down unnecessary power dynamics plaguing current engagement efforts, and more effectively understand, engage and impact Latino communities

\section{Educational Outcomes of Latinos}

Latinos are the largest and fastest growing ethnic minority group in the country, but academically they are significantly behind their non-Latino peers. "Upon entering kindergarten, $42 \%$ of Latino children are found in the lowest quartile of performance on reading readiness compared to just 18\% of White children" (Gándara \& Contreras, 2008). 
A 2005 study found that only $16 \%$ of Latino students were proficient in reading by fourth grade (compared to $41 \%$ of White students), and only $15 \%$ were proficient by eighth grade (compared to 39\% of White students) (National Assessment of Educational Progress, 2005). Fast forward to high school and Latino students are also at a higher risk than their Black, Asian and White peers of dropping out (Chavez, 2017). In spite of this risk, their dropout rate has dramatically decreased over the last ten years. In 2016, U.S. Census Bureau Data reported that the Latino dropout rate had dropped to $10 \%$, six percentage points less than it had been five years earlier (Gramlich, 2018). While this change is significant, it is important to take note that high school graduation does not equate to enrolling in an institution of higher education or graduating with a college degree - something that is largely associated with financial and professional success in the United States (Cunningham, 2016).

According to a 2015 publication, The Condition of Latinos in Education, education attainment remains much lower for Latinos than that of any other group. Furthermore, while Latino students make up a quarter of our country's K-12 student population (U.S. Census Bureau), they are half as likely—when compared to White students - to hold a college degree (Barshay, 2018). In 2016, 47\% of Latino high school graduates between the ages of 18 to 24 were enrolled in a higher education institution. While this number was up from $32 \%$ in 1999 , another study found that only $22.6 \%$ of Latinos actually graduated with higher education degrees (The Education Trust, 2016). When specifically looking at undocumented Latino students, this percentage was lower, with only $17 \%$ of them graduating — something likely associated with their inability to 
qualify for "in-state tuition at public colleges or obtain federal financial aid" (Barshay, 2018). While new research shows that Latinos are closing the racial gap on college degrees, they are still lagging far behind Whites (Kolodner, 2017). This lag matters, as failing to address it will continue to predispose Latinos to lower economic opportunities.

The reason why Latino students are falling behind their peers in K-12 and higher educational settings is complex. Ultimately, “every educational experience from early childhood to high school and into the workforce influences the potential for success," and therefore, if our nation hopes to overturn the status quo for Latinos, elementary, intermediate and secondary school experiences need "intense and immediate strengthening" (Brown, 2014). Amongst the ideas for Latino education reform is supporting the creation of more culturally specific school programs designed and staffed by a diverse network of Latinos (Jasis \& Ordoñez-Jasis, 2012). These culturally specific programs offer Latino families the opportunity to connect to the U.S. education system without compromising their own culture and have over time proven to strengthen student and parent engagement--two things directly associated with student graduation (Cardona, Holtrop, Cordova, Escobar-Chew, Tams, Villarruel, Villalobos, Dates, Anthony, \& Fitzgerald, 2009). While these programs are limited, many educators around the country are interested to see how they may change the current trajectory of Latinos in education.

\section{Addressing Damaging Discourses}

While numerous barriers such as language, immigration status, and fear have historically prevented many Latino parents from engaging in traditional programs, it has 
not completely kept them from engaging with their students at home and in other community settings (Daniel-White, 2002; López, 2010). The gap in our research, however, has brought about damaging discourses that have led many educators, school personnel, and community members at large to erroneously believe that Latino parents feel ambivalent toward their children's education (Leonardo, 2013; Leonardo \& Grubb, 2013). This form of discrimination is deeply rooted in racism and unfairly punishes Latino students, their parents, and the larger community due to a "perceived limitation" that makes them unable or unwilling to participate (p. 127). This culture of poverty argument which absolves social systems of their role in perpetuating social injustices, position Latino students and their families as "damaged and damaging" to the educational system (Glazer \& Moynihan, 1970; Leonardo, 2013, p. 127). As a result, we further isolate communities of color and continue to foolishly wonder: Why are they not engaged? And why do they not trust us?

One matter that has somehow been overlooked in social literature is that immigration to the United States is not unique to people of color. Zeus Leonardo (2013) aptly points out that the idea of "Whiteness conveniently forgets its own history of immigration from European lands" (p. 134). "It forgoes the knowledge that stems from such historical disjuncture" and places all the "othering," or newcomer status, on people of color. As such, community leaders, policy makers and school personnel have a responsibility to challenge inaccurate race representations of Latinos in the media, and counter misleading studies that have proven to be culturally insensitive to the experiences of immigrant families. 


\section{Affirming Non-traditional Parent-engagement}

Non-traditional parent engagement behaviors present themselves in a myriad of ways in Latino communities (Auerbach, 2007; López, 2010). Numerous studies indicate that Latino parents excel at engaging with their children at home by providing them with extensive moral support, and using storytelling as a tool in which to connect children to their cultural background and parents to their children's learning (Daniel-White, 2002; Lopez, 2001; Zarate 2007). These behaviors, though "non-traditional" successfully engage parents and students in learning and therefore should be more widely researched, validated and supported (Auerbach 2007). Believing there is still a lot to learn from these behaviors, this study sought to understand if and how culturally specific programs make room for Latino parents to more openly share the ways in which they engage with their children at home, and how—as a result of stronger relationships between parents and school personnel—educators might then support that learning with supplemental material and tools.

\section{Assessing Culturally Specific Programs}

Community specific programs have become increasingly popular over the last 30 years, as their method of inviting community members to be equal partners in the ideation, development and implementation process of an intervention has proven to strengthen parent engagement and parent-educator relationships (Lawson \& AlamedaLawson, 2011, p. 658). The designs of these programs also vary based on the recommendations of parents. Some are designed to take place on campus, others off-site, 
and all are created to hold space for the unique experience and needs of a particular community (Auerbach, 2007; Darder, 1991). Centered around culture, these programs rely on community leaders, parents, program designers and school personnel to collaboratively work together to identify what would work best in a specific community (Delgado-Gaitan, 1994; Jasis \& Ordoñez-Jasis, 2000, 2004; Quiocho \& Rios 2000). Reliant on partnerships, this method of programmatic design interrupts power dynamics that typically leave parents feeling as if they are ill-prepared to participate, and also yields higher problem-solving opportunities for the community itself (Jasis \& OrdonezJasis, 2012; Lareau, 1989, 1984). In reading through the literature, three culturally specific programs stood out as being worthy of further exploration: La Familia Initiative, Project Avanzado, and Community Action Network (CAN).

La Familia Initiative was created by a group of 5 Latino immigrant mothers at a Northern California middle school (Jasis \& Ordonez-Jasis, 2012, p. 73). At the time of formation, the school had recently experienced a rapid growth in their Latino population - almost tripling in two years (Jasis \& Ordoñez-Jasis, 2012). The initiative was designed and carried-out entirely by parents, enabling them to "forge safe spaces of trust and solidarity" throughout the organizing effort (Jasis \& Ordonez-Jasis, 2004, p. 35). After six months, the size of La Familia grew to 115 parents (p. 73). As an entity, group members of La Familia Initiative discovered that they had a lot of power in organizing for change. They felt empowered to have a role in their children's schooling, and even felt comfortable sharing "stories of discrimination, home and family transitions" and their "reflections about their struggles towards happiness and [finding] existential 
balance" (p. 36). The camaraderie they built allowed for them to take real action and create "a list of specific suggestions for school improvement" which also came with an "offer to actively participate in each of the proposed items" to ensure joint success (p. 36$37)$.

La Familia Initiative's decision to give parents full organizing power in order for them to address their specific needs and find pragmatic solutions to problems is what makes this program successful. In other words, from a critical social work perspective, the success of this program is a result of breaking down Anglonormative structures that place Latino culture as minor. As previously mentioned, normative parent involvement requirements are guilty of class oppression. Prior to this program, Latino parents who were unable to involve themselves with the day-to-day operations of their community school were likely labeled as apathetic or have deficit thinking. By breaking down structural forces and giving Latino parents the opportunity to create an initiative that places their culture and experience as central to learning and success, this program reinvigorated parents to engage in a way that felt authentic to them.

Similarly, Project Avanzado was created to serve the unique experience of a certain demographic: Migrant farm workers in Los Angeles. Their program goals, as delineated by one of the participating mothers was to "begin to think about ourselves, our future, and have a program totally different than what we had in school, with teachers we could talk to, a program we could be proud of, one that could also help our children do better in school" (Jasis \& Ordoñez-Jasis, 2012, p. 76). Started by 30 parents, participants were able to rely on one another for emotional support about acculturation challenges, 
educational fears, and employment setbacks (resulting from an economic recession affecting the agricultural sector) (National Agricultural Worker Survey [NAWS], 2004; Jasis \& Ordoñez-Jasis, 2012). The ability for this group to share a common understanding of struggles faced on a daily basis, enabled them to form a strong bond with their community. They learned how to rely on one another, ask for help, and speak up for themselves and their students. This change in parent advocacy was noted as being directly related to their experience with Project Avanzado (p.78).

Lastly, Community Action Network (CAN) was a partnership initiative that involved the participation of a local non-profit organization, the division of social work at a local university, and a local school district. CAN parents were brought together to engage in dialogue with one another, and openly express their "perceptions of the challenges and barriers that constrain the healthy development and well-being of children, youth, and families in the community" (p. 665). After each session, CAN parents would schedule and organize "group workshops designed to help parents develop and then operate programmatic solutions to the barriers and challenges they identified" with regard to their children's schooling. Aside from CAN's ability to build community, it also supported and empowered undocumented parents whose legal status was one that often steered them away from traditional parent engagement (Lawson \& AlamedaLawson, 2011). 
Allies in the Classroom

The relationship a parent has with their child's teacher--and other school administrators-- has been proven to also play a role in how engaged a parent is in their child's school and academic learning (Quiocho \& Rios, 2000; Quiocho \& Daoud, 2006). Among communities of color, it has been demonstrated that parent-teacher relationships are more common when the teacher is also a person of color (Dilworth, 1990; LadsonBillings, 1993). In spite of these findings, teachers of color have long been in the minority amongst their peers.

In 2010 , communities of color represented $40 \%$ of the public-school student population (Achinstein, Ogawa, Sexton \& Freitas, 2010). In spite of this growing number, only $17 \%$ of public-school teachers identified themselves as a person of color. Hiring and retaining teachers of color has become one of the education system's most challenging obstacles, as over $60 \%$ of recruited teachers of color end of leaving the field within the first 5 years (Branch, 2001). Among the reasons why they leave many cite feeling unsupported, tokenized, and unfairly scrutinized as their reason (Quiocho \& Rios, 2000; Quiocho \& Daoud, 2006).

While many institutions have failed to retain teachers of color, there is no denying that their presence has been crucial in building positive relationships with students and parents of color (Castañeda, Kambutu \& Rio, 2006). Their ability to connect with their student's historical and cultural background makes them allies - and in communities that have a history of strained relationships with educators, that is vital (Marschall, 2006). Furthermore, if a teacher is able to communicate in an immigrant parent's native tongue, 
they are also more likely to ask questions about their child's progress (Quiocho \& Rios, 2000).

As we move forward in thinking about best community engagement practices we must also consider how teacher preparation programs often times fail to attract and serve teachers of color. Though underexplored, there is a dileman in the field of teacher education, many teacher preparation programs are predominantly taught by White instructors (Emdin, 2018; Lathan, 2014; Minkel, 2018). While being White does not equate to being deficit in teaching skills, it is important to be aware of the impact this may have on students of color who are learning how to serve at-risk communities or who entered the field as a result of a poor experience in schooling. As a student teacher of color, in particular, how might having a White instructor teach you about cultural sensitivity feel? And how might being the only student of color in a White teachers cohort impact your ability to engage in critical conversations of race?

\section{Limitations of Literature Review}

While the literature provided important insight, there were a number of gaps that inspired the creation of this study. The first limitation was that there was little information about culturally specific programs that serve newcomer Latino immigrants, and the impact — both short term and long term — they have on Latino educational attainment and parent engagement. In the end, I was only able to find three studies (Jasis \& Ordoñez-Jasis, 2004, 2012, Lawson \& Alameda-Lawson, 2011) that examined how culturally specific initiatives impact parents and their engagement with their children's 
learning. Desiring to add to the field of education and social work's understanding of these programs, and whether or not in which they are worth investing, this dissertation explored how a culturally specific program can specifically strengthen parent-school personnel relationships and parent engagement.

Another limitation was that there was not enough literature detailing how Latino parents engage with their children in non-traditional ways, off-campus and at home. In spite of this, three sources (Auerbach, 2004, Auerbach, 2007; López, 2010) were found indicating that Latino parents excel at talking with their children and providing them with moral support—both of which are key to helping children build healthy relationships, self-confidence and succeed in school. Given that insight, and the belief that there is still much more to learn on this matter, this study sought to learn how a culturally specific program could aid educators in gaining understanding on the types of engagement that takes place between parents and children at home, and subsequently how that insight can help educators better support parent engagement.

\section{Conclusion}

Across the United States, Latino students are significantly trailing their White peers in educational attainment. With educational attainment being strongly correlated to lower earnings and higher poverty rates, this becomes a social problem. Proven to positively impact student achievement, parent engagement has become a central focus for educators working with Latino families. In order to increase engagement, however, research shows that educators must establish positive relationships with parents. With this 
understanding education reformists have long called for supporting the training and hiring of more bilingual educators and educators of color, as well as exploring the impact that culturally specific school programs can have in increasing Latino family engagement. 


\section{CHAPTER III: RESEARCH METHODOLOGY}

\section{Methodology}

This dissertation is a qualitative study that explored a culturally specific intervention within a culturally specific school—Mission Education Center (MEC) — and its related contextual conditions. Its goal is to elevate the voices of Latino immigrant parents, school personnel working with this population, and explore if and how interventions like these can positively impact relationships between immigrant Latino parents and school personnel, and therefore positively impact parent engagement. In order to address these goals, this study used the values of ethnography to honor culture and context and used in-depth interviews, direct observation and focus group methodologies to gather stories of this vulnerable, marginalized, and often stigmatized group. With the hope of capturing as many immigrant voices as possible in order to better understand the impact a culturally specific program like Mission Education Center can have on immigrant families, data was gathered on campus and in other places where participants felt safe. Data was evaluated using critical and intersectionality theory, paying close attention to culture, and how systems of oppression, domination and discrimination silence the unique experience of Latino immigrants.

In-depth interviews. Interviewing has become an effective tool for learning about people's lived experience, what they feel and how they think (Orcher, 2005; Yow, 1994). Since it was important to give parents and school personnel the opportunity to share their candid thoughts, semi-structured interviews that asked specific questions and also allowed for new ideas to be brought up and expressed were conducted. In total, 
seven school personnel and nine parent interviews were facilitated. These interviews provided the study with significant insight into the experience of parents and school personnel, and complemented the data gathered via the single focus group and on-site observation.

Direct observation. Direct observation has been defined as "the systematic description of events, behaviors, and artifacts in the social setting chosen for study" (Marshall \& Rossman, 1989, as described in Kawulich, 2005). Upon approval of the study, time began being spent on MECs campus, observing the flow of the program and the relationships that stemmed from it. This helped gain an additional perspective on how MEC builds relationships with parents. In total, three months were spent directly observing the program, connecting with parents and school personnel, and paying special attention to non-verbal communication and cues. In the end, direct observation was helpful in gaining a visual perspective of the program and the impact it has on parents, students, and engagement.

Focus Groups. Originally designed to assist with market research and opinion polling, focus group techniques have become more integrated into academic research for their ability to provide insights into how people think and provide a deeper understanding of the phenomena being studied (Kamberelis \& Dimitriadis, 2005). Though met with initial resistance, the field of social work began adopting it as a research methodology in the 1980s, proving that it was a useful resource in gathering qualitative data that explores the perceptions and experiences of subjects in which we know little about (Krueger \& Casey, 2000). Lauded by feminist and critical researchers, focus groups also have the 
potential to diminish the hierarchical nature that tends to exist between the researcher and the subject (Wilkinson, 1999), a factor that was central to this study.

Group interactions and non-verbal communication may also encourage participants to make connections to various themes that may not occur during individual interviews. These connections may lead to deeper discussions and may encourage those who are marginalized by immigrant status, language proficiency, social class and other factors to experience feelings of freedom by collectively coming forward with their story (Kamberelis \& Dimitriadis, 2005). Since this study aimed to hear the authentic voice of as many immigrant parents as possible, focus group interviews seemed to be the appropriate. Unfortunately, recruitment efforts did not yield the amount of volunteer participants originally hoped for. In the end, while only one focus group was able to be conducted, there was enough data gathered to reflect on the role Mission Education Center has had on facilitating relationships between parents and school personnel and increasing parent engagement.

Critical Race and Intersectionality Theories

Critical race (CRT) and intersectionality theories were used within the analysis and discussion of this study's qualitative data. CRT helped explain how the education system has created power structures that disadvantage people of color, oppress immigrant families and discredit Latino culture. It also helped inform how the current political climate disadvantages Latino immigrants more than others, and leads them to disproportionally feel fearful, mistrusting and unsafe in schools. 
Intersectionality theory complemented CRT during the analysis of the study, recognizing that social constructions of race, class, gender, educational background, and language intersect with one another, also contribute to the oppression of Latino immigrants in the education system (Murphy-Erby, Hunt, Zajicek, Norris, \& Hamilton, 2009). Furthermore, these two theories helped frame the belief that complexities experienced by Latino immigrants in this study are not mutually exclusive, and rather work together to construct how immigrants are perceived in society (Crenshaw, 1998; Cooper, 2005).

\section{Research Questions}

The research questions driving this study were:

1. How can culturally specific programs deepen the relationship immigrant parents have with school personnel?

2. How can culturally specific programs lead educators to gain insight on engagement taking place between parents and children at home?

3. How can culturally specific programs support overall parent engagement?

\section{Context of Research Site}

Mission Education Center (MEC) is a K-5 elementary school for newly arrived Latino families whose first language is Spanish. At the end of the 2017 school year, there were 140 students matriculated at MEC, and $96.6 \%$ of the student population identified as Latino (San Francisco Unified School District, 2017). MEC's school model 'helps 
new arrival students achieve the necessary skills and confidence" they need to succeed in full English instruction schools. Teachers are bilingual, Spanish speakers and have extensive experience and the necessary qualifications to work with newcomer populations. MEC encourages parents to become engaged in and supportive of their child's education, through bi-weekly parent education workshops. This study sought to understand if and how a culturally specific program like MEC could positively impact relationships between immigrant Latino parents and school personnel, and result in increased parent engagement off campus.

\section{Researcher Positionality}

I have spent the last 12 years working with Spanish-speaking immigrants, helping them integrate into U.S. society, navigate the education and health systems, and find ways in which to maintain connections to their Latin American culture. More specifically I have spent the last six years investigating what factors build bridges between educators and immigrant parents, and how culturally specific programs have the ability to set support integration without forced assimilation. As an immigrant, my work is personal. It is highly reflective of my own experience and the experience of my family.

Originally from Lima, Peru, I arrived to Los Angeles at the age of five with my mother, father and three siblings. I went to school in the states, learned how to ride a bicycle in the states, and came of age in the states. I have always considered myself to be Peruvian and estadounidense, though in reality, much of my early life was spent feeling “othered" by society. In addition to being an immigrant, I was undocumented for 16 
years, a reality that further isolated me from living my life like many of my U.S.-born, native English-speaking peers. For my parents, our undocumented status was simply a hurdle they had to creatively jump through every day. They gave my siblings and I everything they could. At home we were an incredible unit, but when it came to them engaging in our educational and social lives, language barriers and lack of cultural understanding often left them to be isolated.

My parents' desire to emigrate was fueled by their desire to escape growing terrorism in Peru. They had the means and support to do it, and so they did... twice. They arrived in the United States as seasoned professionals with remarkable careers, though their immigrant status and lack of dominance of the English language left them unable to participate in the workforce they were accustomed to. As difficult as this was for them, they adjusted. In the end, the sacrifice was for us, their children, not for them.

On a daily basis my parents were driven by the dreams they had for my siblings and me. They did everything they could to give us a "normal" life, though that often did not translate to them understanding key things, like how the U.S. school system worked or the best ways for them to engage with our learning or school experience. They tried. They really did, but so often they were misunderstood, and this led them to feel unwelcome in the classroom and on campus by my teachers and other parents. Things could have been better for them. Things should have been better for them-and that's what makes this study so personal to me. I view it as an opportunity to honor the experience of my parents and other immigrants close to me.

It has been 27 years since I arrived in the United States. While so much has 
happened in that time, I am still closely tied to the undocumented immigrant experience. Though now naturalized, I will always be DREAMer and will always fight for the rights of immigrants around the world. My experience has fully inspired this study and therefore it would be senseless to think this study would be absolved from bias and subjectivity. Subjectivity has guided everything I have done during this study: The site I chose, methodologies I selected, and the theories I used to interpret my data. Aware of my bias, I reflected often on the values and objectives I brought to this study and how it might affect my findings and recommendations.

With the expected population growth of Latinos, I want to ensure that educators have as much information available to them so that they can create culturally appropriate parent programs in their respective communities. This being said, schools cannot do it alone. Educators, social workers, and other service professionals are key to building community, bridging experiences, and making schools safe spaces for new immigrants. Mission Education Center has an incredibly unique program any my hope is the voices from this study inspire people in power to advocate for reform.

\section{Research Participants}

Prior to the school year beginning, MEC was expected to have a total of 78 registered parents and 12 staff members. With that population size in mind, the study initially proposed to conduct 15 parent interviews, seven school personnel interviews, and two parent focus groups. Given the predicted population size, the proposed sample was believed strong enough to obtain necessary information and attain saturation in a 
qualitative study. By the time data gathering began in March 2018, the parent population fell to 52, and two months later it dropped to 48. This drop in parent population greatly affected parent recruitment.

Participant recruitment. School personnel recruitment took place with the support of the school principal and social worker. The first step was presenting the proposed study to school personnel during their all-staff meeting, shedding light on why Mission Education Center was worth learning about and how the design hopes to capture stories of both parents and school personnel. This led to staff members asking questions, expressing interest and two teachers immediately volunteering to participate. Following the presentation, an email was sent to all of the staff members - with a personalized note sent to those who had expressed explicit interest. After a month of recruitment, seven school personnel staff members were interviewed.

When it came to recruiting parents, there was no one-way of inviting them to participate. Aware that many parents have difficult schedules, the family liaison and social worker were asked to distribute flyers inviting parents to attend an informational session that would further detail the objectives of the study. The information sessions garnered a lot of interest, and led to securing two school personnel interviews. It also led to recruiting six parents to participate in the sole focus group of the study (four of whom agreed to also be interviewed individually).

In spite of this seemingly successful first round, it was difficult to secure more participants in later rounds of recruitment. Many parents and school personnel members that expressed initial interest and support for the study were unable to schedule time to 
meet due to their work schedules. Due to this, every person who had been to an informational sessions was followed up with via e-mail. This extensive follow up led to coordinating two more school personnel interviews, but zero parent interviews. In addition to this, both the family liaison and social worker helped follow up with parents during their parent sessions or in candid conversation. The final attempt at recruiting participants was to host "drop-in hours" for people who were willing and able to participate in interviews before or after school, or after parent workshops on campus. This led to five additional parent interviews and three school personnel interviews.

In the end, through a combination of recruitment methods, nine parent interviews and seven school personnel interviews were coordinated. Participation in this study was completely voluntary and all participants were given a consent form to fill out in their language of choice. Participation was not permitted if not completing as signed consent form. At the beginning of each interview, parents were also reminded that they could end their participation at any time.

Parent participants. Parent participant stories were at the heart of this study. In order to strengthen the study's findings, multiple data sources (triangulation) were used to increase the understanding of their experience. In particular, this study invited all participants to partake in a demographics questionnaire, a focus group and one-on-one interview. While not everyone participated in all of the offerings, the data collected was enough to cross-verify stories. Table 1 (page 131) outlines parent participation in this study along with certain demographic data. 
School personnel participants. All of the school personnel participants participated in a one-on-one interview. With regards to identity, all of the school personnel participants identified as bilingual, and six out of seven identified as Latino. The non-Latino participant expressed that their identity did not prevent them from doing their job, but that it did make it more challenging to establish initial trust. With regard to workplace experience, six out of seven participants were seasoned MEC professionals, having worked at the school for a period of five to ten years. Lastly, only three of the participants were current classroom teachers, though everyone expressed feeling committed and connected to parent and student learning. Table 2 (page 132) outlines school personnel participation in this study, along with demographic data.

\section{Data Collection}

Timeline. In July 2017, San Francisco Unified School District's (SFUSD) Internal Review Board approved the collection of data at MEC for the 2017-2018 school year. In November 2017, Portland State University's (PSU) Internal Review Board approved the application to collect data on human subjects at MEC. Data collection for this study began on March 1, 2018, and was completed on May 16, 2018. During those two and a half months, Mission Education Center's (MEC) campus and parent engagement and empowerment workshops were observed in action.

Observation field notes. This study involved spending time on campus observing the relationships that exist between parents and school personnel. While a wide range of parents and school personnel members were interviewed, observation was limited to the 
school's main office and parent-engagement classroom. All people in attendance were always made aware of the researcher's presence and the goal of the study. In total, the site was observed once every other week between March 1-May 16, 2018. Each visit lasted between 1-3 hours depending on whether or not there was a parent workshop. This ethnographic method of data collection helped observe the how relationships manifest on campus, and how relationships function as a series of interlocking events (Jonesetal, 2006). Due to the inherently reflexive nature of this study, extensive notes and memos were also taken during the observation of the site.

School personnel interviews. School personnel interviews were conducted to gain perspective on how administrators, educators, and other school staff members view the impact of a culturally specific program. For the purposes of minimizing confusion, anyone who works at MEC will be referred to as a school personnel member. The first person to be interviewed was the school social worker, followed by the family liaison and five other school personnel staff members. These interviews led to understanding MEC's programmatic goals, as well as their strengths and limitations, as identified by the staff. All interviews were audio recorded, and extensive notes were taken to summarize dialogue. Summaries were then member-checked by participants to ensure reliability. The records of this study were kept strictly confidential and all records are kept in a locked file. All electronic information was also coded and secured using a password-protected file. No information that would make it possible to identify any participant was included in the analysis or discussion.

Loosely structured, school personnel interviews were guided by nine questions 
that asked staff participants to think about MEC's overall impact, relationships, parent engagement and program limitations. Each interview began by giving staff participants the opportunity to share the many ways in which they believe MEC, as a culturally specific program, impacts immigrant families. These questions led many to focus heavily on parent-school personnel relationships. The next set of questions pertained to engagement, giving educators the opportunity to express in their own words what they identified as being "parent engagement" and how they think MEC best supports parents in engaging with their children. Lastly, participants were given the opportunity to share what they believe to be are MEC's program limitations, why they exist, and how they think they can be addressed and overcome.

Focus group. Following the school personnel interviews, and with the help of the family liaison, one focus group of six parents, made up entirely of mothers who had arrived to the United States in the last 12 months was conducted. This focus group allowed the study to learn how this group of mothers engage with their children at home, how they engage with each other on and off campus, how MEC supports their engagement, and how MEC can better support them moving forward. As with the MEC educator interviews, parents were given pseudonyms, and the session was audio recorded, with extensive notes taken to summarize dialogue. Summaries were member-checked by participants to ensure reliability. The records of this study were kept strictly confidential and all records were coded and kept in a locked, password-protected file. No information that would make it possible to identify any participant was included. 
The purpose of this focus group was to better understand the holistic experience of new immigrant parents with school-aged children and how MEC has impacted their integration. Each session began with a 5-minute guided brainstorm in which parents were asked to privately reflect on the circumstances that lead them to emigrate. They were then prompted to think about their hopes, dreams and fears regarding coming to the United States, and lastly asked to think about the progress they have made since arriving to the Bay Area. After five minutes of thinking about these questions, participants were asked to start sharing their thoughts. They were encouraged to freely state any questions or frustrations that came up for them during the process. 15-20 minutes was allotted for this part.

The next 10-15 minutes focused on engagement—more specifically, engagement that is had at home between them and their students. Participants were asked to share their favorite methods for learning about what their students are learning at school. They were encouraged to think about various ways in which they do this, and were encouraged to share examples. The purpose of this was to affirm their actions and give them an opportunity to share their techniques with other parents.

The next 20-30 minutes centered on the role Mission Education Center (MEC) has had on supporting parents in navigating the U.S. education system. They were asked to share about their experience on campus, the support they received, and how the program as a whole has supported their engagement. The final 10-20 minutes served to wrap up the experience and encouraged participants to think about questions they would like to ask and statements they would like to make. They were thanked for their 
participation and invited to partake in individual interviews should they want to share more of their experience. This led to four of them agreeing to be interviewed on their own.

Parent interviews. Following the focus groups, interested parents were invited to partake in an individual interview that would give them the opportunity to further share about their experience, their engagement with their children's learning, as well as the impact Mission Education Center's (MEC) program has had on their integration and understanding of the U.S. school system. Of those that participated in the focus group, four agreed to participate in the parent interviews. Like the focus groups, these interviews were voluntary and loosely structured. Unlike the focus group, these interviews were oneon-one conversations, and therefore certain things that participants did not want to share in public came out in these interviews. Extensive notes were taken and at the end of each interview, each participant was asked to confirm that the notes taken accurately summarized the conversation.

Though loosely structured, the parent interviews were guided by a series of questions that began by asking each parent about their personal experience with learning and with educational institutions in and out of the United States. Following those first two questions, parents were asked to detail their overall experience with MEC, and how the school catered to their specific experience as immigrants. The next set of questions explored parent-school personnel relationships, and whether or not parents felt they were a part of a community. This then led to questions about how they engage with their children, and the role MEC has played in supporting their engagement with their 
children's learning. All interviews ended by giving each parent the opportunity to make recommendations to MEC.

Demographics questionnaire. In order to better understand the population, the entire group of parent participants was asked to fill out a demographics questionnaire. This questionnaire was anonymous and was distributed solely to understand the level of diversity in the room. All but four parents chose to complete the form. Some of the reasons stated for why they did not want to complete the questionnaire was that they did not feel comfortable answering certain questions and that it was lengthy. While not everyone completed the form, demographic information consistently came out in individual interviews and to a great extent, during the focus group.

\section{Analysis of Data}

Focus groups and interviews were audio recorded to minimize error and allow for transcription and closer study. Each interview was summarized, and participants were asked to member-check the summary that pertained to them. This exercise gave participants the opportunity to add, edit or redact statements. Upon the completion of member-checking, Hay's (2005) two-step coding strategy was employed, first distinguishing overarching themes, and then identifying sub-themes within each category that allowed for more complex analysis.

With data being collected from two separate groups of people with two different experiences, it was necessary to distinguish separate overarching themes for both parents and school personnel. Guided only by the research questions, it was not until the data was 
analyzed that major themes and sub themes emerged. This allowed for the data to naturally occur and move in the direction that seemed most important to the people interviewed.

\section{Risks and Benefits}

This study experienced medium risk. With all of the parents being immigrants and English language learners, there was a possibility that some would feel socially stigmatized by their English language skills, immigrant status, or history with engagement in school. To minimize the chances of this, informational sessions were delivered in Spanish, as were all distributed written items. For those who participated, consent forms were made available in both English and Spanish, and all parent focus groups and interviews were led in Spanish. Despite conducting the focus group and interviews in Spanish, it is possible that vocabulary used and the researcher's educational background could have intimidated participants. In order to counter this, significant amount of time was spent on campus building rapport.

Another possible risk was that questions asked, or subjects discussed may have led participants to revisit preexisting traumas. In order to minimize this risk, it was reiterated numerous times that participation was at-will, and could end whenever the participant desired. Participants were also provided with community resources post participation. In spite of these risks, parents were given the opportunity to share their story and perspective in their native language, an exercise that may not otherwise be available to them. Furthermore, their feedback has the potential to improve educational 
support services across the country for future immigrant families, and therefore their stories can impact generations of immigrants to come. Due to these assertions, the benefits of this study greatly outweighed the risks.

\section{Limitations and Reflection on Data Collection}

Though the original plan was to conduct two focus groups, recruiting parents to participate in a study that required them to be vulnerable with someone they did not know, was more difficult than anticipated. It was predicted that engaging this population would be a challenge, but it was believed that the researchers connection to the experience as a Latino immigrant would make parents more likely to participate in the study. Within a couple of weeks of attempting to recruit participants, however, it became evident that shared cultural connection was not enough given the country's political climate and the fear the parent population at MEC lives in as a result of it.

While being undocumented has always meant living "under the radar," the current political state of the United States is especially intimidating to any immigrant wanting to protect their anonymity. The majority of parents - as described by school personnel and other parents interviewed - live in constant fear of deportation and family separation. This was also evident in interactions with parents during the recruitment process. While the interview guide specifically refrained from asking questions about immigration status, there were always questions regarding the use of the data: Who would see it? Would they know where it came from? Would they know who wrote it? Though participants were always assured that the data was solely for the purpose of this dissertation, many 
parents still felt that participating in this study was too risky. In addition to not wanting to participate in the study, fear brought on by the national government's stance on immigration also led to many parents leaving MEC.

Originally estimated at 78 in September 2017, at the time in which data gathering began in March 2018, the population of parents at MEC had shrunk to 52. By the time data collection was completed in May, the number dropped to 48. As explained by the principal, social worker and family liaison, a drop-in student enrollment—and therefore size of parent population — is normal and has to do with a number of things like cost of living in the Bay Area and natural relocation. Unlike other years, however, all school personnel members interviewed pointed out that attrition is at an all-time high. National hysteria towards immigrants - fueled by the current administration's stance on 'illegal immigration" has led to more people outwardly justifying racism and xenophobia. While many parents and children see MEC as a second home, the current state of affairs is pushing many families to disaffiliate themselves with any institution that could potentially keep a record of their existence.

As limiting as this was from a scientific perspective, it makes absolute sense why families would think that removing their children from a registered school is the best way to protect themselves and their family from being detained, deported or separated. In a world post-DACA, any form of registry is seen as dangerous for undocumented immigrants. Despite the challenges encountered, nine parent interviews and one focus group of six parents was conducted, achieving saturation based on the population.

Similar to parents, the number of staff members also decreased during the 2017- 
2018 school year. Due to student attrition, a number of educators who started the year as classroom teachers became educational specialists—supporting individualized learning with math or reading — without a classroom. Some staff members who preferred classroom instruction were moved to other schools needing support, but the majority of staff members who were shuffled into new positions chose to stay at MEC because, as one teacher said, "[they are] a family, and [they] strongly believe in the impact [they] have on the community." In the end, out of the 12 staff members working at MEC, seven of them participated in an interview. 


\section{CHAPTER IV: RESULTS}

Introduction

The purpose of this study was to identify how culturally specific programs can positively impact immigrant parents, the relationship immigrant parents have with school personnel at their child's educational institution, and the level of engagement they have with their child's learning. The challenge for immigrant parents, as it was evidenced in the findings, is multifaceted. They are juggling transitions, language barriers, racism and xenophobia, and are often doing it alone--without the support of the community they left behind. These limitations affect their mental health and their abilities to engage on campus, with their children, and with their children's educators. Culturally specific programs are designed with this reality in mind, and therefore this study sought to understand how a program like Mission Education Center addressed these needs creatively. Once again, the research questions driving this study were:

1. How can culturally specific programs deepen the relationship immigrant parents have with school personnel?

2. How can culturally specific programs lead educators to gain insight on engagement taking place between parents and children at home?

3. How can culturally specific programs support overall parent engagement?

Themes of Parent Focus Group and Interviews

The parent population at MEC during the time of data collection was between 4852 parents. The parent sample size for this study was 11 . Five solely participated in the 
one-on-one interview, four participated in both the one-on-one interview and focus group, and two solely participated in the focus group. All of the participants were mothers. Given the size of the focus group and the fact that four of the six participants went on to also participate in an individual interview, the findings of both methods were merged in the analysis, as many of the themes discussed in the focus group were also discussed in the individual interviews.

The four main themes that emerged with parents were 1) community and belonging, 2) Power of a culturally specific program, 3) engagement and 4) resiliency. The four main themes and their subthemes are depicted in Table 3 (page 133). Within the community and belonging theme, the subthemes explored were homesickness and nostalgia, MEC as community, and community beyond MEC. Under power of a culturally specific program, the subthemes that emerged were adaptability, integration with community served, and cultural capital. When analyzing the foundational theme of this study, engagement, the sub themes that arose were preparation and support, oncampus engagement, off-campus engagement and limitations. Given that program limitations provided a holistic understanding of the experience of parents at MEC, the following sub-sub-themes were also explored: Finite student enrollment, educational background, time (and other limited resources), and political climate. Lastly, the theme of resiliency emerged as was analyzed within the context of confidence, worthiness and self-actualization via capacity building programming. 
Findings: Parent Stories

An immigrant parent's ability to engage in their child's learning is heavily influenced by a number of personal and social factors that often compound. One's ability to feel welcomed and safe on campus or develop relationships with school personnel, may be affected by their personal experience with schooling, their mental health, as well their perceptions of how their race, gender, class, language, or immigration status might prevent them from feeling a part of the community. Aware of the diverse realities of immigrants, this study collected parental data in the form of a focus group of six parents and nine one-on-one interviews in order to gain a wide insight on how a culturally specific program like MEC could impact newcomer Latino parents. As a means in which to honor the immigrant experience and the voices of the participants, parent quotes were written in Spanish (as indicated in italics) and English.

\section{Community and Belonging}

Membership in a group or organization is a compound experience. When conducting the focus group and one-on-one interviews, it was clear that belonging to a community was important to parents feeling human and worthy. Since the three sub themes that emerged touched upon past, present and future community belonging, homesickness and nostalgia - feelings that connect to the past and contribute to present day belonging — was examined first. Following that analysis, parent perceptions towards MEC as a current community space, and feelings and thoughts on what community may look like for parents beyond their time at MEC, were explored. Full of insight, these 
stories helped answer the first research question: How does a culturally specific program deepen the relationship immigrant parents have with school personnel?

Homesickness and nostalgia. While all of the parent participants indicated that coming to United States was the best "choice" they could have made for themselves and their families, many of them expressed that the decision was not entirely voluntary, nor that it was their first choice. All of the mothers were Central American women, four of them from Guatemala, three from Honduras, two from El Salvador, one from Nicaragua, and one chose not to disclose this information in the demographics questionnaire or interview. Seven of them were married, but only four of them lived with a partner or spouse. Those that lived with their partner or spouse emigrated from their home country together. All of them expressed that their motive for emigration was to seek better opportunities for themselves and their families. Four of the participants expressed they were escaping domestic violence situations, and therefore while leaving was "their choice", there was not much of an alternative. In short, many of them came alone, and in spite of the reasons why they left, there were many things they missed including, familia (family), amigos (friends), el clima (the weather), la comida (food) and the familiarity of home.

Regardless of their disdain and dislike for certain things, all of the parents expressed "missing knowing how things worked." Things may not be as efficient in their home countries as they are in the United States, but they could advocate for themselves and express their feelings and thoughts in a language they felt comfortable speaking. This makes perfect sense. Immigrating to a new country is difficult, especially when you're 
doing it alone and when you have children to take care of. Feeling demonized and rejected by an entire country also takes a toll on your feelings and ego. Hay que mantenerse fuerte con la cara en alto. In other words, "we have to stay strong and keep our heads held high in order to survive trying times" said the first mother interviewed. Tenemos que apoyarnos, "we have to support one another," para no sentirnos solas, "to not feel alone."

Prepared for this, MEC does a number of things to help address homesickness and nostalgia like hosting on-campus gatherings that celebrate holidays and feature homecooked foods and popular music. Por lo menos una vez al mes nos estamos juntando para celebrar algo. Siempre preparo pepián—una comida de mi país (Guatemala)—para compartir con los demás. "At least once a month we get together to celebrate something. I always prepare pepián — a dish from my home country (Guatemala) — to share with the rest," said a single mother of two. No exigen nada de nosotros, pero es mi manera de contribuir y es una manera de recordar de donde soy y que estaría comiendo si estuviéramos celebrando en mi país. "They don't expect us to bring anything, but it is my way of contributing, and it is also a way to remember where I am from and what I would be eating in my home country to celebrate." Conversations around food did not end there.

During the focus group, participants spent about 20 minutes talking about how much they missed their home country's cuisines and the fresh ingredients. La comida no es igual acá, pero bueno, tampoco está mal. "Food is not the same here, but it is also not bad," shared a woman with a chuckle, leading others to also nod their heads with a smile. 
Por lo menos ahora sabemos donde conseguir nuestros productos. "At least we now know where we can get our products." What they meant by that is that at the beginning of the school year, the family liaison connected them to local grocers, based on where they lived, where they could find imported goods from Latin America. Hay una cerca de donde vivo y ahi encuentro todo--hasta productos que no conocía de otros países. Esto me hace sentir un poco más cerca a casa. "There is one close to where I live and there I find everything — even products I did not know about from other countries. This makes me feel a little closer to home." While this might seem small, the immediate connection that MEC provided to these parents with these places shows their acute awareness of what might make someone feel a little less far from home.

MEC as community. In all of the conversations, participants were quick to point out how MEC had become central in their lives-as a community center, educational institution, resource center and social space. Es como nuestro segundo hogar, "it is like our second home," said a mother of three. Somos familia, "we are family," said another. Given the population it serves, MEC brings together people of similar backgrounds with shared experiences. Almost immediately, parents connect with school personnel. From the moment they arrive, the relationship begins. It starts with small talk in the front office and evolves into longer conversations whenever they are dropping off or picking up their children from school. Those same connections occur between parents and other parents. And all relationships are deepened once parents start spending more time in the parent program. 
Those that are able to participate in the parent program truly have a social advantage. In the beginning, most of them are strangers to one another, but come the end of the first month they are exchanging telephone numbers and making plans. Nos entendemos...hablamos el mismo idioma...nos gusta la misma música, comida, televisión. "We understand each other... we speak the same language, like the same music, food, television," said a single mother who moved to the United States on her own with her two children. Son mis mejores amigas. "They're my best friends." Community is certainly something MEC provides. Everyone that arrives to the school has fears, but they also have dreams and those dreams are explored during workshops and gatherings housed in the parent engagement classroom. Creating space for this vulnerability undoubtedly creates ties.

The parent program at MEC is housed on campus in a classroom managed by the family liaison. The family liaison was a parent at MEC many years ago, so they understand what it feels like to arrive alone, scared and intimidated. Given the need for support, MEC created this drop-in program as a means for which to create another learning and engagement opportunity for parents. Most of the learning revolves around personal, familial and professional development, and each week a topic frames the gathering. Flexible in nature, the program also adapts to current affairs and takes into consideration what parents may want to learn. MEC nos brinda bastante ayuda. Sea lo que sea, si queremos información acerca de inmigración or queremos aprender cómo usar el autobús, la maestra lo coordina. "MEC helps out tremendously. Be it what it may be, if we want information regarding immigration, or how to use the bus, the [liaison] 
coordinates it," said a mother two and aunt of another student. Rather than being a traditional program, where missing a session essentially paralyzes you from knowing what is going on in other weeks, the gatherings are non-sequential and are open to all parents on a drop-in basis. Attendance is not taken, and people can miss months of workshops and still feel welcomed when they are able to show up. A veces tengo que trabajar, o estoy cansada, y no llego. Pero sé que cuando regrese la próxima semana, no me van a ver mal. "Sometimes I have to work, or I am tired, and I will not make it. But I know that when I return the following week, they're not going to look at me with disapproval." This flexibility defines the parent program and it is what the administration thinks keeps parents feeling welcomed and invested in MEC.

Community beyond $M E C$. While this study was centered around the experience parents had on campus, there is no denying that something on the back of everyone's mind was: What will happen once a student leaves MEC? What will happen to the community that these families became so ingrained with? According to parents, this question is one they ask themselves on a daily basis. Parents become so attached to MEC that it makes it very difficult for them to leave once the time comes. Enrollment is meant to only be for one year, and therefore it has been known from the beginning that students will transition into a new school come the following fall and that MEC will no longer be the community center for many parents.

When asked specifically about other communities they have become a part of since arriving to the United States they mention a series of things. Amongst their favorite new community spaces, the public library and their reading program has generated a lot 
of excitement amongst parents. There they are exposed to more families, more children, and more life outside of MEC. Es bueno para nosotros tener otros contactos y no ser tan dependientes. "It is good for us to have other contacts and not be so dependent," said a mother who went on to discuss how important it is to see MEC as a foundation but not a solution or an answer to everything. Es importante tomar chances y conocer a otra gente...hacer nuevos amigos. "It is important to take chances and meet other people and make new friends." This sentiment garnered a lot of laughter and nods.

While campus gatherings are appreciated and anticipated, parents also expressed joy in spending time off campus. Nos gusta ir al parque, a la alberca, al centro Latino en la Misión, y caminar por el malecón para ver las focas... no es como era antes, pero es bonito. "We like to go to the park, the pool, the Mission Cultural Center for Latino Arts, and walk along the pier to see the seals... it is different than where we came from, but it is nice" said the married mother whose husband typically only gets nights, and some weekend days, off. Los maestros nos an enseñado que éstas experiencias independientes son importantes para nuestra familia. Juntos planeamos aventuras, resolvemos problemas y creamos memorias. "The teachers have taught us that these independent experiences are important for our family. Together we plan adventure, resolve problems and create memories." These statements directly answered the second and third research questions: How can culturally specific programs lead educators to gain insight on engagement taking place between parents and children at home? And how can culturally specific programs support overall parent engagement? 
MEC knows that the classroom is just one space in which learning takes place. Exploring city life is also a prime way in which to engage with other forms of learningespecially planning, teamwork and problem solving. When speaking to the family liaison and the principal, they confirmed that indeed their goal is to prepare and encourage families to do numerous things around the Bay Area that are accessible and fun with the hope that these experiences creatively engage parents with student learning in everyday life. "If we see that something is going to be happening somewhere, we let them know about it. There's so much in this city, and these opportunities all for them to bond and learn together," said the school principal.

Summary. Community and belonging are an important part of the human experience. As learned from talking to all eleven mothers, belonging to the MEC community has been powerful in supporting their integration into U.S. society. It has helped them face their own homesickness, connect with peers, gain personal and professional skills, and connect to outside resources, that come June, will be their main communities. In exploring community and belonging, it is clear that culturally specific programs like MEC deepen the relationship immigrant parents have with everyone: Their children, their children's teachers, parental peers, and outside communities. Examining MEC as a culturally specific program will help us better understand how and why.

\section{The Power of a Culturally Specific Program}

MEC was designed to reflect the unique experience of its students and their families. As stated on the San Francisco Unified School District website, MEC is for 
"newly arrived Spanish-speaking immigrant students... [their] main focus is oral English proficiency, academic success in Spanish and English, and [orienting families] to life in a new community" (2018). Powerfully stated, the goal of the institution is to make it understood that while English language acquisition is important, academic success can come in both the Spanish and English language. MEC's school principal confirmed that the program was intentionally designed to be culturally specific to the experience of Latino immigrants. "It is vital that families step foot on campus and feel as if they can advocate for themselves, understand what is being said to them... it is important that they feel that they belong." First impressions are everything, especially to families that may be balancing trauma and homesickness in the process of acclamation. When it comes to exploring the theme of MEC as a culturally specific program, this study will explore how adaptability, bilingual education and cultural capital have the potential to deepen the relationship immigrant parents have with school personnel.

Adaptability. As a culturally specific program, MEC pays special attention to the fact that what may work for a cohort of parents one year, may not work for a cohort of parents the following year. Adaptability is key to staying relevant and MEC educators know it. According to parents, the family liaison and their children's teachers are always checking-in to see if the methods in which they are communicating are working. Siempre me preguntan si es que me siento informada. Quieren saber como mejor ayudarme, y me escuchan cuando les hablo. "They are always asking me if I feel informed. They want to know how to best help me and they listen when I talk to them." Intrigued by this statement, the parent was asked to further elaborate. Al comienzo nos mandaban notas, 
pero aveces mi niño se olvidaba que lo tenía. Le dije a la maestra que mensajes de texto serían más fácil—como broma—pero a la semana entrante, me empezó a llegar la nota semanal via text. No pensé que lo haría, pero estoy muy agradecida. "In the beginning they used to send the kids home with weekly notes, but sometimes my child would forget they had them. I told the teacher that text messages would be much easier—as a jokebut the following week, I began to receive the weekly note via text. I didn't think it would happen, and I am very grateful.”

Another way in which adaptability plays out is in the way MEC flexes to families and their relationship to school and schooling. Not every parent that arrives to MEC has a positive history with educational institutions. Tenía miedo cuando llegue a MEC por primera vez. No me gustaba la escuela cuando era joven. Me iba mal y pues, me salí. "I was scared when I arrived to MEC for the first time. I didn't like school when I was young. It went poorly for me and so I left," said a quiet mother during our focus group. Certainly, a negative past experience with school can inevitably influence someone's perception of all schools. No sabia si me iban ha recibir bien ... me daba pena. "I didn't know if they we going to welcome me... I was embarrassed." In spite of her fears, this mother showed up to MEC one morning in August, and enrolled her two children in school. Since then, she has become a familiar face on campus. Like her, another shared a similar sentiment.

No sabía como iba ser las cosas. Algo que me ha sorprendido es la voluntad de los maestros para hablar con nosotros. "I didn't know how it was going to be. One thing that has surprised me is the willingness of teachers to talk with us." According to her, and 
many of others, this was not common practice in their native countries. Típicamente los maestro se mantienen distantes. No es común que conversemos o que les hagamos preguntas. Si es que nos hablan es porque algo está mal. "Typically, teachers keep their distance. It is not common for us to chat or for us to ask them questions. If they are talking to us it is because something is wrong." When asked how they felt about this they shared that first they didn't know how to engage with teachers. They didn't want to be disrespectful and talk back or ask questions, but they soon realized that people on campus wanted to talk to them and wanted them to feel as if they could ask any questions. Me tomó un poquito de tiempo, pero ahora soy yo las que siempre les está molestando con querer hablar. "It took me a little bit of time, but now I am the one who is always bothering them and wanting to talk." According to the teachers, this is a big shift for parents, and therefore they need to ease parents into communication situations. "Not everyone is ready for a parent-teacher conference on day one. It is really intimidating for some parents who only associate teacher communication with bad behavior," said a fourth-grade teacher. "We have to adapt to their needs, start slowly, and start with something they're familiar with like hola (hello), bienvenidos (welcome)." Integration with community served. MEC pays attention to the fact that culture(s) and languages (both English and others spoken at home) influence the lives of children and families and should be respected and supported. This is why parents and students are greeted in their native language the moment they step foot on campus. It is also the reason why every person that works on campus is fluent in Spanish (as either a first, concurrent or second language) and why the curriculum in taught in two languages, 
English and Spanish. Since the goal of MEC is to prepare its students to transition into an English-language school the following year, the primary educational focus is to work towards oral English proficiency.

During the first two months, $80 \%$ of instruction for students is in Spanish, meaning they are learning to read, write, solve math problems and express themselves in their native language. The other $20 \%$ is English-language acquisition. Over the year, the language instruction transitions to 60/40 Spanish/English, then 40/60 Spanish/English, and during the last month of the school, instruction is delivered in 20/80 Spanish/English. While English is still very much their second language, their ability to read and write in Spanish gives them the structure to start learning how to read and write in English. Furthermore, their ability to continue learning how to express themselves in Spanish, gives them the opportunity to strengthen their emotional intelligence and in turn make them more likely to openly share their feelings about their process and struggles with integration (Wang, Xie \& Cui, 2016). And the same can be said for parents. Rather than being limited by a language they do not know, they are empowered to express themselves in a way that minimizes the power imbalance between the English-language learner and English-language speaker.

Being a culturally specific program, it is important for students to learn in their native language and to associate it with learning and knowledge. Upon transitioning to a new school, this will no longer be the case, and therefore this one-year of Spanish instruction will be fundamental in how students perceive the value of their language and culture. Additionally, parents are able to engage at higher levels by having their 
children's instruction be in Spanish throughout the year. No tendría idea de lo que lo están haciendo si es que la tarea no estuviera en español. "I would have no idea what they are talking about if their homework was not in Spanish," said one mother. Gracias a dios puedo leer los cuentos con ellos. "Thankfully, I can read the stories with them." And while engaging parents in their native language is a priority for MEC, a secondary goal is to support some language acquisition for them as well. "Los padres no van aprender el inglés al mismo ritmo de sus hijos, pero van a poder aprender importantes cosas que les ayudará en el futuro. "Parents are not going to learn English at the same rate in which their children do, but they'll learn important things that will help them in the future," said the family liaison. It was evident in the observations that parents felt comfortable using certain English words here and there and that they were having fun in repeating things they had overheard elsewhere. "There is no expectation that parents are going to be fluent by the end of the year, but the school's bilingual model also impacts parents," said the principal.

Cultural capital. Being a culturally specific program, MEC believes in the power of and presence of Latino culture on campus. It believes that representation not only builds rapport, it also builds personal buy-in from educators who have a tie to Latino culture. "Immigrant parents are intimated left and right into renouncing their cultural identity," said a long time MEC schoolteacher. "MEC recognizes that parents have already begun to question the value of their culture in the United States, and in order to counter that negative sentiment, we make room for parents to be reminded of why their traditions are special and matter preserving." As of May 2018, all but one staff member 
identified as Latino or bicultural-Latino. Everyone was bilingual and felt connected in some way or another to the experience that was taking place on campus. When talking to the parents it became clear that this aspect of MEC made it possible to build relationships in the first place.

No sabía qué esperar cuando llegamos aquí. Sabía que la maestra de mi hija hablaba español pero no tenía idea de que todos iban hablar español! "I did not know what to expect when we arrived here. I knew that my daughter's teacher spoke Spanish, but I had no idea everyone spoke Spanish," said the parent who most recently immigrated to the United States. Pensé que la iban puesto en la clase especial—de los recién llegados. Pero no, es que todos los maestros hablan español. "I thought they had placed her in a special class - for new arrivals — but no, it is that all the teachers speak Spanish." And not only do all campus professionals speak Spanish, those interviewed expressed having memories of learning a new language.

Los que trabajan aqui son de todas partes. "The staff that work here are from all over," said one mother and prompted others to start calling out where they are from: Republica Dominicana ... Puerto Rico... México, Guatemala, El Salvador...Colombia y Estados Unidos, también. Es bueno que representen tantos lugares. Nosotros llegamos con miedo que no nos entiendan, pero el saber que muchos de ellos también son inmigrantes, nos da tranquilidad. It is good that they represent so many places. We arrive with fear that people will not understand us, but knowing that many of them are also immigrants, gives us comfort." Indeed, this is not a mistake. It is all part of the critical design of this program. 
"These things were thought about when the program was first started," said the school principal. "We still think about these things when making hires today: How might hiring non-Latino educators affect the experience of parents? Affect the experience of child learning?" They went on to express that "every person that works at MEC has a reason for wanting to work here. It is personal. They either experienced emigrating as a child or they remember the struggle their immigrant parents had to endure when connecting to their teachers." And according to parents it does make a difference.

No es que no quería al maestro de mis hijos si es que no fuera latino, pero el que lo sea es una ventaja y me da calma-especialmente ahora cuando recién estoy aprendiendo el sistema educativo. "It is not that I would not like my child's teacher if they were not Latino, but the fact that he is an advantage and it calms me-especially now when I am still learning the educational system." Sharing a similar culture with that of your students is powerful to all people involved. Students grows up seeing someone that looks like them (and speaks the same language as their family members) in a position of power, and parents are more likely to engage with staff and advocate for themselves. Some staff members can even relate to the experience of the child with one MEC teacher, in particular, having once walked the halls of MEC as a child.

El maestro de mi hijo fue estudiante aquí. "My son's teacher was also a student here," said a smiling mother whose son has been excelling in school. Es un orgullo "It is something to be proud of." When asked how it makes her feel she went on to say: Me da fé que todo va salir bien y que tal vez un día mi hijo también sea profesor y ayude a otras personas. "It gives me hope that everything is going to work out and that perhaps one day 
my son will also be a teacher and help other people." Having someone to look up to, and whose experience is not far from her own, has allowed her to open up more to her son's teacher. That relationship has also been instrumental in building trust with other educators. El maestro fue quien me empujo para que vaya a las reuniones de los padres.

"The teacher was the one who encouraged me to start going to the parent gatherings." Had it not been for their rapport, this mother may have not given it much thought. Like her son's teacher, the family liaison is also a source of inspiration.

Summary. MEC's culture of care has brought down barriers, built bridges and has had a long-lasting effect on people. As mentioned by a parent, the fact their son's teacher spoke Spanish, inspired them to ask questions. Those questions led to establishing a relationship with that teacher, and that relationship led the parent to engage in the parent program and strengthen their at-home engagement skills. For the teacher involved, this parent's engagement was a reminder for why they are in the field of immigrant education. Invested in one another, parents and school personnel at MEC have become partners in activating social change, making the school a powerful culturally specific program that highly impacts engagement.

Engagement

Driven by the desire to learn how a culturally specific program can impact parent engagement, this section explored how MEC supports parents with their engagement on and off campus. More specifically, it aimed to answer research questions two and three: How can culturally specific programs lead educators to gain insight on engagement 
taking place between parents and children at home? (A question aimed at understanding how the relationships built at MEC lead to parents to open up about non-traditional forms of engagement at home). And how can culturally specific programs support overall parent engagement? (A question aimed at understanding how MEC can help enhance impact). The subthemes explored in this section were: Preparation and support, oncampus engagement, off-campus engagement, and program limitations.

Preparation and support. It takes time, energy and skills to engage with one's child's learning. MEC recognizes that its parents have varying levels of experience with engagement and therefore looks to support them through a number of methods, beginning with school orientation. School orientation is vital to welcoming parents and initiating parent-school relations for the year. It gives parents the opportunity to learn more about MEC's history, its goals, its program offerings, and its staff. Antes que comenzara la escuela nos juntamos para aprender sobre el programa. Ahí conocí a la trabajadora social, a la [enlace familiar] y a otros padres. No recuerdo todo, pero si recuerdo llegar esa noche a la casa y empezar hablar con mi hija acerca de la escuela. "Before school began, we gathered to learn about the program. There I met the social worker, [family liaison], and other parents. I do not remember everything, but I do remember coming home that night to talk to my daughter about her new school," said one mother during the focus group. Si, también lo recuerdo. "Yes I also remember that," said another. Ese fue el primer día que conocí a los otros padres y la primera vez que me sentí 'excited' para que la escuela comience. "That was the first time I met the other parents and the first time I felt excited for school to start," said another mother who has since that orientation only 
missed two parent gatherings. Ahi fue cuando me di cuenta que el programa también es para nosotros. Por eso decidí regresar la semana entrante. Aquí siempre se aprende algo $y$ por eso trato de no faltar. "I realized then that the program is also intended for us and that is why I decided to return the following week. You always learn something here and that is why I try not to miss any gatherings." In the end, parents were sent home from these orientation sessions with practical engagement tools to help prepare their children for the upcoming school year, an open invitation to come back on campus on a weekly basis, and numerous affirmations for the work they had already begun at home with their children.

When parents arrive to MEC they are exhausted and are often times dealing with varying levels of trauma. Their strength merits recognition and their actions should be affirmed whenever relevant and possible. During the orientation process parents were asked to think about their daily interactions with their children. They were asked to recall any time they eat together, laugh together, clean together, play games together and talk together — and to think about how those things impact the relationship with their children. These behaviors are forms of engagement. They might not be subject-matter learning, but they are indicative of emotional learning and relationship building. It is during this session that parents realize for the first time that certain behaviors can have a great impact on their child. Nosotros siempre cenamos juntos--desde antes. Es nuestro tiempo para discutir en familia lo que hemos hecho y aprendido ese día. "We always dine together-since before. It is our time to share as a family what we've done and learned that day," said the mother with two enrolled children. No sabia el valor de esta práctica 
hasta que me lo dijeron. Ahora no hay noche que faltamos. "I did not know the value of this practice until I was told. Now there is not a night we miss."

Intended to build bridges, these orientation sessions allow parents and school personnel to learn from one another, and contribute to gaining insight on engagement taking place between parents and children at home. This gives school personnel the opportunity to affirm parent behaviors and efforts, and gives them the chance to start thinking about strategies for how to best complement powerful home engagement. This relationship thus becomes balanced and enables parents to see themselves as valuable contributors to their child's learning.

On-campus engagement. When it comes to on-campus engagement, anything that prompts a parent to be on campus is considered engagement. Whether it is dropping off or picking up one's child at school, having a scheduled or unscheduled meeting with a staff member or participating in the parent program - if the parent is on campus, they are engaging. This section will explore how on-campus engagement enables staff and parents to get to know and support one another and how it then allows for school personnel to support parent engagement with their children at home.

Although it is not expected for parents to drop-off and pick-up their children from school on a daily basis, many parents do one or the other, often times taking turns with other parents who have become friends. Si es que lo puedo traer a la escuela, lo traigo. Igual en recogerlo. A veces no puedo, pero es una prioridad para mi-especialmente por que me da la oportunidad de ver a la directora y a otros padres. "If I can bring him to school, I bring him. Same goes with picking him up. Sometimes I cannot, but it is a 
priority for me - especially because it allows me to see the principal and other parents," said a mother whose weekly schedule changes, but at times is flexible enough to do one or the other at least three times a week. This simple practice becomes valuable, as their drop off or pick-up practice often leads to other forms of engagement.

During the focus group, parents revealed that they find themselves staying for the entirety of the school's drop-off or pick-up hour, so that they can socially connect with other parents or with school personnel. Since many of their schedules are constantly changing, this hour becomes something to look forward to. A veces no llego a la reunión de padres, pero si llego a dejar o a recoger a mis hijos. Ahi me veo y hablo con bastante gente. "Sometimes I do not make it to the parent gatherings, but I do make it to drop-off or pick up my children. There I see and catch up with a lot of people," said a mother of three who went on to share how grateful she feels that she gets a new opportunity each day to say speak with others. For them, the experience is more than just taking their children to school, it is also having a social outlet - one that is otherwise nonexistent for many. Es una buena oportunidad para sentirse parte de algo. "It is a great opportunity to feel like you are a part of something." While the drop-off and pickup hour is more like 30 minutes, this has led many parents to bond with one another and get valuable facetime with other school personnel.

In addition to offering an orientation, a parent program and parent-teacher conferences, the school also makes it known that their school social worker is always available to speak with parents. Por lo menos una vez al mes vengo temprano para poder hablar con el maestro o la trabajadora social. A veces tengo cita y otras veces solo estoy 
pasando para saludar "At least once a month I try to come early so that I can speak with my son's teacher or the school social worker. Sometimes I have an appointment and other times I am just stopping by to say hello," said a parent who appreciates quarterly parentteacher conferences, but also appreciates the ability to have flexibility on when she can stop by and speak to school personnel about the successes and limitations of her son. Las conferencias son importantes, pero aún más importante es saber que puedo hacer un cita con el maestro o la trabajadora social cuando lo necesite. "The [parent-teacher] conferences are important, but even more important is knowing that I can make an appointment with the teacher or social worker whenever I need it.” This flexibility has allowed parents to deepen the relationship they have with school personnel. It has strengthened their lines of communication and it has inspired them many of them to participate in the parent program.

The parent program engages on average about 10 parents - a fourth of the parent population—on a weekly basis. According to the family liaison, social worker and school principal, this program will impact about 32 parents by the end of the 2017-2018 school year (as the weekly 10 participants are not always the same people). This method of engagement is quite successful as over the course of one year it will engage close to $75 \%$ of the parent population. When asked why they keep coming back to the workshops the parents almost unanimously answered, nos ofrecen mucho. "They offer us a lot." Es una buena oportunidad para aprender muchas cosas y conectarnos. "It is a great opportunity to learn many things and to connect with one another." When it comes to what they are learning they shared that they learn how to use a computer, navigate the internet, set up 
email, and use programs like Excel. Esta ayuda vale mucho y nos enseñan sin hacernos sentir inútil. Nos tienen paciencia. "These skills are worth a lot and they teach us without making us feel unintelligent. They have patience for us," said one parent. Nunca habia aprendido a usar la computadora. Ahora se como usarla y puedo ayudar a mi hijo encontrar información. "I had never been taught how to use the computer. Now I know how to use one and I can help my son access information," said another. In addition to these workshops, guest lecturers are also brought in to supplement the learning that goes on with more specialized information. Por lo menos una vez cada ocho semanas, nos visita un profesional con información útil. "At least once every eight weeks, a professional visits us and shares useful information," said the family liaison. "We've had a nurse who works at a free clinic, a lawyer who specializes in immigration, a dentist, a nutritionist... we have arranged for a wide set of experts to come and share some of their knowledge completely pro-bono." Given the limited resources many parents have, these might be the only opportunities they get to ask an immigration lawyer or a nutritionist questions without a cost associated. Los talleres han sido muy informativos. He aprendido mucho y estoy muy agradecida. "The workshops have been very informative. I have learned a lot and I feel very grateful.”

The attainment of useful skills, however, does not end there. The parent program also refers parents to off-campus resources than can be of value to families, and also teaches them a number of skills for how to engage with their child's learning at home. Nos dicen que la cosa más importante es que hablemos con nuestros hijos. "We're told that the most important thing is to talk with our children." Indeed, engaging in dialogue is 
engagement, but there are specific tools one can learn that can enhance the level of connection between parents and their children such learning how to ask a good openended question. Antes no sabía lo que eran preguntas con final abierto. Ahora casi todas las conversaciones que tengo con mis hijos son con el propósito de aprender-no solo responder si o no. "I didn't know before [the parent workshops] what an open-ended question was. Now, almost all of the conversations I have with my children revolve around learning — not just getting a yes or no answer." The simple act of asking a good question can truly change the course of a conversation. It can give the person answering the opportunity to think critically and personally about their response. It can also inspire conversation, versus just one-word responses. Learning how to ask good questions takes practice, and therefore parents spend a significant amount of time hearing what a good question sounds like and practicing amongst themselves to experience what it feels like to be asked an open-ended question that gets them thinking and talking. Al principio fue algo muy raro para mi...practicar con los demás...tenía pena. Pero estoy muy agradecida. A cambiado completamente como hablo con mi hijo cómo aprendo lo que él está aprendiendo en la escuela. "At first it was very strange for me...practicing with others... I was embarrassed. But I am very thankful. It has completely changed how I talk with my son and how I learn about what he is learning in school."

Another way in which parents learn best practices is by sharing with one another way in which they are already succeeding at connecting with their child at home. Una de las mamas compartió con nosotros que ella y su hija se levantan al mismo tiempo y se preparan juntas para el dia. Se alistan, se arreglan, toman desayuno y hablan de lo que 
esperan lograr ese dia. Nos contó que la práctica se a convertido en algo muy importante para ellas dos. Me impresionó tanto que ahora quiero comenzar hacerlo yo con mi hija menor. "One of the mothers shared with us that she and her daughter wake up at the same time and they prepare for their day together. They get ready, have breakfast and discuss what they hope to achieve that day. She told us that the practice has become very important to both of them. It has left me so impressed that I now want to begin to do that with my younger daughter." Other things they learned from one another was that doing things together around the house—like cooking or cleaning—were valuable way in which to spark conversation and model responsibility. Complement these already important and valuable behaviors with strong open-ended questions, and you have a parent set up for off-campus engagement success.

Off-campus engagement. As mentioned in the previous section, a lot of offcampus engagement is already taking place between parents and their children. In addition to providing parents with a lot of useful personal skills, the on-campus parent program also provides them with tools and resources that help maximize learning off campus. Throughout the year, parents are sent home with a weekly report of what children have learned that week and what they will begin to learn the following. The goal of that report is to quickly summarize the learning and provide suggestions for how to engage with their children in conversations about the material. The suggestions are simple and are mostly geared at learning how to ask good open-ended questions that get children talking about the lessons. Nos sugieren preguntas—las cuales harán que nuestros hijos hablen. Es muy útil. "They suggest questions for us to ask—ones that will 
get our children talking. It is very useful." Even more than useful, the suggestions given are practical. Parents do not have to be experts on the subject to engage in dialogue with their children, nor do they need to have infinite time on their hands. También toman en cuenta que no tenemos mucho tiempo. Pero aún cuando estoy muy ocupada, me animo para conversar por lo menos 10-20 minutos. "They also keep in mind that some of us do not have a lot of time. But even when I am very busy, I encourage myself to talk for at least 10-20 minutes." Based on a one's schedule, a parent can choose between 10, 30and 60-minute question and answer prompts which allow even the busiest parent to use morning-prep time, dinner time, clean up time, or any other time as an opportunity to engage. Incredibly useful, these reports have changed the dynamic parents can have with their children and have increased the amount of parent engagement that occurs at home. Much like these reports, MEC has also developed a storytelling program that also supports off-campus learning.

Storytelling was one of the ways in which parents identified spending quality time with their children. Many of the stories parents described sharing were folkloric, passed down to them from their parents or grandparents, and comforting to tell their children as it connected them to the past they left behind. MECs objective is not only providing resources but also acknowledging and appreciating other sources of local knowledge and ways of learning. Local knowledge, also known as folkloric, indigenous or traditional knowledge, is a form of knowledge that is embedded in the cultural traditions of the regional, indigenous, and local communities in which one is from. This form of knowledge is representative of one's cultural daily patterns of living, and is oftentimes 
subject to be lost when emigrating from the region. Placing a high value on local knowledge and understanding the power of storytelling, MEC developed a multifaceted storytelling curriculum that supports parents and elevates their local knowledge.

The storytelling curriculum looks to pool parent knowledge — so that other parents can learn from other parents - and supplement local stories with other cuentos (stories) that introduce U.S. life from the point of view of Latino characters. The pooling of knowledge occurs at special storytelling workshops held on-campus. Here, parents are taught that their stories are valuable, and merit being learned by their children and community. Parents are asked to share some of their favorite stories and are often encouraged to share one another's tales. Es bonito venir y compartir cuentos ...asi aprendemos algo nuevo y nos acercamos aún más. "It is nice to come [to the workshops] and share stories...that way we learn something new and get even closer [with one another]," said a parent who met her closest friend at one of the storytelling workshops at the beginning of the year. In speaking to all of the parents, it became clear that these storytelling and story-sharing workshops better equip parents to engage with their children at home. They also elevate traditional knowledge and place parents as teachers with worthy resources to share. Though these workshops are transformative to those that can attend, all MEC parents — regardless of their ability to attend the parent workshopsreceive monthly storytelling support.

Each month, students are sent home with a grade-level appropriate book and a supplemental guide that helps explore the content of the story. In many ways, this experience is like a book club, with parents and students both engaging with and 
discussing the storylines. El programa de cuentos es muy popular con los padres e hijos. Cada mes esperamos que llegue el nuevo cuento para juntarnos y leerlo en familia. "The storytelling program is very popular with parents and children. Each month we wait for the new story to arrive so that we can gather and read it as a family." For many families, this practice has heightened their desire to read, with eight of participants stating that it prompted them to apply for a library card. All interviewees also stated that the monthly story shapes their family free time and is often reread in some capacity 5-15 times throughout the month. For parents who cannot always attend the storytelling workshops, these take-home guides allow them to still make story time a priority at home. Como no siempre puedo atender los talleres, estoy agradecida que por lo menos me llega el formulario con preguntas. "Since I don't always get to attend the workshops, I am grateful that I at least get the form with questions," said a mother who at best attends a parent workshop once every six weeks. Los cuentos son importantes y aprecio la oportunidad de participar de alguna manera. "Stories are important, and I appreciate the opportunity to participate in some capacity."

True in their commitment to serve as many parents as possible, MEC has created a number of opportunities to support parents and their engagement with their children off-campus. In spite of all of their efforts, MEC does not reach every parent the same way. This was noted during the focus group with six parents, as they candidly detailed programmatic limitations that prevent some parents from fully taking advantage of MEC's offerings. 
Program limitations. While MEC focuses heavily on parent engagement, there are a number of factors that make engagement difficult for parents on and off campus. These limitations primarily revolve around a student's finite enrollment, a parent's educational background, a family's limited time (and other resources) and the current political climate. These factors are important to understand because they are a true limitation for many parents. While apathy might be a reason that some parents choose not to engage with the resources made available to them, conversations with the parent participants indicate that other realities are to blame for the limited engagement of other parents.

Finite enrollment. The prime organizational limitation of MEC is its regulation on enrollment, making students only eligible to be enrolled for one year. As stated earlier in this paper, the program is specifically intended to support new immigrant students in transitioning into a 100 percent English language speaking school by the beginning of the following school year. This becomes a limitation because some families see this as a reason to not become as invested in a school where their child may be a student much longer. Una de las madres-que vive cerca a mi-me ha dicho que no viene porque no ve el sentido en venir. Que es solamente un año y mejor no acercarse mucho. No me parece, pero tampoco la tengo que estar convenciendo que está perdiendo varias oportunidades. "One of the mothers - that lives close to me - has told me that she does not come because she does not see the point in coming. That is it only one year and that it is best to not get too close. I do not agree, but I am also not going to try to convince her that she is missing out on a lot of opportunities," said a mother who continued on to share that she thinks her neighbor is just trying to manage her relationships to avoid being disappointed or sad 
when the time comes to transition out of the program. Comparto con ella algunas cosas que aprendemos, y creo que lo agradece pero prefiere mantener su distancia. Perdió mucho muy rápidamente. Todos, en realidad. "I share with her some of the things we have learned, and I think she appreciates it but is choosing to keep her distance. She lost a lot very quickly. In reality, we all did [lose something]." This account was important to hear, as other parents might also share these feelings.

Regarding leaving, the mothers unanimously agreed that it will be tough. Sé que va ser dificil [ir me]. Paso casi todo mi tiempo libre aqui. "I know it is going to be difficult [to leave]. I spend most of my free time here," said a mother of four who is one of few parents who has been at MEC for two years. Sometimes, depending on the circumstance, a student will be admitted for a second year — but this is so seldom and difficult that it is not advertised. Clearly, people want to stay. No quiero que mis hijos se vayan de aqui. Nos quieren mucho, y nosotros apreciamos todo lo que han hecho por nosotros. 'I don't want my kids to leave [MEC]. They love us here, and we appreciate everything they have done for us," said the same woman visibly getting emotional. Pero se que es necesario y que vamos ha estar bien. Nos han dado mucha ayuda y nos han enseñado cómo tener confianza. "But I know that it is necessary and that we are going to fine. They've given us a lot of help and they've taught us how to be confident in ourselves.”

Educational background. A parent's educational background and their experience with schooling can also be a determinant of engagement. If a parent's time as a student was marred by feelings of ineptitude or deficit thinking, their negative past experience 
with educational institutions could be a reason why they are choosing not to engage or build relationships on campus. Hay algunos padres que no vienen por que no les gusta estar en una escuela, no saben que pueden contribuir... excusas, pero bueno... aya ellos. "There are some parents who do not come because they do not like being in a school, they do not know what they can contribute...excuses, but well... that is up to them," candidly said a parent who went on to express frustrations towards those who are letting the opportunity pass them by. Tenemos muchas oportunidades acá. Más que nada, me da tristeza por ellos. "We have a lot of opportunities here. I am sad for them more than anything."

During the focus group, a similar discussion emerged around reasons why parents may be choosing not to engage. This was a great opportunity to hear parents candidly express why they at first contemplated opting out. No me fue bien en la escuela. Me salí a los 14 años y no recuerdo muchas de las cosas que aprendí. "It did not go well for me at school. I left when I was 14 years old and I do not remember many things I learned," said a mother smiling who has since come to realize that in spite of her limited education she has a lot to contribute to her child's learning. El que no me haya ido bien en ese entonces, no significa que no me puede ir bien ahora. No hay que tener miedo de no saber or recordar cosas... o si no que ejemplo les estamos dando a nuestros hijos? "It not going well for me then does not mean it cannot go well for me now. You cannot be scared of not knowing or remembering things... or else what kind of example would we be giving our children?" And while that and other similar statements were powerful to hear, it is 
also important to recognize that things can become more complicated when taking into account community mental health.

Experiencing stress as a child can have long-term effects on one's psyche and feelings of self-worth — especially if therapy or other forms of support were never sought out. It is not unreasonable for someone who has experienced stress in school, to choose to abstain from reengaging in a situation that might trigger negative memories or feelings from their past. Undoubtedly, some parents are experiencing this inner turmoil. School personnel recognize this and are committed to supporting parents the best they can without overwhelming over overpromising the level of mental health care they can offer. "Some parents are dealing with severe trauma. Not just trauma induced by the move, but by unresolved trauma that is just now being explored. We always aim to support our parents the best we can, but we also have limitations," said the school social worker who spends a lot of her time providing counseling support for parents who are limited or deeply traumatized by numerous things. "There is only one of me, and there are a lot of things that need to be dealt with on campus. I provide the support I can, but if I cannot I do my best to refer them to free local services that I personally know."

While it is a priority to engage as many parents as possible, there is only so much that MEC can do. Simply stated, there are not enough resources to support each parent's individualized needs, especially when it comes to mental health. Over the last 20 years, public school budgets have drastically cut helping professional roles. Across the United States, school counseling, psychology and social work roles are disappearing, or they are being combined with other positions that make it close to impossible to meet the needs of 
both roles. This is not sustainable-even in a place like MEC where parent size was relatively small throughout the 2017-2018 school year.

Time and other limited resources. A lack of expendable resources is another factor preventing parents from engaging in more school-related functions. All of the parents interviewed, identified money and time as being the most difficult assets to come by. They also expressed that not having enough money or time has led to increased tension in their household. El no tener dinero es muy estresante. Mis niños están creciendo, necesitan nuevos zapatos, quieren juguetes y necesitamos también pagar la renta y la comida del mes. "Not having money is very stressful. My kids are growing, they need new shoes, they want toys and we also need to budget for food and rent," said a parent who identifies financial stress as a major limitation to her everyday happiness. Cada mes pienso que no los va alcanzar el dinero, pero gracias a dios, hasta ahora lo hemos logrado. Otros padres lo tienen peor... sin seguridad de nada. "Each month I think that we are not going to have enough money, but fortunately, we have made it work. Other parents have it worse...with no security whatsoever."

Lack of expendable time is another factor that limits parent engagement. Often working two jobs in order to make ends meet, free time is a commodity that is hard to come and when it does, it is often used for rest and recovery. Many parents are unable to engage at the same rate as other parents due to the mere fact that they do not have time. Seven of the 11 parent participants all live with a partner. When discussing this subject, all seven stated that due to their partner's work schedule, workshops and meetings taking place during traditional working hours, are things they are never going to be able to 
attend. El horario de mi esposo es muy difícil. Trabaja todo el día y cuando llega por la noche solo quiere comer y dormir. "My husband's schedule is very difficult. He works all day and when he arrives at night all he wants to do is eat and sleep." Many of the mothers I interviewed also expressed their own struggle to find free time for themselves and quality time with their partners. Siempre estamos hacienda algo, nunca paramos. Por eso a veces no vengo... necesito el tiempo para poder descansar. "We are always doing something, we never stop. That is why sometimes I do not come...I need the time to rest." Though understandable why a parent would choose to spend their free time at home or on their own, this inevitably is a limitation to engagement.

Political climate. The final factor preventing parents from engaging at higher rates with their children's learning on and off-campus was the current political climate. Xenophobia has been rapidly increasing in the United States since the War on Terrorism began in 2001 (Massey \& Pren, 2012). Over the last three years, however, anti-immigrant sentiment has been the loudest it has ever been, mostly attributed to the Trump Administration's ruthless stance against unauthorized immigration. In 2018, tensions reached an all-time high for the undocumented community, as those being detained at the border were systematically separated from their families in detention centers. Needless to say, people were scared. Even in a place like San Francisco-known for years as a sanctuary city—-people living in the united states without authorization were scared to leave their homes and engage in communities they had been a part of for some timeincluding school. 
The 2017-2018 school year was particularly difficult for MEC, as the majority of its families live with some sort of immigration uncertainty. In response to the palpable fear of parents, MEC decided to implement a series of workshops for parents during their weekly on-campus drop-in workshops that would allow for them to ask questions about immigration and the political climate. Invitaron a una abogada, un maestro, un representante de un centro de comunidad—nos brindaron mucha información. Pero claro, mucha gente sigue con miedo, incluyendo yo. "They brought in an immigration lawyer, a teacher, a representative from a community center - they provided us with a lot of information. But of course, many people are still scared, including me.”

While MEC has done a number of things to show their parents support, the difficult reality is that they cannot protect parents from the city, state or federal government. Providing useful resources, and being a support system for its parents, is all that MEC can really do at this moment. The country's lack of immigration reform has always been a limitation for MEC, however the current climate has made things drastically more difficult for all parties involved. In the end, MEC supports all parents and the decisions they choose to make to protect their families.

Summary. There is not one but many reasons why some parents are unable to engage with MEC and its numerous offerings. Considering that this study only met with 11 parents, there are likely more limitations than the ones analyzed. This part of the study solidified the notion that it is important to take a step back and listen intently to what people are and are not saying. As educators and social workers, it is important to make a 
concerted effort to read between the lines and adjust to new factors as they present themselves.

\section{Resiliency}

Based on the data collected via the focus group and one-on-one interviews, resiliency was a defining theme for parents. As greatly detailed in this analysis, MEC parents have endured a lot since arriving to the United States. Many of them came with nothing, and still have very little possessions. Material items aside, parents who have been able to participate in some or all of MEC's program offerings have notably benefited from the program. Primarily when it comes to having greater confidence in themselves, feeling worthy and self-actualizing.

Confidence. Confidence is hard to measure. Based on conversations with parents, however, it is clear in how they speak about their journey that their levels of confidence have likely increased from when they first arrived on campus. No sabia nada cuando llegué a los estados unidos. Ahora se como navegar la ciudad y me siento parte de una comunidad. "I did not know anything when I first arrived in the United States. Now I know how to navigate the city and I feel part of a community," said a mother who has chosen to move to the east bay once the school year is over due to the ever-increasing prices in rent. Voy a extrañar a MEC, pero tengo confianza que me va ir bien en nuestra próxima etapa. "I am going to miss MEC, but I am confident that it will go well for us in the next stage.” And just like this mother expressed her confidence in the next stage, 
other women also used that same word to describe how they felt about transitioning into another school.

Nos han enseñado confianza. "They've taught us confidence."

Tengo confianza en mí misma. "I have confidence in myself."

Con un poco de miedo, pero con confianza. "A bit fearful, but with confidence."

Al final del día hay que confiar. Y yo confio. "At the end of the day you have to have confidence, and I have confidence."

Ahora tengo la confianza que necesitaba. "Now I have the confidence I needed." Gracias a esta preparación, confío que nos irá bien. "Thanks to this preparation, I have confidence that it will go well for us."

Tengo confianza que puedo apoyar a mis hijos. "I am confident that I can support my children."

In wrapping up the interviews, it was heartwarming to see how confident these women felt. It was clear that the journey had been a struggle, and that many of them were still experiencing daily obstacles and managing setback. Todavía me cuesta. Tengo varias cosas en la mente, pero aquí estoy. Un paso cada dia y se van mejorando las cosas. "It is still difficult. I have many things on mind, but here I am. One step at a time and things get better." And indeed, MEC reminds parents that all they need to take is one step at a time. Todo no se resuelve en un día... cada día es mejor que el día anterior. "Things do not get resolved in a day, but each day is better than the day before."

Worthiness. Another quality noticed was worthiness, as in feeling that one is good enough to contribute and is deserving of respect. While this study was not longitudinal, it 
was clear in the conversations with parents that they had experienced a shift in their selfesteem as it pertained to worthiness. No pensé que iba llegar el día cuando me iba sentir útil... He aprendido que no necesito ser maestra para ayudar a mis hijos en la escuela... la relación en casa es igual de importante. "I did not think that the day would come when I would feel useful ... I have learned that I do not need to be a teacher to help my children with school...the home environment is just as important." This mother went on to detail how feeling valued on campus by school personnel made it possible to start seeing herself as someone worthy of respect and someone worthy of contributing the community's learning. Todos contribuimos algo, cada padre tiene algo para compartir. "We all contribute something; each parent has something to share." During the focus group, when asked if being a part of the MEC program had boosted their self-esteem, all of the parents unanimously said yes. Sin duda. MEC me ha enseñado a ver cosas en mi misma que nunca habia visto. "Without a doubt, MEC has taught me to see things in me that I had never seen in myself," said a mother who has become a quick leader amongst her peers. Aqui nos apoyan y aprendemos ha apoyarnos. "Here they support us and we learn how to support one another." Other statements that related back to feelings of worthiness were:

Tenemos que valorarnos. "We have to value ourselves." Nuestra experiencia vale mucho "Our experience is worth a lot." Nuestros hijos nos necesitan. "Our children need us." Tengo mucho que ofrecer. "I have a lot to offer." 
Across the board, parents described their experience at MEC as being central to the development of their self-esteem, as it pertained personally and communally. Si no fuera sido por esta oportunidad y la ayuda que nos brindó la escuela y los maestro, no sé donde estaría. Al valorarnos ellos, nos han enseñado a valorarnos a nosotros mismos. "If it were not for this opportunity and the help MEC and the teachers offered us, I do not know where I would be. In valuing us, they have taught us to value ourselves."

Self-actualization. The final way in which resiliency was observed in parents, was in how they attributed their time at MEC as formative in developing lifelong skills that would support their continued growth beyond their time at MEC. Sabia muy poco antes de venir a MEC. No sabía cómo usar la computadora, usar programas como Excel, tomar el autobús, usar la biblioteca... ahora me siento más preparada y con ganas de aprender más. I did not know a lot before coming to MEC. I didn't know how to use the computer, how to use programs like Excel, how to use the bus, or the library... Now I feel more prepared and have a desire to learn more." Another mother interjected and said that since she learned about the free classes at the community college, she now hopes to enroll in one of the the upcoming English-as-a second-language (ESL) programs. Si es que hay la oportunidad para aprender mejor el inglés, por qué no hacerlo? No va ser fácil, pero quiero tratar. "If there is an opportunity to better learn English, why not take it? It is not going to be easy, but I want to try."

While moving on from the program will be difficult for many, the skills they've obtained go beyond the practical. Sé que va ser dificil. Paso casi todo mi tiempo libre aqui. "I know it is going to be difficult. I spend most of my free time here," said a 
mother of four who is one of few parents who has been at MEC for two years. Sometimes, depending on the circumstance, a student will be admitted for a second year-but this is so seldom and difficult that it is not advertised. Clearly, people want to stay. No quiero que mis hijos se vayan de aqui. Nos quieren mucho, y nosotros apreciamos todo lo que han hecho por nosotros. "I don't want my kids to leave [MEC]. They love us here, and we appreciate everything they have done for us," said the same woman visibly getting emotional. Pero se que es necesario y que vamos ha estar bien. Nos han dado mucha ayuda y nos han enseñado cómo tener confianza. "But I know that it is necessary and that we are going to fine. They've given us a lot of help and they've taught us how to be confident in ourselves."

Referencing time as a limitation and not an excuse was also another way in which resilient behavior was noted. Mi vida siempre a sido mi familia. Desde que me case y tuve mi primer hijo, no habia tiempo para otras cosas. "My life has always been about my family. From the moment in which I got married and had my first child, there was not much time for other things.” And this remains true for the majority of parents at MEC. Simply because some are able to attend workshops here and there does not mean they had expendable time throughout the day or even week. Often managing complex work schedules that did not follow a rhythm, the parents interviewed acknowledged that in spite of their heavy workload, they now feel a desire to make time and do things for themselves. Los talleres nos han ayudado ha abrir los ojos y a desear más para nosotros. Aunque no tenga mucho tiempo, tengo que seguir aprendiendo para mi y mi familia. 
"The workshops have help us open our eyes and desire more for ourselves. Even if I do not have much time, I need to keep learning for mi and my family.”

This level of commitment is nothing short of resilient behavior. Even in the face of limitations, parents are committing themselves to continue seeking personal development opportunities because it makes them feel worthy and adds to their level of confidence. While MEC has taught parents a lot, it could never be their intention to teach them everything. With the goal of helping launch many lives in the United States, MEC has supported parents in becoming independent seekers of knowledge.

Summary. Resiliency, though not immediately apparent, is a direct result of the relationships parents have been able to develop with MEC and its school personnel. On a weekly basis, parents who were able to attend workshops were made vulnerable. Struggle surely was a part of the process, but they came back time after time, and are now departing the program more confident than ever. For the first time, many of them feel valued, and realize that their experience merits respect. They are worthy contributors to their child's education and are also worthy of learning more and of pursuing their dreams of self-realization in a new country. Espero que este programa siga. Conozco muchos padres que podrían aprender mucho aca. Sin duda, el ser parte de esta comunidad a cambiado mi vida. "I hope this program continues. I know many parents that could learn a lot here. Without a doubt, being part of this community has changed my life." 
Findings: Demographics Questionnaire

Seven parent participants completed the questionnaire; others revealed answers asked in the questionnaire during the focus group or one-on-one interview. Some notable findings were that those that completed the survey expressed that they either felt "comfortable" or "very comfortable" being on campus (physically) and asking questions to educators. Those that completed the form also expressed that they enjoy attending and learning at school functions. Two participants expressed struggling to adapt to their new home environment, and another two expressed a desire to become a parent-leader. Table 4 (page 134) and 5 (page 135) detail participant responses. "N/A" indicates that they did not answer the question, either because they did not fill out the questionnaire or because they chose to not answer the question.

When it came to identifying feelings of belonging, enjoyment and struggle, some questions yielded more answers than others. While only two expressed that they were explicitly "struggling" to adapt to their new home environment, the concept of "struggling" is subjective, and could have been interpreted a number of ways. In the focus group and individual interviews, the biggest struggle was identified as homesickness, followed by financial resources. With regards to "enjoyment" of school functions, the majority of mothers expressed that they had favorable feelings towards "attending" and "learning at" school functions. During the focus group and one-on-one interviews it was revealed that enjoyment comes from connecting with other parents and learning tangible application skills that strengthen relationships. Lastly, when it came to leadership and being a "parent-leader," this question was not in reference to a particular 
role or status, but rather a feeling of wanting to lead others at some point or another. Given these answers, I think it would be great to continue studying what leadership development looks like amongst immigrant groups in culturally specific programs.

\section{Themes of School Personnel Interviews}

The major themes that emerged during the analysis of school personnel interviews were 1) institutional culture, 2) engagement, and 3) parent resiliency. The three main themes and their subthemes are depicted in Table 6 (page 136). Under institutional culture of a culturally specific program, the sub themes that emerged were official and unofficial goals, parent-school personnel relationships, and staff conviction for MEC program. The sub themes of engagement were on-campus engagement, off-campus engagement and limitations, and under parent resiliency, the sub themes were overcoming trauma, gaining confidence and verbalizing hopes and dreams.

Findings: School Personnel Interviews

The school personnel interviews were equally powerful in understanding the impact MEC has had on parent cohorts overtime. Candid and honest, the seven one-onone interviews provided this study with a multidimensional look at how different school personnel members perceive MECs strengths and weaknesses. No two interviews were alike, but in the analysis, it was clear that three major themes saturated the data that explored the three research questions. The three themes and their subthemes were: Institutional culture (official and unofficial mission, parent teacher relationships and staff 
conviction for MEC program), engagement (on-campus, off-campus and limitations), and parent resiliency (overcoming trauma, gaining confidence, verbalizing hopes and dreams).

Institutional Culture of a Culturally Specific Program

Designed to help newcomer students and families, MEC has developed a strong cultural identity in the twenty-six years it has served recently arrived Latino immigrants. During this time, its mission — to prepare its students in gaining the necessary skills and confidence needed to succeed in an English-language program - has also positively impacted families, most notably parents. In many ways, supporting parents and their growth has become a secondary mission for this program. In analyzing the data collected from school personnel, it became evident that in order to understand MEC's institutional culture as a culturally specific program, it is important to also understand the official and unofficial goals of the program.

Official and unofficial goals. Mission Education Center's (MEC) primary goal is to equip students with the necessary skills needed to succeed in a standard San Francisco Unified School District (SFUSD) English-language curriculum school. Given the time constraints, MEC has one year to do everything it can to strengthen its students' language acquisition and overall confidence. No easy feat, school personnel know that achieving these goals is much more cumbersome than it sounds. Simply put, one year is not enough time to guarantee that a child will be ready to transition and excel in a standard SFUSD school. While there is a strong desire to achieve these goals, it was clear in all of the 
interviews with school personnel, that supporting parents and their growth was just as important —if not more important—-than solely focusing on student English language acquisition.

The school social worker was very candid in their belief towards holistic family engagement and empowerment.

"Learning English is vital. Depending on the age in which the child arrives to the United States, however, they are going to learn it. Already, the majority of students are speaking English interchangeably with Spanish. It comes more naturally when you are young and that is why I focus more of my attention on building relationships with parents. Everything we are asking of our students needs to be supported by them. They need to be our allies, and the only way that happens is through building relationships.”

The school social worker went on to detail that a lot of things have been put in place to support this endeavor, such as hiring a full-time family liaison to be the main bridge between parents and school personnel and hiring an all-bilingual staff. "First come basic needs, then come academics. Relationships are part of those basic needs. Parents need people they can trust when acclimating to a new environment. Or else who are they going to ask for help?"

In another interview, the school principal praised the front desk manager, family liaison and social worker for their commitment to meeting with every parent various times throughout the year. "Our social worker and family liaison meet with every parent at intake and at least twice throughout the year. And our front desk manager... [they're] 
hands down the most popular person on campus." Considering they are only three people and are managing a wide range of schedules and needs, that is quite the achievement in reaching families. In addition to these on campus meetings, the family liaison, social worker and many individual teachers make themselves available throughout the year for home visits and digital communication. While these methods are useful and appreciated by a number of parents, "we want to be respectful of space, so we do not push them [home visits]," said the principal. "We have to balance thinking creatively and respecting boundaries. The hope is that they realize that we are willing to meet them where they are. That communication with them is valuable. All of that builds trust and trust helps build relationships."

Indeed, communication is central to building ties. Another method they employ to activate parent-personnel communication is sharing their work mobile numbers with all parents. "I still get text messages from parents from past years," laughed the principal. "For them, sharing our phone numbers is a big step in wanting to build bridges. They see that as a sign of friendship, and that is what we want," said the social worker. "Constant communication is my medium for building relationships," said another teacher.

"I call parents on a weekly basis, to give them positive and not so positive news. We also send every student home with a weekly newsletter, and parents receive automated messages with information regarding on-campus activities or programs. We really try to get creative when it comes to showing our commitment to parents. We have to get them on our side so that we can teach them as many skills as possible before they transfer to a new school. Getting 
parents on board, is without a doubt what I think will make a long-term impact on student education."

In short, MEC's mission has gone beyond what is listed on SFUSD's website. While student learning will always remain a priority, on-campus personnel know the learning and strengthening engagement behavior, is what will set parents up to be a lifelong resource for their children. As a culturally specific program, MEC is adapting to the needs of their population and electing to focus on building relationships as they belief this investment will lead to better achieving their main institutional purpose in the long run.

Parent-school personnel relationships. Parent-school personnel relationships are a fundamental experience at MEC. They define the culture of the program and are vital to achieving the goals set out by MEC each year. Though crucial, these relationships are not built overnight. They require mental and physical energy and are largely made possible due to the cultural capital. As outlined in the previous section, in this dissertation, cultural capital refers to the value of shared culture between two or more people. More specifically how cultural capital impacts the ability for relationships to be built between members of a shared culture. According to school personnel, cultural capital "is vital to build trust." Given that the immigrant experience is unique, in particular for Latino immigrants, "it is important that parents feel as if they have allies in the classroom and on-campus" said the school principal. "When thinking about the team we want to build, one of the things we look for is how well a candidate can relate to the experience of 
parents and students. We also want parents to feel as if they can relate to the teacher. It goes both ways."

As it currently stands, all but one staff member is Latino or bicultural-Latino. "This is an asset for us. We send a message by having a team of leaders that looks like the people we serve." Even the one staff member who is not Latino or multicultural agrees. "I am in the minority and I understand why it is important that we hire a predominantly Latino staff," said the social worker. Though fluent in Spanish, as the only White employee, they recognize the positive impact that having Latino professionals on campus has. "I have a great relationship with parents, but I know that there are certain things I will never fully understand. And I think that is fine, but that is why we need hire mostly Latino educators. There's a different connection. A different bond.” On the spectrum, MEC also has two employees with personal ties to the program. One being a former student and another being the family liaison. Cuando se enteran que fui parte de esta comunidad como madre, no me creén. Es importante que me vean en este puesto. "When they first find out that I used to be a part of the parent community, they don't believe me. It is important that they see me in this role." Evidently, as detailed in the parent interviews, it is empowering for parents to see someone that was once in their shoes, in such a prestigious role today. The family liaison's presence matters, it builds rapport and that rapport helps build mentor and peer relationships.

While not a direct priority, many parent-school personnel relationships become mentor-mentee experiences. This is primarily seen in the relationships that the family liaison develops with parents. Given her background, history and trajectory with MEC, 
many parents not only admire her, but also seek out her advice with regard to personal and professional growth. Muchos de los padres llegan con el autoestima muy bajo. Como madre que estuvo en la misma situación, los entiendo. Es dificil y toma bastante tiempo salirse de ese espacio mental. "Many parents arrive with really low self-esteem. As a mother who was in their shoes, I understand it. It is difficult and it takes a long time to get out of that mental space," said the family liaison in reference to the state in which parents arrive to MEC. According to her, the first couple of months are about acclimating to one's new environment. Getting to know one's surroundings and feeling safe. Toma tiempo sentirse bien, pero cuando uno lo empieza a lograr es importante también empezar a ver maneras de salir adelante. "It takes time to feel well, but once one starts to achieve this it is important that they also start finding ways in which to move forward." To the highly esteemed family liaison, moving forward is in reference to finding a new sense of purpose given the circumstances.

Todo inmigrante vuelve a empezar. Yo estoy aqui para apoyar a los padres, no presionarlos. "Starting over is part of the immigrant experience. I am here to support parents, not to pressure them." When asked if they felt like a mentor to other parents, the family liaison said yes. While their goal is not to have parents see their footsteps as the only ones worth following, it is important to them that people view them as a resource and inspiration. Es importante que los padres vean que si es posible salir adelante. Mi meta es poder darles toda la ayuda posible, compartiendo recursos y manteniendo las lineas de comunicación abierta entre nosotros. "It is important that parents see that it is 
possible to move forward. My goal is to help them as much as possible by sharing resources and keeping lines of communication open between us."

Two teachers and the school principal also brought up the mentor-mentee relationship. "Having someone they can look up to is an important part of the relationship we want parents to have on campus" said the school principal who credits the family liaison for providing the program a more personalized approach. A teacher added, "the fact that the family liaison is someone who can truly relate to [the parent] experience is unique and makes for a completely different relationship." According to her, it "leads to a different type of trust" that inspires parents to become more vulnerable when asking for support. Lastly, what makes these relationships so powerful are the way in which they demonstrate the staff's conviction and belief in the program.

Conviction for program. Deeply committed to the success of parents and students, educators at MEC have to have conviction for the program in order to be working there for as long as the majority has. Llegué y nunca me fui. "I arrived and I never left," said the family liaison, a former MEC parent and psychologist in Colombia, who has since transitioned to a fulltime SFUSD position. Creo completamente en el valor de este programa. Por eso es que estoy aqui. Tenemos la oportunidad de impactar a muchas familias. "I completely believe in the power of this program. That is why I am here. We have the opportunity to impact many families."

A former classroom teacher that now specializes in individualized reading support shared similar feelings. 
"We are seeing parents transition from being bystanders to being fully engaged with their child's education. This happens because we're empowering them to feel like collaborators and we're teaching them that asking questions-about anything - is important. We want them to feel like they can communicate with us whenever they want. The more we talk, the more we are able to personalize our work to their needs. This flexibility defines who we are as a school, and you don't find that everywhere. As a teacher who has been working for over twenty years, I have never seen any this anywhere else. I truly believe this program changes lives. I know it does."

They went on to share that due to low enrollment, they were given the option to temporarily move to another school and be a classroom teacher. "Absolutely not, I am not leaving this program. As much as I enjoy being in the classroom, I feel that my skills are best used here. That is why we created this role [for me]. I can't imagine being anywhere else."

Not wanting to leave the program was a sentiment shared by all of the school personnel interviewed. All of them had been with the program for at least five years, and they had no desire to go elsewhere as they believe that this role has been the most impactful role they have ever had as educators. "It feels like family here," said the school secretary that in many ways has become the face of MEC, as they are the person you first see when you arrive on campus. "I can't imagine having the same impact anywhere else. I love bringing positivity to the program, and reminding parents that things are going to get better." More than just an intake administrator, they have really gone above and 
beyond their job description to make an impact on the program and they do it because they believes in the power of what they are doing. "Students and parents are arriving to our school throughout the year with different needs and we're the only school who receives them in their native language. That's powerful. I am proud to be a part of a program that is able to offer that support."

Committed to the success of this program, it is clear that MEC personnel believe in the value of what they are doing, especially because they are able to flex with the needs of the community. Institutionally, it is clear that the culture of the program revolves around building relationships with parents. Yes, it is important to them that their students learn English and succeed academically, but that is only one aspect of learning. In order to ensure the continued success takes place beyond this program, parents need to learn how to become active participants in their child's learning journey. Learning to do this requires time and it requires vulnerability. Vulnerability is only achieved if parents feel they can trust the system, and trust is achieved via relationships, which is why building relationships with parents also defines the mission of this culturally specific program.

Summary. Given its unique mission and population, it takes a certain type of school professional with a certain type of conviction to work at Mission Education Center. Unlike other schools in which educators solely measure their impact on student success, MEC's institutional culture also pays close attention to the parent experience, and how a positive parent experience can positively impact student learning. In order to address this, MEC places a special emphasis on building relationships that will help transform the way in which parents experience education and how they in turn view 
themselves as contributors to their child's learning via on-campus and off-campus engagement practices.

\section{Engagement}

Supporting parents in developing a personalized practice of engagement is one of Mission Education Center's primary goals. In their approach, they begin by providing parents with the opportunity to personally grow and develop skills they might not otherwise attain, and then proceed to support them in becoming confident resources in their child's off-campus learning. While these two forms of engagement are important, MEC recognizes that given numerous limitations, not all parents will be able to engage the same way. With this understanding, MEC continues to explore various ways in which to support families beyond their current model.

On-campus engagement. With the hopes of getting more parents on campus, MEC designed a program specifically meant to address varying topics affecting parents and their families. Each week, parents are offered the opportunity to learn something that can be of great personal use to them, their families or their child's learning. While a strong emphasis is placed on hosting workshops that teach parents useful educational tools for home learning and engagement, it is not the only goal of the program. "Learning home engagement skills are important, but it is also important that parents see this time as an opportunity to personally connect with other parents, and to attain skills that might only be of use to them," said the school principal. In other words, according to the school 
social worker, "parents need to be given the opportunity to put themselves first every now and then" and this program allows them to do just that.

\section{Para muchos padres, nuestros talleres son una oportunidad para estar en} comunidad con otros padres. "For many parents, our workshops are an opportunity to be in community," said the family liaison when explaining that there needs to be a balance of learning and community building when hosting the weekly parent programs. Queremos que aprendan, pero más que nada queremos que vengan a la escuela y que se sientan bienvenidos. Si es que siempre estamos en talleres, se van a cansar. Hay que tener un balance. "We want them to learn, but more than anything we want them to come to school and feel welcomed. If we are always in workshops, they are going to get tired. We need to have a balance." And according to other school personnel members, striking a balance is important in order for parents to not feel as if they are falling behind or as if they are letting teachers down. One of MECs second grade teachers described this balance as "crucial in cultivating the relationship we want with parents." While providing learning tools are an important part of their service, so is "providing space to just be and feel comfortable on campus."

Off-campus engagement. While the parent program has become a vital part of MEC's engagement strategy, the school's primary goal is to support parents in learning how to creatively engage with their children off-campus. "Each week we provide parents with a summary of their child's learning and give them ideas for ways in which to continue that learning at home with their children," said the second grade teacher. "Whether it is by sending them a question guide, or a follow up story in which to share 
with their kids, or an unrelated activity that gets them talking, my hope as a teacher is to support parents in connecting with their children and showing them that learning comes in various forms." As an educator that values more than just academic learning, they went on to explain that in addition to sending home tools for academic learning, they send parents encouraging notes reminding them of their value. "Parents shouldn't have to stress about teaching their children division, they should focus on providing them moral support and love. It is important that they realize the value they themselves can only bring their children.”

Similar sentiments arose concerning off-campus engagement in all school personnel interviews. "Home learning does not have to involve homework, it can also involve teamwork between family members," said the education specialist when explaining that splitting tasks around the house are valuable ways in which for parents to teach their children important skills and engage in other forms of social learning. "Reading is important, but so is knowing the importance of cleaning up after yourself and taking care of your environment." One teacher noted that "learning goes beyond sitting down and reading a book" and that it is important that we support parents in seeing any opportunity they have with their children as an opportunity to learn something new. "Learning how to use the bus, learning how to measure out ingredients for a cake, learning how to ask for help... all of those skills are vital and it is important that we support parents in seeing all of these opportunities as methods for off-campus engagement." 
Program limitations. When it came to identifying limitations that prevent parents from fully engaging in the programs or resources offered, the two main concern identified by educators were a parent's limited time and a student's finite enrollment. In all of the interviews, it became clear that time was constantly against the success of the program. Whether it was in regard to the limited time parents have to dedicate to on-campus or offcampus engagement, or the limited time families have at MEC to acclimate to a new environment, "more time" seemed to be the answer all personnel gave when asked what they would like to see in order to better deliver success.

"Parents are pressed to do many things in a limited amount of time," said a teacher when detailing the struggles that many of their parents experience when it comes to engagement. "We can provide them as many resources as possible, but if a parent is working two jobs to support their family, I can understand why they may choose not to participate in our parent program or use the resources we send home with their child." In all of the parent interviews, free time was identified as being so precious that when it did come around, parents often chose to spend it on themselves. "This is why it is important that we teach parents that engagement does not have to be subject based. Encouraging them to talk with their children about anything is just as important as encouraging them to ask what their child learned in math class," said one teacher when detailing their strategy for engaging busy parents with their children. "Parents have different realities. We should keep our parent program, but we should also give parents various points of entry into the world of engagement." 
Much like a parent's limited free time, another factor that proved to be limiting in engaging parents was the one-year enrollment time limit for students and their families. According to all educators, the one-year limit is "arbitrary" and "unreasonable" given how long it can take parents to adjust to their new environment. Demora entre tres a cinco meses para que los padres se acostumbren al ritmo del programa. "It takes three to five months to get parents accustomed to the flow of the program," said the family liaison. With only ten months in a school year, es muy difícil decirles adiós a los padres cuando tu notas que necesitan mucho más apoyo "it is very difficult saying goodbye to the parents when you see them in need of much more support."

While the goal of MEC is to transition students into English language schools, the one-year limit can be daunting, considering that adapting to a new culture can take years if not a lifetime to achieve. This is especially true for parents who are balancing a number of changes to their reality. "It takes time to build relationships... having to then send parents off to another school feels as if we're letting them down after working so hard to gain their trust" said a teacher. Another felt similarly on the matter adding, "we are not supposed to keep students past a year, but it is impossible to do all the work that is expected of us in ten months when you take into consideration each family's unique needs." The school social worker felt especially torn by this time constraint: "Trauma does not disappear overnight, but it can be aggravated quickly. Having to depart from our program so soon may only add to some parents' trauma." A notable strain on their work, I asked personnel, why the limit? "The district," they all said, adding that SFUSD's main goal will always be to transition students into English schools. The school principal 
added, "learning English is of course a priority, but given how many things need to be learned in one year, it cannot be our only goal."

Summary. Considered to be the key to continued student success, supporting parent engagement remains a top priority for MEC. Taking into account the various needs of the community, the program has designed numerous opportunities for parents to engage in positive learning experiences on-campus and off-campus. In spite of all of their work to make these experiences accessible, certain limitations--a parent's limited free time and finite family enrollment--still prevent a number of families from fully engaging the way MEC would like to see them doing so. Noted as obstacles, these limitations are not taken for granted or ignored by the administration, and each year MEC explores new ways in which to close the gap of opportunity so that more parents gain the necessary skills needed to succeed in the school programs beyond MEC.

\section{Parent Resiliency}

The final theme that emerged when interviewing school personnel was parent resiliency. "Our parents do not get enough credit," said the school secretary. Like her, the rest of the staff members see MEC parents as modern-day heroes worth admiring and learning from. "I am constantly amazed by the strength of our parents," said one of the teachers. "Who needs superman when you have MEC parents?" And though there is no denying that parents will still need support once they leave the program, there is a sense of relief knowing that they will head into the next stage of their life with a greater sense of confidence in themselves and their journey. "My wish is that they continue to work 
through the pain while also dreaming the way they deserve to dream... BIG."

Constantly adapting to new situations, MEC parents are a true example of what it means to be resilient. To parents, the family liaison — once an MEC parent — is an inspiration and someone who symbolizes hard work and resiliency. Si es que ellos alcanzaron poder ser profesionales en este país, sé que también puedo yo. Tal vez no de la misma manera, pero tengo esperanza que pueda hacer algo de valor. "If they were able to become professionals in this country, I know I can too. Perhaps not in the same manner, but I hope that I can do something of value," said another mother who worked as a secretary in her home country and now balances a number of jobs under the table. Notably, the presence and stories of these educators are powerful. They impact how parents see themselves.

According to all school personnel, parents should be "admired" and "given respect" for everything they have had to endure and overcome in such a limited amount of time. More specifically, they noted that the MEC parent population demonstrated strength in working to overcome trauma, gain confidence, and begin the process of selfactualization all within a year's time. Important to the morale of this study, it is important to wrap up this analysis by including the ways in which school personnel admire parents and their resiliency.

Overcoming trauma. Though impossible to overcome in a year's time, trauma is something that many parents are managing on daily basis. According to the school social worker, "trauma is not something that is easily overcome... there are good days and there are bad ones." They went on to note that various things can trigger trauma, and 
sometimes parents and students may not even realize they are affected by something until a memory is triggered by an outside source. As the only school social worker, they meet with all parents at least twice a year to assess how they might best be supported on campus and off. "During my first meeting with families it is heartbreaking to see how much pain parents and students are experiencing. Trauma is a very real thing for people who have had to leave everything behind only to start over in a place where they might still feel unsafe." In reference to the current political climate, they noted that antiimmigration sentiment only "adds to the trauma" already being experienced by families. "The fear of deportation and family separation is very real in our community. Parents who choose to stay at MEC are facing their fears on a daily basis while also addressing varying levels of trauma they arrived to the United States with."

Though quick to assure that trauma is not something that is easily overcome, the school principal noted their admiration for all parents and students considering how trauma many of them are having to work through while also managing to adapt to a new environment. According to them, it is "incredible to see how resilient our families are." Given the limited resources available to them on campus and off, they noted that their resiliency is a direct result of their strength. Three teachers all added that they also feel inspired by the resiliency of their parents. "Considering how much they are managingoften times alone - they are nothing short of an inspiration to me," said one. "Parents deserve our admiration... in spite of all the limitations they face, they are constantly moving forward." 
Gaining confidence. The second most noted way in which school personnel observed resiliency, was in the way parents developed confidence. "Even though parents are only with us for a year, their confidence levels soar as a result of their participation in our program," said the school principal. Adding to this theme, the school social worker noted, "it is in the way they ask follow up and clarifying questions" that parents demonstrate their increased level of comfort and confidence. "The growth that occurs between the first and second time I meet with them is astonishing. It is clear they feel more confident and in getting their point across or asking for clarity."

The school's family liaison corroborated the school principal and social workers sentiment noting that, cuándo comienza el año, muchos de los padres exhiben timidez...sin embargo, al empezar el segundo semestre, la actitud de ellos ha completamente cambiado. "When the year first starts, many parents exhibit shyness... when the second semester begins, however, their attitude has completely changed." Increased confidence is also noted in the way parents "begin to independently seek out advice and information" from teachers. "It takes time, but parents get there," added another teacher. "Everyone needs a boost when they first get started, but once parents see the power they actually have, they begin to be more proactive. This is clearly a sign of how empowered they've become."

Culturally specific programs are constantly working to reverse the negative effects that the U.S. education system has had on celebrating the worthiness and knowledge of communities of color. As one of the second grade teachers described in the closing of their one-on-one interview, "It is [MECs] duty to on daily basis let our families 
know how beautiful their culture is and how vital they are to our community. They are not hearing it from anyone else, and if we do not encourage them to love who they are and where they come from now, we will let hundreds of children grow up thinking that there is something wrong with them." By countering the de facto mode of education, these programs provide immigrant families the opportunity to learn about their culture in a positive light, leading them to build confidence and develop positive self-esteem.

Verbalizing hopes and dreams. As parents begin to overcome trauma and gain confidence, they also begin to explore their personal desires. During the second semester of school, this was witnessed when MEC parents were invited to anonymously share their hopes and dreams with the school community. With no guidelines, parents were given the freedom to say whatever they wanted without feeling judged. Muchos padres nunca han verbalizado sus sueños. Este ejercicio les da la oportunidad de decir lo quieran sin sentirse avergonzados. "Many parents have never verbalized their dreams. This exercise gives them the opportunity to say what they wanted without feeling embarrassed." Presented with the opportunity, 30 parents wrote notes ranging from what they wanted to do with their lives, to what they wanted to see, and where they wanted to go.

Displayed in one of the hallways, these notes became inspirational to all who passed by them. Each week, new notes would pop up, and in those notes new hopes and dreams were released into the universe. "The anonymous aspect of this exercise makes this activity even more powerful for me" said the school principal. "It reminds me that everyone has a dream." The school social worker noted that this exercise was important for students as well: "Seeing parents engage in a vulnerable activity also inspires students 
to do the same." One of the teachers was also moved by the activity and decided to replicate a similar exercise in their classroom. "It is admirable how much parents have overcome and how much they teach us in the process."

In addition to sharing their personal dreams, parents often took the time to share their hopes for their children. This was especially touching, as it marked for many the first time they felt comfortable enough giving their children advice on school and learning. Ver a los padres aconsejar a sus hijos es muy emotivo. Demuestra que confían en sí mismo y en el valor de sus consejos. "Seeing parents give their children advice is very moving. It shows that they trust in themselves and in the value of their advice." Among some of the notes that moved me were:

Eres un niño muy inteligente... se que lograras todo lo que te propongas, "you are a very intelligent boy... I know you will achieve everything you set your mind to."

Te deseo exitos y te [apoyaremos] en tus [decisiones] de los estudios. "I wish you success and we will support you in all of your school decisions." Me siento muy orgullosa de ti, hija. "I am so proud of you, daughter." Siempre ten esperanza y sueños. "Always have hope and dreams." Eres un tesoro valioso para tus padres. "You are valuable treasure to your parents."

Aunque no puedo escribir bien, [tienes] todo mi apoyo. "Even though I do not write well, you have all of my support." 
Creo en ti, y que puedes salir adelante con éxito. "I believe in you and your success."

Puedes contar conmigo siempre. "You can always count on me."

Esfuerzate y se valiente. "Try hard and be brave."

These notes, though simple in nature, demonstrated a parent's desire to not only selfactualize but also support their children in doing so. "Resiliency isn't just about parents, it is also about parents teaching their children to dream."

Summary. Constantly adapting to new situations, MEC parents are a true example of what it means to be resilient. "Our parents do not get enough credit," said the school secretary. I couldn't agree more. Like her, the rest of the staff members I spoke to, see MEC parents as modern-day heroes worth admiring and learning from. "I am constantly amazed by the strength of our parents," said one of the teachers. "Who needs superman when you have MEC parents?" And though there is no denying that parents will still need support once they leave the program, there is a sense of relief knowing that they will head into the next stage of their life with a greater sense of confidence in themselves and their journey. "My wish is that they continue to work through the pain while also dreaming the way they deserve to dream... BIG." 


\section{CHAPTER V: DISCUSSION}

Introduction

After spending the better part of a year interviewing and observing parents and school personnel at Mission Education Center, it is clear that the work being carried out at this culturally specific program is critical, highly important to the field of education and social work, and worth being further explored. Interventions like these, which call for immigrant families and school educators to work together in identifying best practices for creating a secure, vibrant, and cohesive community, are vital in ensuring that immigrant families have the opportunity to integrate with necessary support. Not only are these programs crucial in integrating students and parents into the U.S. school system, they vital in interrupting current systems of oppression that fail to integrate immigrants in a way that honors their cultures and histories. Program like these are key in supporting the development of a healthy, multicultural and multifaceted community, that pay close attention to the unique experience of immigrant peoples with diverse needs.

Data gathered was enough to assert that culturally specific programs like MEC have the potential to deepen the relationship immigrant parents have with school personnel, and therefore strengthen their engagement on and off campus. More specifically, parent testimonials answered the study's three research questions: 1) How can culturally specific programs deepen the relationship immigrant parents have with school personnel? 2) How can culturally specific programs lead educators to gain insight on engagement taking place between parents and children at home? And 3) how can culturally specific programs support overall parent engagement? Connected by culture 
and language, parents and school personnel have numerous opportunities to establish and deepen relationships. This leads to increased levels of communication, sharing and learning.

When it came to non-traditional forms of parent engagement, the study revealed numerous methods in which parents engage with their children's learning, including storytelling, cooking together, reading together and visiting the community centers off campus together. Moreover, it confirmed that the relationships established between parents and school personnel made it possible for parents to expand upon and strengthen their engagement at home via tools like reading guides. It also demonstrated that strong parent-school personnel relationships inspire more parents to engage in traditional forms of on-campus engagement - even if their time is limited and inconsistent due to work schedules. In order to better understand conclusions, I will process the various themes in the discussion below.

The Power of a Culturally Specific Program

Belonging, community and inclusivity. Belonging is difficult to describe and even more difficult to measure. It involves feeling as if your dreams and goals are respected and valued, and that your life and holistic wellbeing are important to those around you. It is a measure of inclusivity that measures one's "insider" (versus “outsider") status. In its simplest form, it is the feeling of comprehending how your community operates. As defined, belonging is complex, and becomes even more complex for people of color who 
belong to communities that have been historically oppressed and ignored by systems that are solely informed by White culture, experience and history.

Aware of the systemic racism experienced by Latinos and immigrants in other programs, Mission Education Center aims to create an inclusive space for all of its community members. While subject matter learning is important, the school's focus is supporting integration, encouraging cultural exploration, facilitating Spanish language dominance, and building English language skills. In all of the parent interviews, participants made it clear that MEC had become more than just their child's school, it had become a center for culture, capacity building and networking. Aqui me siento recibida y aceptada... es mi segundo hogar. "Here I feel welcomed and accepted... it is a second home." Similar sentiments were expressed by other parents: Me siento a salvo, querida, apreciada, "I feel safe, loved and appreciated." While these expressed feelings were limited to the mothers interviewed, they were enough to conclude that MEC values inclusivity, relationships and respect amongst all partners.

As previously defined, belonging is complex and fluid. One can feel they belong and feel as if they are on the outside. I encountered Gloria Anzaldúa's Borderlands/La Frontera: The New Mestiza (1987) when I was an undergraduate, but I didn't really feel the power of the text until I was a graduate student researching the multifaceted Latino experience. Today, the text is central to my life and one that I often turn to when seeking strength and resiliency in the face of a verbal or physical attack on Latinos, immigrants and other people of color. Beautifully complicating the idea of belonging, Anzaldúa details the fluid condition of being ni de aquí, ni de allá. "Neither from here, nor from 
there," regardless of what side of the border you are on. Relating Anazaldúa's text to the experience of MEC parents helps one understand that lives can be shaped and informed by multiple places. Belonging is a human desire, but it is also fluid. What was once home, may no longer feel like home, and vice versa or both. For parents at MEC, the struggle for belonging and community is surely complicated. While they may establish new positive relationships, there is no denying there are unsolved feelings and sustained memberships in other places. For many, these feelings will be pushed aside and result in homesickness and other mental health issues. Aware of this possibility, the social worker—also a licensed therapist—provides MEC families with on-campus mental health support services year-round.

In order to give all parents and students the opportunity to identify and start working through mental health issues, it is required that they meet with the school social worker at the start of the school year. During those initial assessments, the social worker provides direct support, creates a plan for continued support or immediately refers parents and students to off-campus resources that are free, safe and have a history of working with new immigrant families. The family liaison also steps in when necessary to support the social worker, adding a level of support and camaraderie. This sort of process answers the first and second research question. Designed to be culturally specific, a program like MEC that values Latino histories and experiences allows parents to feel a sense of agency at school, which in turn leads them to deepen their relationship with school personnel. Though the impact this process has is limited to the time in which students are enrolled at MEC, giving parents the opportunity to take on leadership roles, 
lead workshops, celebrate birthdays in community, and create art that will be displayed on campus, and co-create art that will be displayed on campus leads many to feel as if they belong.

Skill building. Given the reality that MEC is a short-lived experience, and that many parents become attached to the program, MEC does a number of things to help parents feel somewhat prepared to continue living a healthy and social life beyond their tenure. When it comes to skill building opportunities, parents are taught how to use the library, how to access free programs offered by the city or county and how to enroll in free city college classes. They are also taught how to use public transportation and are connected with free cultural centers that explore Latino heritage and more

Holistic design. Critical in its design, Mission Education Center is a successful, culturally specific program because it flexes and evolves to the needs of its community. Its power lies in its adaptability, its ability to create an inclusive space for immigrant families, its integration with the community served, and its ability to give parents and students cultural capital, or power, in its system—sidestepping traditional, hierarchical roles and relationships (Curry-Stevens, Deloney \& Morton, 2018). Parents and students that arrive to MEC have little to no experience with the English language or how the education system works in the United States. They are newcomers, often times with limited formal education themselves, and since there is a lot to learn, MEC focuses one being more holistic in responding to the range of their needs. They value relationships, they treat their community members with respect, they recognize and affirm the work 
parents are doing on and off campus, and school personnel members are advocate for broader social change.

Given the holistic approach, MEC sets up time for the school social worker to meet with every family before the school year even begins and throughout the year offers numerous opportunities to continue evaluating a student and family's mental health needs. These meetings - especially the ones' that take place in the beginning - lead to the creation of an individualized plan for support and can also lead to the early identification of other mental health needs needing to be met by off-campus resources. As the year progresses, administrators and teachers are continuously able to refer students and parents to the school social worker, and students and parents themselves can individually ask for support. If ever the school social worker is not able to support a parent or student - be it because of their workload or the need of a specific service - they refer them to a number of trusted community resources that they have developed relationships with overtime.

Relationships and respect. MEC's focus on bilingualism and Latino culture make this a culturally specific program that values relationship building. Culturally specific programs that are designed with the needs of a specific cultural experience in mind make a difference in the lives of immigrant families by giving participants numerous opportunities to connect with other members of their community in a respectful way. Detailed at length by parents and school personnel, MEC's programmatic structure and offerings is what allows for their relationship with one another to deepen. The simple act of being able to communicate with their children's teachers is the first bridge parents build with the United States. This connection then facilitates the formation of a 
relationship, and that relationship leads to heightened curiosity and learning. As mentioned by a parent, had it not been for the rapport they had with their son's teacher, they would not have explored the parent program or paid much attention to the take-home reading guides. La relación que tengo con los maestros me anima a usar las cosas que crean. "The relationships I have with teachers encourage me to use the things [like reading guides] they create." While not meant to be a pressuring, the established relationships have proven to facilitate engagement, and ultimately that is what the school sees as a success.

Cultural capital. In sociology, the term cultural capital refers to tangible and intangible assets that support someone's social mobility (Bordieu, 1984; Swartz, 2018). In this study, shared culture is a tangible and intangible asset that supports the growth of the Latino community. As previously mentioned by parents, if it were not for the school personnel being bilingual, they might have not engaged with their children's learning in the same way. According to them, the relationships they built with their children's teachers and other school personnel led them to feel bought in to the learning experience. The visibility of bilingual Latino educators attributed to deepened relationships and it contributed to parents more actively engaging with their children at-home. Whether it be reading together or asking their children questions about what they learned in school, the relationships parents built at school motivated parents to increase their own parent-child dialogue.

Above anything else MEC offers parents the opportunity to come as they are and participate in higher learning. Be it social or information driven, they are on campus, in a 
classroom, and feeling safe. Nunca pensé que estaría de vuelta en la escuela. Pero aquí estoy y me siento bien. "I never thought that I would be back in school. But here I am, and I feel good." The opportunity to gather has given these parents not only an opportunity to deepen relationships with educators on campus, it has clearly been central to building their social lives, and in turn made them feel as if they belong to the MEC community.

Application of Critical Race and Intersectionality Theory

Rooted in the theoretical frameworks of critical race and intersectionality theory, this study explored how an intervention program could respond to the historical devaluing of Latinos in education. As noted in the previous section, there is tremendous power in culturally specific programs, as they are designed to interrupt "othering" of communities of color (Leonardo, 2013). In designing an intervention where a participant's intersecting culture is at the center of the experience, participants are able to move past the feelings of being on the outside and start fully exploring what makes them unique (Crenshaw, 1998; De Gaetano, Williams and Volk, 1998; Inger, 1992; LadsonBillings and Tate, 1995; Nicolau and Ramos, 1990).

While Latino parent engagement in traditional school programs remains low (DeGaetano, 2007), this study affirmed that compounding factors like language, immigrant status, resources, gender roles, and mental health, amongst others, must be taken in consideration when designing culturally specific programs for immigrant populations (De Gaetano, Williams \& Volk, 1998; Inger, 1992; Ladson-Billings \& Tate, 
1995; Nicolau \& Ramos, 1990). These compounding factors support the theory of intersectionality, which recognizes that social problems experienced by a group of people, is generally the result of numerous discriminations and disadvantages compounding (Crenshaw, 1998; Leonardo, 2013). While it is important to recognize the many barriers Latino immigrants face, it is imperative that we understand that these barriers do not equate to deficit thinking.

Aware of the disparaging narratives that exist about Latinos, this study successfully countered deficit thinking narratives by giving immigrant mothers an opportunity to share their stories, and by giving school personnel the chance to share what educational and political structures they think continue to oppress immigrant parents. Critical race and intersectionality theory helped us analyze the numerous challenges that prevent Latino families from excelling in academia, and helped frame how culturally specific programs can have exponential impact by empowering community members to continue developing and celebrating their cultural identity (Ladson-Billings, 2013).

\section{Limitations of the MEC Experience}

According to the findings of the focus group and one-on-one interviews, parents have a generally positive view of MEC. Organizationally, the greatest limitation identified and outlined in the findings, is finite enrollment. While MEC offers a number

of services to help families strengthen their engagement skills and integrate into their new home environment, I can not help but wonder if one year is truly enough to acquire the 
necessary skills to survive in a new country? Learning about and adapting to a new set of cultural norms takes time. Taking into consideration that many immigrants are also learning a new language and managing a delicate immigration situation, why the one year limit? While the program offers great resources, this organizational limitation is one worth further exploring in another study.

Another constraint experienced by parents was time (and other limited resources). In order to get the most out of MEC's programming one needs to be able to experience the workshops on campus. This is a large limitation given that many parents are working inconsistent hours to simply make ends meet at the end of the month. While finances were never directly discussed, parents expressed that financial stress caused by financial insecurity is a reality for many people across the United States (Taylor, Stevens, Agho \& Raphael, 2017). A 2018 poll conducted by mobile-banking firm Varo Money, found that $85 \%$ of people "sometimes," and $30 \%$ of people "constantly" feel stressed by their finances (Ruark, 2018). This level of stress can become even more augmented when one takes into account that a lot of MEC families are limited to the types of work they can do based on their immigrant status and ability to work legally. While significant, perhaps the most alarming issue becomes that chronic financial stress is something that can be passed down to children (Taylor et al., 2017), and this stress is something that can greatly affect one's academic experiences. Understanding this experience, the same question arises, why limit the program to only one year? If time and money are obstacles that prevent parents from participating as much as possible, why limit access to this program. With more time, it is possible that overtime more families would be able to engage at various 
levels. Moreover, their long-term participation could help MEC reimagine how their current services actually impact long-term needs. Worth exploring, I think these questions and themes are worth exploring with the school district.

\section{Critiques of Culturally Specific Programs}

Critics of culturally specific programs will argue that ethno-specific organizations threaten national unity (Dei \& Kempf, 2013; Guo \& Guo, 2011). Others take it a step further by igniting fear and implying that culturally specific programs will foster a sense of resentment in students of color that will then lead them to hate White people. In Australia, movements to support the creation of Islamic schools have been largely opposed by public officials claiming that Muslims "oppress [Australian] society, take [Australian] welfare and don't want to accept [the Australian] way of life" (McCulloch, as cited in Curry-Stevens, Deloney \& Morton, 2018, p.12). Racist at their core, these critiques ignite fear and often times prevail and block culturally specific programs from coming to life.

Pertaining to MEC, the loudest critique is that in providing too much culturally specific support underequips parents to survive in a world outside of the school program. Given that students and parents will transfer after a year to an all-English language program, there is a fear that parents will come to expect similar support that is simply not available. In spite of this critique, the family liaison, principal and social worker were firm in their belief that the work MEC is doing is powerful, and that perhaps the limitation lies in that the district is underfunded to continue adequate support. 
Nonetheless, by providing parents with numerous opportunities to strengthen their morale, expand their personal and student-engagement skills, and build social networks on and off campus, the school is preparing parents to succeed well beyond their time at MEC. While transitions will undoubtedly be difficult, these transferable skills and networks will be undeniably helpful.

Study Limitations and Directions for Future Research

The greatest limitation of this dissertation is that it only observed and collected data from one school program. In spite of this limitation, I think the data I collected contributes a significant amount of knowledge to our understanding of how we can better serve newcomer Latino populations in schools, and arms educators already doing similar work with new insight. Seeing as this initial study found MEC to be successful at integrating and supporting a number of families, as well as teaching parents how to become more active in their children's learning, I recommend studying other culturally specific programs so that we can have a more extensive understanding of best practices for serving diverse newcomer populations. I also think it would be wise to study MEC for a second year (to see if we can get a larger sample size and compare experiences from two cohorts). Lastly, I would be in support of a longitudinal study that follows students and parents over a course of five years to better understand the long-term outcomes of a program like MEC.

Now more than ever, activists, educators, and social workers are being pressed to stand up for what they believe in regarding the fate of our country's immigrant 
population. While this study took place in San Francisco, the constant movement of immigrants between California, Oregon and Washington merits careful attention. In thinking about recommendations for future research, I think it is important that we also take a look at what culturally specific interventions are best serving immigrant communities in the Pacific Northwest—where a place like Portland currently ranks 11th among United States cities resettling immigrants and refugees (The City of Portland, 2018). According to Communities of Color in Multnomah County: An Unsettling Profile, a 2008 report by the Coalition of Communities of Color, immigrant and refugee communities in Portland face sharp disparities compared to their White neighbors in education and income. The report goes on to recommend that "our pathways to effective practice lead us to prioritize service delivery that stretches far beyond the framework of 'cultural competency' into 'culturally specific services” (Curry-Stevens, Cross Hemmer, 2010). Taking into account that Portland's refugee and immigrant population makes up approximately $13 \%$ of the total population within the city limits (The Refugee Center, 2018), I concur with this assessment and recommend that we continue to find ways in which to support surrounding school districts in Clackamas, Multnomah and Washington County in learning about and developing culturally specific programs like MEC.

Implications for Field of Social Work and Education

While our country's leaders engage in a never-ending national debate on immigration, school administrators, social workers and teachers are amongst the first in line to support and respond to immigrant families. Upon arrival to the United States, one 
of the first things immigrant parents do is enroll their children in school in order to begin the process of establishing a new routine and providing themselves with necessary time to work and/or seek employment. In most places, however, this experience is not as seamless as it sounds. Many immigrant parents will struggle to communicate and connect with their children's educators, live with uncertainty or shame about their place on their child's school campus, and gain little insight on how to engage with their children's learning. Furthermore, many will experience anxiety, depression, fear, homesickness and trauma associated with immigration, and therefore will be at higher risk for long-term mental health problems. Given this reality, we must better equipped social workers working in large immigrant populations the opportunity to strengthen their awareness of mental health needs associated with immigration and their skills so that they can best support communities in need.

With regards to best practices, this study provides education social workers, and other on-campus support specialists, a lot of think about regarding community mental health services and social work education. I strongly believe that culturally specific programs are the future of social work practice, and therefore our social work education programs should also focus on providing future practitioners and policy makers the opportunity to learn how anti-oppressive practice and critical and intersectionality theories help explore and interrupt various social injustices experienced by people who are marginalized in society. "As social work practitioners, we have a moral, ethical and legal responsibility to challenge inequality and disadvantage" (Burke and Harrison, 2017, p.131) and it is important that our educational institutions actively draw theories from 
other disciplines and move towards trans-disciplinary practice. One example of this would be to explore how design thinking can complement the work community based practice is trying to achieve.

Lastly, it's important to address that budget cuts are drastically affecting the level of support services families across the United States receive-especially working class families that do not have resources to seek support services off campus. In particular, these cuts are leading to the drastic reduction of school counselors, social workers and psychologists, leading overworked teachers - who may not have a mental health background — to become the only family support resource (Sanchez, Freeman \& Martin, 2018). As far as how this further affects immigrants, a recent nationwide survey found that $90 \%$ of school personnel "reported observing emotional and behavioral problems among immigrant students" who fear deportation or have experienced deportation of a family member, classmate or friend, our students are in need of more support services (Gatlin, 2018). Based on these additional findings, it is imperative that we also push for the activation and retention of service positions in K-12 schools. Failure to protect and further fund these positions has the potential to catastrophically lead to an increase in student anxiety and community detachment.

Implications for Policy

Now more than ever, educators, social workers and policymakers must take a stand with regard to our country's immigration policy. Critical reform is needed, and the families we serve are counting on us to interrupt the varying levels of oppression 
experienced by immigrant families. Over the last two decades there have been major success for the Latino community in education. The high school dropout rate fell to 10 percent — an all-time low and exactly 24 percentage points since 1999, and Latino college enrollment increased to a record high (US Census Bureau, 2016; Gramlich, 2017). In order to maintain the successes of the Latino community, educators, social workers and policymakers must invest more time in understanding how immigration policies impact learning and educational attainment.

The current aggressions towards immigrants in the United States - in particular the repeal of Deferred Action for Childhood Arrivals (DACA), the executive order on refugees and travel ban, family separation and detention, and ongoing talks about a U.S.Mexico border - could undo decades of progress. More notably, when it comes to the intersection of immigration and education reform, we have to think about the 800,000 DACA recipients currently at risk, half of whom are currently pursuing an education, and most of which are undocumented Latinos (Migration Policy Institute, 2018). More specifically, an estimated 9,000 teachers are DACA recipients (Education Reform Now, 2018) and an estimated 200,000 US-born children and have a parent with DACA status (Alvarez, 2017). The end of this program means the end of an era of limited protection for undocumented students, and the harsh reality that if you were ineligible to enroll for DACA, you will continue to live in the United States without any protections. This includes the undocumented parents of nearly five million children (Migration Policy Institute, 2018). 
There's no denying that our nation is in desperate need of overhauling its immigration policies. There are a lot of lives at hand, and now more than ever we need educators, social workers and policymakers to better inform themselves about the rights of immigrants and begin to push for immediate reform. On a local level, we must learn about and protect the U.S. Supreme Court's Plyer v. Doe decision to ensure that all students regardless of their immigration status have the right to a K-12 public school education. We must also continue to push for the protection of in-state tuition fees for undocumented students living in states in which their status does not prevent them from seeking a community college education. Currently 18 states-California, Colorado, Connecticut, Florida, Illinois, Kansas, Maryland, Minnesota, Nebraska, New Jersey, New Mexico, New York, Oklahoma, Oregon, Texas, Utah, Washington, and Wisconsin—have passed legislation extending in-state tuition rates to undocumented students who meet specific requirements.

A learning from employing the demographics questionnaire in this study is that we must eliminate any barrier that could prevent parents from enrolling their children in school, such as asking for personal information (legal status, driver's license information, social security number, etc.) on student enrollment forms. Like the remaining 11 million undocumented people living in the United States (Migration Policy Institute, 2018), MEC parents and students live in constant fear of detention, deportation and family separation. Asking parents to provide this information puts them in a situation that might reveal their sensitive legal status, make them feel uncomfortable, force them to lie or induce unnecessary stress. By removing these obstacles, parents are less likely to feel that there 
is a record of themselves and their family and are more likely to register their children in school.

Lastly, it is vital that school educators and social workers understand the role they have in protecting the rights of their student community. The Family Educational Rights and Privacy Act (FERPA) states that there is no legal obligation for educators and school districts to turn over information about any students or their families to federal immigration officers without a warrant, subpoena, or court order. This is vital. A city does not need to declare itself a "sanctuary" city in order for school personnel to protect its students The goal of educators and social workers is to serve their student population, under no circumstances should they ever feel obliged to turn over any information without legal representation. Furthermore, it is imperative that we continue to have laws in place that protect school personnel from ever being put in a situation other than that of best serving their population.

\section{Self-Reflection}

Deeply passionate about education, immigrant integration, and the preservation of Latino culture, this study has recommitted me to further researching and supporting culturally specific school interventions that lift up the culture and spirit of communities of color. Spending time at Mission Education Center (MEC) in particular, was a powerful reminder of how educators and social workers can be partners in disrupting existing forms of systemic oppression and activating change. Not only do educators and 
social workers impact the lives of students, they impact the lives of parents, extended family members, and entire communities.

As someone who vividly remembers their first day of school in the United States, this study left me wondering: How might my childhood self-esteem been impacted had my first teacher known how to pronounce my name correctly? Would I have chosen on my own to go by the nickname “Anna?” And how might my parents' on-campus engagement differed had they been able to communicate confidently with my teachers? Would I have I felt they belonged on campus? Or would I have still been embarrassed about their inability to speak English? Given the work I do now, these questions may seem irrelevant to some. However, seeing as I introduced myself as "Anna" for 13 years, and did everything I could to simply be accepted as a typical estadounidense girl, I believe these questions are important to consider. Some of my early childhood experiences negatively impacted my sense of cultural identity, self-esteem and family relationships. Fortunately, I had the opportunity to meet educators of color during my undergraduate studies, and learning from people that looked like me gave me permission to see myself as worthy. Needless to say, I was given a second chance to love myself, and my only wish is that I had been given that chance sooner.

Perhaps the most important part about this dissertation was that it gave me the opportunity to find peace with my own experience as an immigrant, and honor the memory of my parents. For over twenty years, my mother worked as a head start teacher, and my father worked as a GED instructor, both dedicating their lives to serving others and empowering immigrants to believe in themselves and realize their highest potential. 
As a child, I did not quite understand the value of my parent's work, but this study powerfully reminded me that I got into this field because of them. Walking the halls of MEC was particularly triggering, as it reminded my of the many summers spent helping my mother prepare her pre-school classroom. While the memories I have are warm, it saddens me that I cannot tell my mother just how proud I am of all the work she did to ensure that all families - regardless of race, class, national origin — have an equitable start to education. Regardless of my inability to physically say this to my mom, this study served as a way in which to honor her memory, something I am very thankful for.

\section{Conclusion}

This study demonstrated that culturally specific programs have the ability to positively impact immigrant parent engagement behaviors. Built around the experience of specific communities, and staffed with professionals that strongly relate to the experience of the population being served, these culture-positive, ethno-centric programs support the integration of immigrants without forcing them to compromise their dignity or cultural values and traditions. Given the Latino community's current size and predicted growth over the next 15 years, it is vital that intervention designers, educators and social workers continue to explore how culturally specific programs can help serve a population whose culture has been historically undermined and excluded from U.S. history and education.

While this study was specific to the Latino community, culturally specific programs are adaptable and can be reimagined to fit the needs of an entirely different demographic. Aligned with the ethics and values of the social work profession, these 
types of interventions directly address and interrupt the historical disparities experienced by communities of color in the education system, as explained in this study via critical race and intersectionality theories. Moving forward, this study hopes to serve as a starting point for social work educators, practitioners and researchers desiring to implement and investigate new culturally specific ways in which to serve diverse communities. 


\section{TABLES}

Table 1.

\begin{tabular}{|c|c|c|c|c|c|}
\hline \multicolumn{6}{|c|}{ Parent Participant Data } \\
\hline Parent Pseudonym & Focus Group & 1:1 Interview & Demo Quest. & Gender & $\begin{array}{c}\text { Country of } \\
\text { Origin }\end{array}$ \\
\hline Parent 1 & $\mathrm{X}$ & & $\mathrm{X}$ & $\mathrm{F}$ & Guatemala \\
\hline Parent 2 & $\mathrm{X}$ & & & $\mathrm{F}$ & Honduras \\
\hline Parent 3 & $\mathrm{X}$ & $\mathrm{X}$ & $\mathrm{X}$ & $\mathrm{F}$ & Guatemala \\
\hline Parent 4 & $\mathrm{X}$ & $\mathrm{X}$ & $\mathrm{X}$ & $\mathrm{F}$ & Guatemala \\
\hline Parent 5 & $\mathrm{X}$ & $\mathrm{X}$ & & $\mathrm{F}$ & Honduras \\
\hline Parent 6 & $\mathrm{X}$ & $\mathrm{X}$ & $\mathrm{X}$ & $\mathrm{F}$ & Nicaragua \\
\hline Parent 7 & & $\mathrm{X}$ & $\mathrm{X}$ & $\mathrm{F}$ & El Salvador \\
\hline Parent 8 & & $\mathrm{X}$ & & $\mathrm{F}$ & El Salvador \\
\hline Parent 9 & & $\mathrm{X}$ & $\mathrm{X}$ & $\mathrm{F}$ & Guatemala \\
\hline Parent 10 & & $\mathrm{X}$ & $\mathrm{X}$ & $\mathrm{F}$ & Honduras \\
\hline Parent 11 & & $\mathrm{X}$ & & $\mathrm{F}$ & $\mathrm{N} / \mathrm{A}$ \\
\hline
\end{tabular}


Table 2.

\begin{tabular}{|c|c|c|c|c|c|}
\hline \multicolumn{7}{|c|}{ School Personnel Participant Data } \\
\hline $\begin{array}{c}\text { Personnel } \\
\text { Pseudonym }\end{array}$ & $\begin{array}{c}1: 1 \\
\text { Interview }\end{array}$ & $\begin{array}{c}\text { Years at } \\
\text { MEC? }\end{array}$ & $\begin{array}{c}\text { Identifies as } \\
\text { Latino? }\end{array}$ & Bilingual? & $\begin{array}{c}\text { Classroom } \\
\text { teacher? }\end{array}$ \\
\hline Personnel 1 & $\mathrm{X}$ & $5-10$ & & $\mathrm{X}$ & \\
\hline Personnel 2 & $\mathrm{X}$ & $5-10$ & $\mathrm{X}$ & $\mathrm{X}$ & \\
\hline Personnel 3 & $\mathrm{X}$ & $>5$ & $\mathrm{X}$ & $\mathrm{X}$ & \\
\hline Personnel 4 & $\mathrm{X}$ & $5-10$ & $\mathrm{X}$ & $\mathrm{X}$ & $\mathrm{X}$ \\
\hline Personnel 5 & $\mathrm{X}$ & $5-10$ & $\mathrm{X}$ & $\mathrm{X}$ & $\mathrm{X}$ \\
\hline Personnel 6 & $\mathrm{X}$ & $5-10$ & $\mathrm{X}$ & $\mathrm{X}$ & \\
\hline Personnel 7 & $\mathrm{X}$ & $5-10$ & $\mathrm{X}$ & $\mathrm{X}$ & $\mathrm{X}$ \\
\hline
\end{tabular}


Table 3.

\begin{tabular}{|c|c|c|c|}
\hline \multicolumn{4}{|c|}{ Themes of Parent Focus Group and Interviews } \\
\hline $\begin{array}{l}\text { Community and } \\
\text { Belonging }\end{array}$ & $\begin{array}{l}\text { Power of a culturally } \\
\text { specific program }\end{array}$ & Engagement & Resiliency \\
\hline $\begin{array}{c}\text { Homesickness and } \\
\text { nostalgia }\end{array}$ & Adaptability & Preparation and Support & Confidence \\
\hline MEC community & $\begin{array}{l}\text { Integration with } \\
\text { community served }\end{array}$ & On-campus engagement & Worthiness \\
\hline \multirow[t]{2}{*}{$\begin{array}{c}\text { Community beyond } \\
\text { MEC }\end{array}$} & Cultural capital & Off campus engagement & Self-actualization \\
\hline & & $\begin{array}{ll}\text { Program limitations } \\
\text { - } & \text { Finite enrollment } \\
\text { - } & \text { Educational } \\
& \text { background } \\
\text { - } & \text { Time and other } \\
& \text { limited resources } \\
\text { - } & \text { Political climate }\end{array}$ & \\
\hline
\end{tabular}


Table 4.

\begin{tabular}{|c|c|c|c|c|c|c|}
\hline \multicolumn{7}{|c|}{ Questionnaire Findings (Part One) } \\
\hline $\begin{array}{c}\text { Parent } \\
\text { Pseudonym }\end{array}$ & $\begin{array}{c}\text { Time in } \\
\text { USA }\end{array}$ & $\begin{array}{c}\text { Civil } \\
\text { status }\end{array}$ & $\begin{array}{c}\text { No. of } \\
\text { children }\end{array}$ & $\begin{array}{c}\text { Language at } \\
\text { home }\end{array}$ & $\begin{array}{c}\text { Level of comfort } \\
\text { on campus? }\end{array}$ & $\begin{array}{c}\text { Level of comfort } \\
\text { asking Qs? }\end{array}$ \\
\hline Parent 1 & $>1$ year & Partnered & 2 & Spanish & Comfortable & V. Comfortable \\
\hline Parent 2 & $>1$ year & N/A & N/A & Spanish & N/A & N/A \\
\hline Parent 3 & $>1$ year & Partnered & 2 & Spanish & V. Comfortable & V. Comfortable \\
\hline Parent 4 & $>1$ year & Single & 2 & Spanish & V. Comfortable & V. Comfortable \\
\hline Parent 5 & $>1$ year & N/A & N/A & Spanish & N/A & N/A \\
\hline Parent 6 & $>1$ year & Partnered & 2 & Spanish & V. Comfortable & V. Comfortable \\
\hline Parent 7 & $>1$ year & Partnered & 3 & Spanish & Comfortable & V. Comfortable \\
\hline Parent 8 & $>1$ year & N/A & N/A & Spanish & N/A & N/A \\
\hline Parent 9 & $>1$ year & Partnered & 2 & Spanish & Comfortable & Comfortable \\
\hline Parent 10 & $>1$ year & Partnered & 2 & Spanish & V. Comfortable & V. Comfortable \\
\hline Parent 11 & $>1$ year & N/A & N/A & Spanish & N/A & N/A \\
\hline
\end{tabular}


Table 5.

\begin{tabular}{|c|c|c|c|c|c|}
\hline \multicolumn{6}{|c|}{ Questionnaire Findings (Part Two) } \\
\hline $\begin{array}{c}\text { Parent } \\
\text { Pseudonym }\end{array}$ & $\begin{array}{c}\text { Frequency on } \\
\text { campus? }\end{array}$ & $\begin{array}{l}\text { Struggling to adapt } \\
\text { to new home } \\
\text { environment? }\end{array}$ & $\begin{array}{l}\text { Enjoy attending } \\
\text { school functions? }\end{array}$ & $\begin{array}{l}\text { Enjoy learning at } \\
\text { school functions? }\end{array}$ & $\begin{array}{c}\text { Interested } \\
\text { in } \\
\text { becoming } \\
\text { a parent- } \\
\text { leader? }\end{array}$ \\
\hline Parent 1 & $1 /$ month & N/A & $\mathrm{X}$ & $\mathrm{X}$ & $\mathrm{X}$ \\
\hline Parent 2 & $\mathrm{~N} / \mathrm{A}$ & N/A & N/A & $\mathrm{N} / \mathrm{A}$ & N/A \\
\hline Parent 3 & Weekly & N/A & $\mathrm{X}$ & $\mathrm{X}$ & N/A \\
\hline Parent 4 & Weekly & $\mathrm{X}$ & $\mathrm{X}$ & $\mathrm{X}$ & N/A \\
\hline Parent 5 & N/A & N/A & N/A & N/A & N/A \\
\hline Parent 6 & Weekly & N/A & N/A & $\mathrm{N} / \mathrm{A}$ & N/A \\
\hline Parent 7 & $1 /$ month & N/A & $\mathrm{X}$ & $\mathrm{X}$ & N/A \\
\hline Parent 8 & $\mathrm{~N} / \mathrm{A}$ & N/A & N/A & N/A & N/A \\
\hline Parent 9 & $1 /$ month & $\mathrm{X}$ & $\mathrm{X}$ & $\mathrm{X}$ & N/A \\
\hline Parent 10 & Weekly & N/A & $\mathrm{X}$ & $\mathrm{X}$ & $\mathrm{X}$ \\
\hline Parent 11 & $\mathrm{~N} / \mathrm{A}$ & $\mathrm{N} / \mathrm{A}$ & N/A & $\mathrm{N} / \mathrm{A}$ & $\mathrm{N} / \mathrm{A}$ \\
\hline
\end{tabular}


Table 6.

\begin{tabular}{|c|c|c|}
\hline \multicolumn{2}{|c|}{ Themes of School Personnel Interviews } \\
\hline $\begin{array}{c}\text { Institutional Culture of a } \\
\text { Culturally Specific Program }\end{array}$ & Engagement & Parent Resiliency \\
\hline Official and unofficial goals & On-campus engagement & Overcoming trauma \\
\hline $\begin{array}{c}\text { Parent-school personnel } \\
\text { relationships }\end{array}$ & Off-campus engagement & Gaining confidence \\
\hline Conviction for program & Limitations & Verbalizing hopes and dreams \\
\hline
\end{tabular}


Table 7. Parent Focus Groups Guide x Research Questions

\begin{tabular}{|c|c|c|c|}
\hline & $\begin{array}{l}\text { How can culturally } \\
\text { specific programs } \\
\text { deepen the relationship } \\
\text { immigrant parents } \\
\text { have with school } \\
\text { personnel? }\end{array}$ & $\begin{array}{l}\text { How can culturally } \\
\text { specific programs } \\
\text { lead educators to } \\
\text { gain insight on } \\
\text { engagement taking } \\
\text { place between } \\
\text { parents and } \\
\text { children at home? }\end{array}$ & $\begin{array}{l}\text { How can } \\
\text { culturally } \\
\text { specific } \\
\text { programs } \\
\text { support overall } \\
\text { parent } \\
\text { engagement? }\end{array}$ \\
\hline $\begin{array}{l}\text { Describe how MEC's school model has } \\
\text { played a role in your transition into the } \\
\text { U.S. }\end{array}$ & $\mathrm{X}$ & & \\
\hline $\begin{array}{l}\text { In what ways do you think the parent- } \\
\text { engagement program on campus has } \\
\text { impacted the relationship you have with } \\
\text { MEC school personnel? }\end{array}$ & $X$ & & \\
\hline $\begin{array}{l}\text { In what ways, if any, do you feel more } \\
\text { supported or understood as a result of the } \\
\text { program? }\end{array}$ & & & \\
\hline $\begin{array}{l}\text { What is your current relationship with } \\
\text { your child's teacher? How do you } \\
\text { communicate with them? }\end{array}$ & & & \\
\hline $\begin{array}{l}\text { Tell me a little bit about your daily } \\
\text { routine with your children? }\end{array}$ & & $X$ & \\
\hline $\begin{array}{l}\text { What are some of your favorite way in } \\
\text { which you become familiar with the } \\
\text { material your child is learning in school? }\end{array}$ & & $X$ & \\
\hline $\begin{array}{l}\text { In the past, how have educators tried to } \\
\text { engage you and your family with your } \\
\text { child's learning? School? What has been } \\
\text { successful and what has not? }\end{array}$ & & & $\mathrm{X}$ \\
\hline $\begin{array}{l}\text { How has MEC's parent-engagement } \\
\text { program impacted your understanding of } \\
\text { the material being taught to your } \\
\text { children in school? }\end{array}$ & & & $X$ \\
\hline $\begin{array}{l}\text { How can MEC support and strengthen } \\
\text { the existing relationship you have with } \\
\text { your child's educational experience }\end{array}$ & & & $X$ \\
\hline
\end{tabular}




\begin{tabular}{|l|l|l|c|}
\hline (learning/ institution)? & & & \\
\hline $\begin{array}{l}\text { What are some injustice or inequities } \\
\text { you've experienced or witnessed at } \\
\text { school? }\end{array}$ & & & $\mathrm{X}$ \\
\hline $\begin{array}{l}\text { Are you interested in learning practices } \\
\text { for combining family time with learning? }\end{array}$ & & $\mathrm{X}$ & $\mathrm{X}$ \\
\hline $\begin{array}{l}\text { Moving forward, how would you like to } \\
\text { envision your relationship with your } \\
\text { child's teacher? School? Education? }\end{array}$ & & & \\
\hline
\end{tabular}


Table 8. Parent Interview Guide x Research Questions

\begin{tabular}{|c|c|c|c|}
\hline & $\begin{array}{l}\text { How can culturally } \\
\text { specific programs } \\
\text { deepen the } \\
\text { relationship } \\
\text { immigrant parents } \\
\text { have with school } \\
\text { personnel? }\end{array}$ & $\begin{array}{l}\text { How can culturally } \\
\text { specific programs } \\
\text { lead educators to gain } \\
\text { insight on } \\
\text { engagement taking } \\
\text { place between parents } \\
\text { and children at home? }\end{array}$ & $\begin{array}{l}\text { How can } \\
\text { school } \\
\text { personnel } \\
\text { support parent } \\
\text { engagement } \\
\text { that occurs at } \\
\text { home? }\end{array}$ \\
\hline $\begin{array}{l}\text { What has been your personal } \\
\text { experience with school and } \\
\text { learning? }\end{array}$ & $X$ & $X$ & $X$ \\
\hline $\begin{array}{l}\text { Prior to arriving to the U.S., what was } \\
\text { your perception of K- } 12 \text { education? Did } \\
\text { you have a pre-existing relationship } \\
\text { with the U.S. education system? }\end{array}$ & $X$ & $X$ & \\
\hline $\begin{array}{l}\text { What has been your overall experience } \\
\text { with MEC's parent-engagement } \\
\text { program? Do you think it takes into } \\
\text { consideration your experience and } \\
\text { needs as an immigrant parent? }\end{array}$ & $X$ & $X$ & $X$ \\
\hline $\begin{array}{l}\text { How has the program affected and } \\
\text { influenced the relationship you have } \\
\text { with school personnel? How about } \\
\text { other parents? }\end{array}$ & $X$ & & \\
\hline $\begin{array}{l}\text { Do you feel as if you belong to a } \\
\text { community on/off campus? }\end{array}$ & $X$ & & \\
\hline $\begin{array}{l}\text { How has the program empowered you } \\
\text { to engage with your child's education? }\end{array}$ & & $X$ & \\
\hline $\begin{array}{l}\text { Tell me about the time you spend with } \\
\text { your children? Does your time with } \\
\text { them include discussions about school? } \\
\text { If so, when do you have these } \\
\text { discussions? }\end{array}$ & & $X$ & \\
\hline $\begin{array}{l}\text { What factors currently impede you from } \\
\text { engaging? }\end{array}$ & & $X$ & \\
\hline $\begin{array}{l}\text { What are some ways MEC can continue } \\
\text { to empower you? }\end{array}$ & $X$ & & $X$ \\
\hline
\end{tabular}


Table 9. Staff Personnel Interview Guide x Research Questions

\begin{tabular}{|c|c|c|c|}
\hline & $\begin{array}{l}\text { How can culturally } \\
\text { specific programs } \\
\text { deepen the } \\
\text { relationship } \\
\text { immigrant parents } \\
\text { have with school } \\
\text { personnel? }\end{array}$ & $\begin{array}{l}\text { How can culturally } \\
\text { specific programs } \\
\text { lead educators to gain } \\
\text { insight on } \\
\text { engagement taking } \\
\text { place between parents } \\
\text { and children at home? }\end{array}$ & $\begin{array}{l}\text { How can } \\
\text { culturally } \\
\text { specific } \\
\text { programs } \\
\text { support } \\
\text { overall parent } \\
\text { engagement? }\end{array}$ \\
\hline $\begin{array}{l}\text { In what ways do you think the parent } \\
\text { engagement program on campus has } \\
\text { impacted the relationship parents have } \\
\text { with MEC school personnel? }\end{array}$ & $\mathrm{X}$ & & \\
\hline $\begin{array}{l}\text { What are some other ways in which } \\
\text { MEC builds relationships with parents? }\end{array}$ & $\mathrm{X}$ & $\mathrm{X}$ & \\
\hline $\begin{array}{l}\text { How would you describe the current } \\
\text { relationship between parents and school } \\
\text { personnel? How does it differ from you } \\
\text { ideal relationship with them? }\end{array}$ & $\mathrm{X}$ & $\mathrm{X}$ & \\
\hline How do you identify parent engagement? & & $\mathrm{X}$ & $\mathrm{X}$ \\
\hline $\begin{array}{l}\text { What types of informal engagement are } \\
\text { you seeing parents have with their } \\
\text { children? }\end{array}$ & & $\mathrm{X}$ & $\mathrm{X}$ \\
\hline $\begin{array}{l}\text { What are some ways in which MEC } \\
\text { supports parents with home- } \\
\text { engagement? }\end{array}$ & & $\mathrm{X}$ & $\mathrm{X}$ \\
\hline $\begin{array}{l}\text { In what ways do you support at home } \\
\text { learning and parent engagement? }\end{array}$ & & $\mathrm{X}$ & $\mathrm{X}$ \\
\hline $\begin{array}{l}\text { What are some ideas you have to } \\
\text { strengthen learning and engagement off } \\
\text { campus? }\end{array}$ & & $\mathrm{X}$ & $\mathrm{X}$ \\
\hline $\begin{array}{l}\text { Where do you think MEC's limitations } \\
\text { lie? Why do they exist? What does MEC } \\
\text { have to learn? }\end{array}$ & $\mathrm{X}$ & & $\mathrm{X}$ \\
\hline
\end{tabular}




\section{REFERENCES}

Abdi, N. (2016). How to improve education for immigrant students by ending deficit thinking. Achieving Educational Equity. Retrieved from

https://cehdvision2020.umn.edu/blog/improve-education-immigrant-students-endingdeficit-thinking/

Abdul-Adil, J.K., \& Farmer, A.D. (2006). Inner-city African American parental involvement in elementary schools: Getting beyond urban legends of apathy. School Psychology Quarterly, 21, 1-12. doi:10.1521/scpq.2006.21.1.1

Abrams, L.S., \& Gibbs, J.T. (2002). Disrupting the logic of home-school relations: Parent involvement strategies and practices of inclusion and exclusion. Urban Education, 37 (3), 384-407.

Achinstein, B., Ogawa, R.T., Sexton, D., \& Freitas, C. (2010). Retaining teachers of color: A pressing problem and a potential strategy for "hard-to-staff" schools. Review of Educational Research, 80 (1), 71-107.

Adams, R., Dominelli, R. \& Payne, M. (2002) Social work: Themes, issues and critical debates. Basingstoke, UK: Palgrave.

Alemán, J. (2009). Rethinking parent-school-community partnerships. The School Community Journal, 7 (3), 300-307.

Alvarez, P. (2017, October 21). Will DACA parents be forced to leave their U.S.-citizen children behind? The Atlantic. Retrieved from

https://www.theatlantic.com/politics/archive/2017/10/donald-trump-daca/543519/

Anzaldúa, G.E. (1987). Borderlands/ la frontera: New mestiza. San Francisco, CA: Aunte Lute Books.

Auerbach, S. (2001). Under co-construction: Parent roles in promoting college access for students of color. Unpublished doctoral dissertation, University of California, Los Angeles, Graduate School of Education and Information Studies.

Auerbach, S. (2002). "Why do they give the good classes to some and not to others?" Latino parent narratives of struggle in a college access program. Teachers College Record, 104 (7), 1369-1392.

Auerbach, S. (2004). Engaging Latino parents in supporting college pathways: Lessons from a college access program. Journal of Hispanic Higher Education, 3 (2), 125-145. 
Auerbach, S. (2007). From moral supporters to struggling advocates. Urban Education, 42(3), 250-283.

Baker, A. (1997). Improving parent involvement programs and practice: A qualitative study of parent perceptions. The School Community Journal, 7 (1), 127-154.

Barshay, J. (2018, June 18). Behind the Latino college degree gap. The Hechinger Report. Retrieved from https://hechingerreport.org/behind-the-latino-college-degree-gap/

Batalova, J., \& Zong, J. (2017, November). Cuban immigrants to the United States. Migration Policy Institute. Retrieved from

https://www.migrationpolicy.org/article/cuban-immigrants-united-states

Behnke, A.O., \& Kelly, C. (2011). Creating programs to help Latino youth thrive at school: The influence of Latino parent involvement programs. Journal of Extension, 49 (1), 1-11.

Bernal, D.D. (2002). Critical race theory, Latino critical theory, and critical racedgendered epistemologies: Recognizing students of color as holders and creators of knowledge. Qualitative Inquiry, 8(1), 105-126.

Bourdieu, P. (1984). Distinction: A social critique of the judgment of taste. Cambridge, MA: Harvard University Press.

Branch, A. (2001). Increasing the numbers of teachers of color in k-12 public schools. The Educational Forum, 65 (2), 254-261.

Camera, L. (2017, January 26). School officials pledge to protect students in the U.S. illegally. US News. Retrieved from https://www.usnews.com/news/articles/2017-0126/school-officials-pledge-to-protect-students-in-the-us-illegally

Cardona, J. P., Holtrop, K., Córdova, D., Escobar-Chew, A. R., Horsford, S., Tams, L., Villarruel, F. A., Villalobos, G., Dates, B., Anthony, J. C., \& Fitzgerald, H. E. (2009). "Queremos aprender": Latino immigrants' call to integrate cultural adaptation with best practice knowledge in a parenting intervention. Family process, 48 (2), 211-31.

Castaneda, C. Kambutu, J., \& Rios, F. (2006). Speaking their truths: Teachers of color in diasporic contexts. The Rural Educator, 27 (3), 13-23.

Chavez, A. (2017). Latinos in education: Improving the high school dropout rate. UWIRE Text. Retrieved from http://link.galegroup.com.proxy.lib.pdx.edu/apps/pub/4JTO/PROF?u=s1185784\&sid=PR $\mathrm{OF}$ 
Cochran-Smith, M. (2000). Blind vision: Unlearning Racism in Teacher Education. Harvard Educational Review, 70 (2), 157-190.

Cooper, B. (2016). Intersectionality. The Oxford Handbook of Feminist Theory, 1-25. Retrieved from

http://www.oxfordhandbooks.com/view/10.1093/oxfordhb/9780199328581.001.0001/oxf ordhb-9780199328581-e-20.

Crenshaw, K. (1998). Demarginalizing the intersection of race and sex: A Black feminist critique of antidiscrimination doctrine, Feminist Theory and antiracist politics. University of Chicago Legal Forum, 1 (8), 139-167.

Curry-Stevens, A., Deloney, G., \& Morton, M. (2018). Rethinking services for communities of color: Why culturally-specific organizations are the preferred service delivery model. Unpulished paper.

Daniel-White, K. (2002). Reassessing parent involvement: Involving language minority parents in school work at home. Working Papers in Educational Linguistics, 18 (1), 2949.

DeCuir, J.T., \& Dixson, A.D. (2004). "So when it comes out, they aren't that surprised that it is there": Using Critical Race Theory as a tool of analysis of race and racism in education. Educational Researcher, 33 (5), 26-31.

Dei, G. (1996). Beware of false dichotomies: Revisiting the idea of 'black-focused' schools in Canadian contexts. Journal of Canadian Studies, 31(4), 58-79.

Dei, G. \& Asante, M. (2013). New perspectives on African-centred education in Canada. Toronto: Canadian Scholars.

Dixson, A.D., \& Rousseau, C.K. (2005). And we are still not saved: Critical Race Theory in education ten years later. Race, Ethnicity and Education, 8 (1), 7-27.

Delgado-Gaitan, C. (2001). The power of community: Mobilizing for family and schooling. Lanham, MD: Rowman \& Littlefield.

Delgado-Gaitan, C., \& Segura, D. A. (1989). The social context of Chicana women's role in their children's schooling. Educational Foundations, 3, 71-92.

Denessen, E., Bakker, J., \& Gierveld, M. (2007). Multi-ethnic schools' parental involvement policies and practices. The School Community Journal, 17 (2), 27-43. 
Department of Homeland Security (DHS), Office of Immigration Statistics. (2014). Yearbook of Immigration Statistics. Retrieved from https://www.dhs.gov/immigration-statistics/yearbook/2013

Dragnea, C. \& Erling, S. (2008). The effectiveness of Africentric (black-focused) schools in closing student success and achievement gaps: A review of the literature. Toronto, ON: Toronto District School Board.

Eccles, J. S., \& Harold, R.D. (1993). Parent-school involvement during the early adolescent years. Teachers College Record, 94 (3), 568-587.

Emdin, C. (2017). For white folks who teach in the hood... And the rest of y'all too: Reality pedagogy and urban education. Boston, MA: Beacon Press.

Epstein, J.L. (1990). School and family connections: Theory, research and implications for integrating sociologies of education and family. In D.G. Unger \& M.B. Sussman (Eds.). Families in community settings: Interdisciplinary perspectives (pp. 99-126). New York, NY: Haworth.

Epstein, J.L. (1995). School/family/community partnerships: Caring for the children we share. Phi Delta Kappan, 5, 701-712.

Fryberg, S., Covarrubias, R., \& Burack, J. (2013). Cultural models of education and academic performance for Native American and European American students. School Psychology International, 34(4), 439-452.

Gándara, P. C., \& Contreras, F. (2010). The Latino education crisis: The consequences of failed social policies. Cambridge, MA: Harvard University Press.

Gándara, P., \& Ee, J. (2018). U.S. immigration enforcement policy and its impact on teaching and learning in the nation's schools. UCLA Civil Rights Project, 1-24. Retrieved from https://www.civilrightsproject.ucla.edu/research/k-12-education/immigrationimmigrant-students/u.s.-immigration-enforcement-policy-and-its-impact-on-teachingand-learning-in-the-nations-schools/Immigration-enforcement-on-schools-093018.pdf

Glazer, N., \& Moynihan, D.P. (1970) Beyond the melting pot: the Negroes, Puerto Ricans, Jews, Italians, and Irish of New York City. Cambridge, MA: MIT Press.

Goldenberg, B.M. (2014). White teachers in urban classrooms: Embracing non-White students' cultural capital For better teaching and learning. Urban Education, 49, 1, 111144. 
Gonzalez-Barrera, A. (2017, July 29). Mexican lawful immigrants become the least likely to become U.S. citizens. Pew Research Center. Retrieved from

http://www.pewhispanic.org/2017/06/29/mexican-lawful-immigrants-among-least-likelyto-become-u-s-citizens/

Gramlich, J. (2017, September 29). Hispanic dropout rate hits new low, college enrollment at new high. Pew Research Center. Retrieved from http://www.pewresearch.org/fact-tank/2017/09/29/hispanic-dropout-rate-hits-new-lowcollege-enrollment-at-new-high/

Gulson, K. \& Webb, P. (2012). Education policy racialisations: Afrocentric schools, Islamic schools, and the new enunciations of equity, Journal of Education Policy, 27(6), 697-709.

Guo, S., \& Guo, Y. (2011). Multiculturalism, ethnicity and minority rights: The complexity and paradox of ethnic organizations in Canada. Canadian Ethnic Studies, 43(1-2), 59-80.

Haight, W., Kayama, M., \& Korang-Okrah, R. (2014). Ethnography in social work practice and policy. Qualitative Social Work, 13(1), 127-143.

Han Y.C. (2012). Stages of immigrant parent involvement in schools: Survivors to leaders. In Kugler E.G.(Ed.), Innovative Voices in Education: Engaging Diverse Communities (pp. 171-186). Lanham, MD: Rowman \& Littlefield.

Hopson, R., Hotep, U., Schneider, D., Turenne, I. (2010). What's educational leadership without an African-centered perspective? Explorations and extrapolations. Urban Education, 45(6), 777-796.

Iglehart, A. \& Becerra, R.M. (1996). Social work and the ethnic agency: A history of neglect. Journal of Multicultural Social Work, 4(1), 1-20.

Iglehart, A. \& Becerra, R.M. (2007). Ethnic sensitive practice: Contradictions and recommendations. Journal of Ethnic and Cultural Diversity in Social Work, 16(3/4), 4363.

Jackson, T.O., \& Boutte, G.S. (2018). Exploring culturally relevant/responsive pedagogy as a praxis in teacher education. The New Educator, 14 (2), 87-90. 
Jasis, P.M., \& Ordonez-Jasis, R. (2004). Convivencia to Empowerment: Latino Parent Organizing at La Familia. The High School Journal 88 (2), 32-42. The University of North Carolina Press.

Jasis, P.M., \& Ordonez-Jasis, R. (2012). Latino parent involvement: Examining commitment and empowerment in schools. Urban Education, 47 (1), 65-89.

Jeynes, W.H. (2007). The relationship between parent involvement and urban secondary school student academic achievement. Urban Education, 42 (1), 82-110.

Jones, R. (2001). "How parents can support learning: Not all parent involvement programs are equal, but research shows what works." The American School Board Journal, 188 (9), 18.

Kamberelis, G., \& Dimitriadis, G. (2005). Focus groups: Strategic articulations of pedagogy, politics, and inquiry. In N.K. Denzin and Y.S. Lincoln (Eds.), The Sage Handbook of Qualitative Research (pp. 887-907). Thousand Oaks, CA: Sage.

Kawulich, B.B. (2005). Participant observation as a data collection method. Forum Qualitative Social Research, 6 (2), 1-43.

Keierleber, M. (2017). Immigration fears In California schools: Report shows 1 In 8 students have undocumented parents. Huffington Post. Retrieved from https://www.huffingtonpost.com/entry/immigration-fears-in-california-schools-reportshows_us_59076046e4b05279d4edbe40

Kolodner, M. (2017, December 14). New research shows Latinos closing the racial gap on college degrees, but still lagging far behind Whites. The Hechinger Report. Retrieved from https://hechingerreport.org/new-research-shows-latinos-closing-racial-gap-collegedegrees-still-lagging-far-behind-whites/

Krueger, R.A. \& Casey, M.A. (2000). Focus groups: A practical guide for applied research. Thousand Oaks, CA: Sage.

Kumashiro, K. (2001). "Posts" perspectives on anti-oppressive education in social studies, English, mathematics, and science classrooms. Educational Researcher, 30 (3), p. 3-12.

Ladson-Billings, G., \& Tate, W.F. (1995). Toward a Critical Race Theory of education. Teachers College Record, 97 (1), 47-68.

Ladson-Billings, G. (1998) Just what is Critical Race Theory and what's it doing in a nice field like education? International Journal of Qualitative Studies in Education, 11 (1), 7 24. 
Lareau, A. (1989). Home advantage: Social class and parental intervention in elementary education. New York, NY: Falmer.

Lareau, A., \& Horvat, E. (1999). Moments of social inclusion: Race, class, and cultural capital in family school relationships. Sociology of Education, 71, 39-56.

Lareau, A. (2003). Unequal childhoods: Class, race, and family life. Berkeley, CA: University of California Press.

Lathan, C. (2014). Dear white teacher. Rethinking Schools, 29 (1), 1-4.

Lau, K.F. Dandy, E.B., \& Hoffman, L. (2007). The Pathways Programs: A model for increasing the number of teachers of color. Teacher Education Quarterly, 3, 27-40.

Lawson, M.A., \& Alameda-Lawson, T. (2012). A case study of school-linked, collective parent engagement. American Educational Research Journal, 49 (4), 651-684.

Leik, R.A., \& Chalkey, M.A. (1990). Parent involvement: What is it that works? Children Today, 19 (3), 34-42.

Leonardo, Z. (2013). Race frameworks: A multidimensional theory of racism and education (multicultural education). New York, NY: Teachers College Press.

Leonardo, Z., \& Grubb, W.N. (2013). Education and racism: A primer on issues and dilemmas. New York, NY: Routledge.

López, G.R. (2001). "The Value of Hard Work: Lessons on Parent Involvement from an (Im)migrant Household."Harvard Educational Review, 71 (3), 416.

López, G.R., Scriber, J.D., \& Mahitivanichcha, K. (2001). Redefining parental involvement: Lessons from high-performing migrant-impacted schools. American Educational Research Journal, 38 (2), 253-288.

Lopez, M.A. (2010). Listening to undocumented Mexican mothers: The experiences of undocumented Mexican mothers of high school students living in the U.S. and receiving social services. (Doctoral dissertation).

Lopez, M.H., Gonzalez-Barrera, A., \& López, G. (2017, December 20). Hispanic identity fades across generations as immigrant connections fall away. Pew Research Center. Retrieved from http://www.pewhispanic.org/2017/12/20/hispanic-identity-fades-acrossgenerations-as-immigrant-connections-fall-away/ 
Marshcall, M. (2006). Parent involvement and educational outcomes for Latino students. Review of Policy Research, 23 (5), 1053-1075.

Marschall, M.J., Shah, P.R., \& Donato, K. (2012). Parent involvement policy established and new immigrant destinations. Social Science Quarterly, 93 (1), 130-151.

Martinez, E., \& Ulanoff, S.H. (2013). Latino parents and teachers: Key players building neighborhood social capital.

Martinez, M., \& Castillo, M. (2013, September 16). Hispanics show increasing cultural, economic and social diversity. CNN. Retrieved from http://www.cnn.com/2013/03/20/us/hispanics/index.html

Mattingly, D.J. Prislin, R., McKenzie, T.L., Rodriguez, J.L., \& Kayzar, B. (2002). Evaluating evaluations: The case of parent involvement programs. Review of Educational Research, 72, 549-576.

McCarthy, J. (2015, August 20). Immigrant status tied to discrimination among Hispanics. Gallup News. Retrieved from http://news.gallup.com/poll/184769/immigrantstatus-tied-discrimination-among-hispanics.aspx

McGlynn, A. P. (2009, Apr 20). "The condition of Latinos in education" excelencia looks at the data. The Hispanic Outlook in Higher Education, 19, 19-21. Retrieved from http://stats.lib.pdx.edu/proxy.php?url=http://search.proquest.com.proxy.lib.pdx.edu/docvi ew/219235331 accountid $=13265$

McGlynn, A. P. (2015, Jun 15). Recent data on latinos in higher education sets stage for more action. The Hispanic Outlook in Higher Education, 25, 20-22. Retrieved from http://stats.lib.pdx.edu/proxy.php?url=http://search.proquest.com.proxy.lib.pdx.edu/docvi ew/1694002814?accountid=13265

Meyers, B., Dowdy, J., \& Paterson, P. (2000). Finding the missing voices: Perspectives of the least visible families and their willingness and capacity for school involvement. Current Issues in Middle Level Education, 7 (2), 59-79.

Migration Policy Institute. (2018). Deferred Action for Childhood Arrivals (DACA) data tools

Retrieved from https://www.migrationpolicy.org/programs/data-hub/deferred-actionchildhood-arrivals-daca-profiles

Migration Policy Institute. (N.d.). Profile of the Unauthorized Population: United States. Retrieved from https://www.migrationpolicy.org/data/unauthorizedimmigrant-population/state/US 
Migration Policy Institute. (N.d.). Unauthorized Immigrant Population Profiles. Retrieved from http://www.migrationpolicy.org/programs/us-immigration-policyprogram-data-hub/unauthorized-immigrant-population-profiles

National Center for Public Policy and Higher Education. (2005). Income of U.S. workforce projected to decline if education doesn't improve. National Center for Public Policy and Higher Education Policy Alert. Retrieved from http://www.highereducation.org/reports/pa_decline/pa_decline.pdf

Oakes, J. (1985). Keeping track: How schools structure inequality. New Haven, CT: Yale University Press.

Okihiro, G. (2010). The future of ethnic studies: The field is under assault from without and within. The Chronicle of Higher Education, 7. Retrieved from https://chronicle.com/article/The-Future-of-Ethnic-Studies/66092/

Olivos, E.M. (2003). Dialectical tensions, contradictions and resistance: A study of the relationship between Latino parents and the public school system within a socioeconomic structure of dominance. Unpublished doctoral dissertation, San Diego State University/ Claremont Graduate University, San Diego/ Claremont, CA.

Olivos, E.M. (2004) Tensions, contradictions, and resistance: An activist's reflection of the struggles of Latino parents in the public school system. The High School Journal, 87 (4), 25-35.

Orcher, L. (2005) Conducting research: Social and behavioral science methods. Glendale, CA: Pyrczak Publishing.

Paasche-Orlow, M. (2004). The ethics of cultural competence. Academic Medicine, 79(4), 347-350.

Parks, C. (2016, September 15). Oregon's Latino population growing faster than the nationwide average. The Oregonian. Retrieved from http://www.oregonlive.com/pacificnorthwest-news/index.ssf/2016/09/oregons_latino_population_is_g.html

Penninx, R. (2001). Immigrants and the dynamics of social exclusion - Lessons for antidiscrimination policies. In: Flip Lindo and Mies van Niekerk, Dedication and Detachment. Essays in Honour of Hans Vermeulen (pp. 193-211). Amsterdam, Netherlands: Het Spinhuis.

Pon, G. (2009). Cultural competency as new racism: An ontology of forgetting. Journal of Progressive Human Services, 20, 59-71. 
Quiocho, A.M.L. \& Daoud, A.M. (2006, Spring). Dispelling myths about Latino parent participation in schools. The Educational Forum, 70, 255-267.

Quiocho, A., \& Rios, F. (2000) The power of their presence: Minority group teachers and schooling. Review of Educational Research, 70 (485), 485-528.

Ramos, K. (2012, June 1). What Arizona's ban on Ethnic Studies Says About America. Huffington Post Latino Voices. Retrieved from http://www.huffingtonpost.com/kristianramos/what-arizonas-ban-on-ethn_b_1557422.html

Ruffenach, C., Worcel, S., Keyes, D., \& Franco, R. (2016). Latinos in Oregon: Trends and opportunities in a changing state. The Oregon Community Foundation. Retrieved from https://www.oregoncf.org/Templates/media/files/reports/latinos_in_oregon_report_2016. pdf

Sakamoto, I. (2007). An anti-oppressive approach to cultural competence. Canadian Social Work Review, 24(1), 105-114.

Sanchez, S., Freeman, R., \& Martin, P. (2018). Stressed, overworked, and not sure whom to trust: The impacts of recent immigration enforcement on our public school educators. UCLA Civils Rights Project, 1-2. Retrieved from https://www.civilrightsproject.ucla.edu/research/k-12-education/immigration-immigrantstudents/stressed-overworked-and-not-sure-whom-to-trust-the-impacts-of-recentimmigration-enforcement-on-our-public-school-educators/summary-2_sanchez-freemanmartin_ImmigEnforcement.pdf

Scheppers, E., van Dongen, E., Dekker, J., Geertzen, J., \& Dekker, J. (2006). Potential barriers to the use of health services among ethnic minorities: A review. Family Practice, 23(3), 325-348.

Shockley, K. \& Frederick, R. (2010). Constructs and dimensions of Afrocentric education. Journal of Black Studies, 40(6), 1212-1233.

Semple, K. (2014, July 10). Immigrants who speak indigenous languages encounter isolation. New York Times. Retrieved from https://www.nytimes.com/2014/07/11/nyregion/immigrants-who-speak-indigenousmexican-languages-encounter-isolation.html

Shuang Ji, C., \& Koblinsky, S.A. (2009). Parent involvement in children education: An exploratory study of urban, Chinese immigrant families. Urban Education, 44 (687), 687709. 
Sleeter, C.E. (2011). The Academic and Social Value of Ethnic Studies: A Research Review. National Education Association Research Department. Retrieved from http://hin.nea.org/assets/docs/NBI-2010-3-value-of-ethnic-studies.pdf

Smith-Maddox, R., \& Solórzano, D.G. (2002). Using Critical Race Theory, Paulo Freire's problem-posing method, and case study research to confront race and racism in education. Qualitative Inquiry, 8 (1), 66-84.

Solórzano, D.G. (1992). An exploratory analysis of the effects of race, class, and gender on student and parent mobility aspirations. Journal of Negro Education, 61 (1), 30-44.

Solórzano, D.G., \& Delgado Bernal, D. (2001). Examining transformational resistance through a Critical Race and LatCrit Theory framework: Chicana and Chicano students in an urban context." Urban Education, 36 (3), p. 308-342.

Strier, R. \& Binyamin, S. (2014). Introducing anti-oppressive social work practices in public services: Rhetoric to practice. British Journal of Social Work, 44. 2095-2112.

Sue, D. (2010). Microaggressions in everyday life: Race, gender and sexual orientation. Hoboken, NJ: Wiley.

Taylor, P., Lopez, M.H., Martinez, J., \& Velasco, G. (2012). When labels don't fit: Hispanics and their views of identity. Pew Research Center. Retrieved from http://www.pewhispanic.org/2012/04/04/when-labels-dont-fit-hispanics-and-their-viewsof-identity/

Tillman, L.C. (2004). African American parental involvement in a post-Brown era: Facilitating the academic achievement of African American students. Journal of School Public Relations, 25, 161-176.

Undocumented students in California: What you should know. The Education Trust West. Retrieved from https://29v0kg31gs803wndhe1sj1hd-wpengine.netdna-ssl.com/wpcontent/uploads/sites/3/2015/11/ETW_CA-Undocumented-Students-What-You-Need-toKnow-FINAL-April-2017.pdf

Wang, H.L. (2014, July 1). Language barriers pose challenges for Mayan migrant children. National Public Radio. Retrieved from https://www.npr.org/sections/codeswitch/2014/07/01/326426927/language-barriers-posechallenges-for-mayan-migrant-children 
Wang, Y., Xie, G., \& Cui, X. (2016). Effects of emotional intelligence and selfleadership on students' coping with stress. Social Behavior and Personality: An International Journal, 44 (5), 853-864.

Valencia, R.R. \& Black, M.S. (2002). “Mexican Americans don't value education!” On the basis of the myth, mythmaking, and debunking. Journal of Latinos and Education, 1 (2), 81-103.

Yanow, W.B. (2011). Foundations of Critical Race Theory in education. Adult Education Quarterly, 61 (2), 198-204.

Yin, R. K. (2009). Case study research: Design and methods (4th Ed.). Thousand Oaks, CA: Sage.

Yosso, T.J. (2005). Whose culture has capital? A critical race theory discussion of community cultural wealth. Race, Ethnicity, and Education, 8 (1), 69-91.

Yow, V. (1994) Recording oral history: A practical guide for social scientists. Thousand Oaks, CA: Sage Publications.

Uttal, L. (2006). Organizational cultural competency: Shifting programs for Latino immigrants from a client-centered to a community-based orientation. American Journal of Community Psychology, 38, 251-262.

Young, I. (1990). Five faces of oppression. In Justice and the Politics of Difference (pp.39-65). Princeton: Princeton University Press.

Zong, J., \& Batalova, J. (2016, March). Mexican immigrants in the United States. Migration Policy Institute. Retrieved from http://www.migrationpolicy.org/article/mexican-immigrants-united-states

Zong, J., \& Batalova, J. (2016, March). South American immigrants in the United States. Migration Policy Institute. Retrieved from http://www.migrationpolicy.org/article/mexican-immigrants-united-states 
APPENDIX A: INFORMED CONSENT FORM (ENGLISH)

Learning from culturally specific programs and their impact on Latino parentengagement

\section{Introduction}

You are being asked to participate in a research study that is being done by Analucía Lopezrevoredo, who is the Principal Investigator and Roberto Orellana), from the Department of Social Work at Portland State University in Portland, Oregon. This research is studying the engagement of Spanish speaking Latino parents at Mission Education Center in San Francisco, CA.

You are being asked to participate in this study because you are a parent to a Mission Education Center student or you are an educator at Mission Education Center.

This form will explain the research study, and will also explain the possible risks as well as the possible benefits to you. We encourage you to talk with your family and friends before you decide to take part in this research study. If you have any questions, please ask one of the study investigators.

What will happen if I decide to participate?

If you agree to participate, the following things will happen:

- You will participate in a focus group. A focus group is group of people assembled to participate in a group discussion about a particular experience. In this case, it is a discussion about your experience engaging with your child's education. Focus groups will take 60 minutes and participation is fully voluntary.

- Upon completing your participation in the focus group, you will have the opportunity to participate in a one-on-one interview if you would like. one-on-one interviews take 30-60 minutes and participation is fully voluntary.

How long will I be in this study?

- Participation in a focus group will take 60 minutes

- Participation in a one-on-one interview will take 30-60 minutes

What are the risks or side effects of being in this study?

- Participation in this study poses minimal risk.

- This study may bring up feelings of social stigmatization due to being a language learner, and for this reason all focus groups and one-on-one interviews will be conducted in Spanish.

For more information about risks and discomforts, ask the investigator.

What are the benefits to being in this study?

- There are numerous benefits to participating in this study, such as giving you the opportunity to share your story and perspective in your native language. 
- Participating in this study could also lead us to better understand the needs of immigrant parents and as a result improve how the local and national education system supports immigrant parents.

How will my information be kept confidential?

- We will take as many measures possible to protect the security of all your personal information, but we cannot guarantee confidentiality of all study data.

- Focus groups and interviews will be audio recorded, and these records will be kept strictly confidential. All records will be kept in a locked file, and all electronic information will be coded and secured using a password-protected file that no one but the researcher has access to. After three years, these records will be destroyed.

- Participation in a focus group does not allow for the same level of confidentiality as other forms of research. The investigator can only be responsible for the confidentiality of the data collected by that investigator, and confidentiality may be breached by others in the focus group. As a participant in the focus group, you are encouraged not to speak of what was discussed during the group once the group has ended.

- We will not include your name or any information in any report we may publish that would make it possible to identify any participant.

Information contained in your study records will solely be used by study staff. The Portland State University Institutional Review Board (IRB) that oversees human subject research and/or other entities may be permitted to access your records, and there may be times when we are required by law to share your information. It is the investigator's legal obligation to report child abuse, child neglect, elder abuse, harm to self or others or any life-threatening situation to the appropriate authorities, and; therefore, your confidentiality will not be maintained.

Will I be paid for taking part in this study?

- You will not be paid for taking part in this study

Can I stop being in the study once I begin?

- Your participation in this study is completely voluntary. You have the right to choose not to participate or to withdraw your participation at any point in this study without penalty or loss of benefits to which you are otherwise entitled.

Whom can I call with questions or complaints about this study?

- If you have any questions, concerns or complaints at any time about the research study, you may call the PSU Office for Research Integrity at (503) 725-2227 or 1(877) 480-4400. The ORI is the office that supports the PSU Institutional Review Board (IRB). The IRB is a group of people from PSU and the community who provide independent oversight of safety and ethical issues related to research 
involving human participants. For more information, you may also access the IRB website at https://sites.google.com/a/pdx.edu/research/integrity.

Whom can I call with questions about my rights as a research participant?

- If you have questions regarding your rights as a research participant, you may call the PSU Office for Research Integrity at (503) $725-2227$ or 1(877) $480-4400$. The ORI is the office that supports the PSU Institutional Review Board (IRB). The IRB is a group of people from PSU and the community who provide independent oversight of safety and ethical issues related to research involving human participants. For more information, you may also access the IRB website at https://sites.google.com/a/pdx.edu/research/integrity.

\section{CONSENT}

You are making a decision whether to participate in this study. Your signature below indicates that you have read the information provided (or the information was read to you). By signing this consent form, you are not waiving any of your legal rights as a research participant.

You have had an opportunity to ask questions and all questions have been answered to your satisfaction. By signing this consent form, you agree to participate in this study. A copy of this consent form will be provided to you.

Name of Adult Subject (print) Signature of Adult Subject Date

\section{INVESTIGATOR SIGNATURE}

This research study has been explained to the participant and all of his/her questions have been answered. The participant understands the information described in this consent form and freely consents to participate.

Name of Investigator/ Research Team Member (type or print)

(Signature of Investigator/ Research Team Member) Date 


\section{APPENDIX B: INFORMED CONSENT FORM (SPANISH)}

\section{Learning from culturally specific programs and their impact on Latino parent- engagement}

\section{Introducción}

Se le está pidiendo que participe en un estudio de investigación realizado por Analucía Lopezrevoredo, investigadora principal, y Roberto Orellana, del Departamento de Trabajo Social de Portland State University en Portland, Oregón. Esta investigación está estudiando el compromiso de padres Latino de habla hispana en Mission Education Center en San Francisco, CA.

Se le ha pedido que participe en este estudio porque usted es padre de un alumno matriculado en Mission Education Center.

Este formulario explicará el estudio de investigación y también le explicará los posibles riesgos y los posibles beneficios para usted. Le recomendamos que hable con su familia y amigos antes de decidirse a participar en este estudio de investigación. Si tiene alguna pregunta, consulte a uno de los investigadores del estudio.

¿Qué pasará si decido participar?

Si acepta participar, sucederán las siguientes cosas:

- Usted participará en un grupo de enfoque. Un grupo de enfoque es un grupo de personas reunidas para participar en una discusión grupal sobre una experiencia particular. En este caso, es una discusión sobre su experiencia relacionada con la educación de su hijo. Los grupos de enfoque tomarán 60 minutos y la participación es completamente voluntaria.

- Al completar su participación en el grupo de enfoque, tendrá la oportunidad de participar en una entrevista one-on-one si lo desea. Las entrevistas 1: 1 tardan de 30 a 60 minutos y la participación es completamente voluntaria.

¿Cuánto tiempo estaré en este estudio?

- La participación en un grupo de enfoque tomará 60 minutos.

- La participación en una entrevista 1: 1 llevará de 30 a 60 minutos

¿Cuáles son los riesgos o efectos secundarios de estar en este estudio?

- La participación en este estudio presenta un riesgo mínimo.

- Este estudio puede traer sentimientos de estigmatización social debido a que es un estudiante que aprende idiomas, y por esta razón todos los grupos focales y entrevistas 1: 1 se llevarán a cabo en español. 
Para obtener más información acerca de los riesgos y las incomodidades, pregúntele al investigador.

¿Cuáles son los beneficios de estar en este estudio?

- Existen numerosos beneficios al participar en este estudio, como brindarle la oportunidad de compartir su historia y perspectiva en su idioma nativo.

- La participación en este estudio también podría llevarnos a comprender mejor las necesidades de los padres inmigrantes y, en consecuencia, mejorar la forma en que el sistema educativo local y nacional apoya a los padres inmigrantes.

¿Cómo se mantendrá mi información confidencial?

- Tomaremos todas las medidas posibles para proteger la seguridad de toda su información personal, pero no podemos garantizar la confidencialidad de todos los datos del estudio.

- Los grupos focales y las entrevistas se grabarán en audio, y estos registros se mantendrán estrictamente confidenciales. Todos los registros se mantendrán en un archivo bloqueado, y toda la información electrónica se codificará y se asegurará mediante un archivo protegido por contraseña al que solo el investigador tiene acceso. Después de tres años, estos registros serán destruidos.

- La participación en un grupo focal no permite el mismo nivel de confidencialidad que otras formas de investigación. El investigador solo puede ser responsable de la confidencialidad de los datos recopilados por ese investigador, y la confidencialidad puede ser violada por otros en el grupo de enfoque. Como participante en el grupo de enfoque, se le anima a no hablar de lo que se discutió durante el grupo una vez que el grupo haya terminado.

- No incluiremos su nombre ni ninguna información en ningún informe que podamos publicar que permita identificar a ningún participante.

La información contenida en los registros de este estudio será utilizada únicamente por el personal del estudio. La Junta de Revisión Institucional/ Internal Review Board (IRB) de Portland State University que supervisa la investigación de sujetos humanos y / u otras entidades puede tener permiso para acceder a sus registros, y puede haber ocasiones en que la ley nos obligue a compartir su información. Es la obligación legal del investigador de denunciar a las autoridades competentes el abuso infantil, el abandono infantil, el maltrato a personas mayores, el daño a sí mismo o a otras personas o cualquier situación que pone en peligro la vida; por lo tanto, su confidencialidad no se mantendrá.

¿Me pagarán por participar en este estudio?

- No se le pagará por participar en este estudio

¿Puedo dejar de participar en el estudio una vez que empiece? 
- Su participación en este estudio es completamente voluntaria. Tiene derecho a elegir no participar o retirar su participación en cualquier momento de este estudio sin penalización o pérdida de beneficios a los que de otra manera tenga derecho.

¿A quién puedo llamar si tengo preguntas o quejas sobre este estudio?

- Si tiene preguntas, inquietudes o quejas en cualquier momento sobre el estudio de investigación, puede llamar a la Oficina de Integridad de Investigación de PSU al (503) 725-2227 o al 1 (877) 480-4400. El OIIP es la oficina que apoya a la Junta de Revisión Institucional/ Internal Review Board (IRB) de PSU. El IRB es un grupo de personas de PSU y la comunidad que proporcionan supervisión independiente de seguridad y cuestiones éticas relacionadas con la investigación que involucra a participantes humanos. Para obtener más información, también puede acceder al sitio web de IRB en https://sites.google.com/a/pdx.edu/research/integrity.

¿A quién puedo llamar si tengo preguntas sobre mis derechos como participante en la investigación?

- Si tiene preguntas sobre sus derechos como participante en la investigación, puede llamar a la Oficina de Integridad de la Investigación de PSU al (503) 725-2227 o al 1 (877) 480-4400. El OIIP es la oficina que apoya a la Junta de Revisión Institucional/ Internal Review Board (IRB) de PSU. El IRB es un grupo de personas de PSU y la comunidad que proporcionan supervisión independiente de seguridad y cuestiones éticas relacionadas con la investigación que involucra a participantes humanos. Para obtener más información, también puede acceder al sitio web de IRB en https://sites.google.com/a/pdx.edu/research/integrity.

\section{CONSENTIMIENTO}

Usted está tomando la decisión de participar en este estudio. Su firma a continuación indica que ha leído la información provista (o le han leído la información). Al firmar este formulario de consentimiento, no renuncia a ninguno de sus derechos legales como participante en la investigación. Ha tenido la oportunidad de hacer preguntas y todas las preguntas han sido contestadas a su entera satisfacción. Al firmar este formulario de consentimiento, acepta participar en este estudio. Se le proporcionará una copia de este formulario de consentimiento.

Nombre del participante (imprima) Firma del participante

Fecha

\section{FIRMA DEL INVESTIGADOR}

Este estudio de investigación ha sido explicado al participante y todas sus preguntas han sido respondidas. El participante entiende la información descrita en este formulario de consentimiento y acepta libremente participar. 
Nombre del Investigador/a

(Firma del Investigator/a)

Fecha 


\section{APPENDIX C: DEMOGRAPHICS QUESTIONNAIRE (ENGLISH)}

1. Gender: F $\mathrm{M}$

2. What is your relation to a student attending MEC? I am a... (Circle one)

a) Parent/Step-Parent

b) Grandparent

c) Sibling

d) Cousin or Aunt

e) Other (please explain)

3. Which of these terms best describe your national identity(ies)?
a) Argentinian
b) Bolivian
c) Chilean
d) Colombian
e) Costa Rican
f) Cuban
g) Dominican
h) Ecuadorian
i) Salvadorian
j) Guatemalan
k) Honduran
1) Mexican
m) Nicaraguan
n) Panamanian
o) Paraguayan
p) Peruvian
q) Puerto Rican
r) Uruguayan
s) Venezuelan
t) Other (please describe)

4. What best describes your length of time in the United States? (Circle one)
a) Less than 1 year
b) 2-3 years
c) $4-5$ years
d) 6-10 years
e) $10+$ years

5. What is your current marital status? (Circle one)

a) Single, never married

b) Partnered 

c) Separated
d) Divorced
e) Widowed

6. How many children do you have? (Circle one)
a) 1
b) 2
c) 3
d) 4 or more

7. What languages are spoken in your home?
a) English
b) Spanish
c) Other:

8. How comfortable do you feel physically being at MEC?
a) Very comfortable
b) Comfortable
c) Somewhat comfortable
d) Neither comfortable or uncomfortable
e) Somewhat uncomfortable
f) Uncomfortable
g) Very uncomfortable

9. How comfortable do you feel speaking/asking questions to an educator at MEC?
a) Very comfortable
b) Comfortable
c) Somewhat comfortable
d) Neither comfortable or uncomfortable
e) Somewhat uncomfortable
f) Uncomfortable
g) Very uncomfortable

10. How often do you and/or a family member attend school activities?
a) Weekly
b) A couple of times per month
c) About once a month
d) 3-5 times per year
e) About twice a year
f) About once a year
g) Never

11. Please circle however many descriptions identify your experience: 
a) I am struggling to adapt to my new enviornment

b) I am struggling to understand what is expected of me at school

c) I enjoy participating in school functions

d) I enjoy learning at school functions

e) I am interested in becoming a parent-leader at school or the community

f) I consider myself a leader in my community 


\section{APPENDIX D: DEMOGRAPHICS QUESTIONNAIRE (SPANISH)}

1. Sexo: $F$ M

2. ¿Cuál es su relación a la escuela? Soy un... (Circle one)

a) Padre

b) Abuelo

c) Heramano

d) Primo

e) Otro (por favor explique)

3. ¿Cuál de estos términos describe major su identidad nacional?

a) Argentino

b) Boliviano

c) Chileno

d) Colombiano

e) Costariccence

f) Cubano

g) Dominicano

h) Ecuatoriano

i) Salvadoreño

j) Guatemalteco

k) Hondureño

1) Mexicano

m) Nicaraguence

n) Panameño

o) Paraguayo

p) Peruano

q) Puerto Riqueño

r) Uruguayo

s) Venezolano

t) Otro (por favor describa)

4. ¿Cuanto tiempo a vivio en los estados unidos?
a) Menos de 1 año
b) 2-3 años
c) 4-5 años
d) 6-10 años
e) $10+$ años

5. ¿Cuál es su estado civil?

a) Soltero

b) Casado 

c) Separado
d) Divorciado
e) Viudo

6. ¿Cuatos hijos tiene?
a) 1
b) 2
c) 3
d) $4+$

7. ¿Cuáles idiomas habla en casa?
a) Inglés
b) Español
c) Otro:

8. ¿Que nivel de comodidad tiene cuando está fisicamente en la escuela MEC?
a) Muy comodo
b) Comodo
c) Medio comodo
d) Ni comodo, ni incomodo
e) Medio incomodo
f) Incomodo
g) Muy incomodo

9. ¿Que nivel de comodiad tiene haciendole preguntas a los maestros de MEC?
a) Muy comodo
b) Comodo
c) Medio comodo
d) Ni comodo, ni incomodo
e) Medio incomodo
f) Incomodo
g) Muy incomodo

10. ¿Con qué frecuencia asiste usted a las actividades escolares?
a) Semanal
b) Un par de veces al mes
c) Una vez por mes
d) 3-5 veces al año
e) Dos veces al año
f) Una vez al año
g) Nunca

11. Por favor circule las descripciones que identifiquen su experiencia: 
a) Estoy luchando para adaptarme a mi nuevo hogar

b) Estoy luchando para saber lo que se espera de mi en las escuela

c) Disfruto participar en las funciones de la escuela

d) Disfruto aprender en las funciones de la escuela

e) Estoy interesado en ser un lider en la escuela o comunidad

f) Me siento como un lider en mi comunidad 


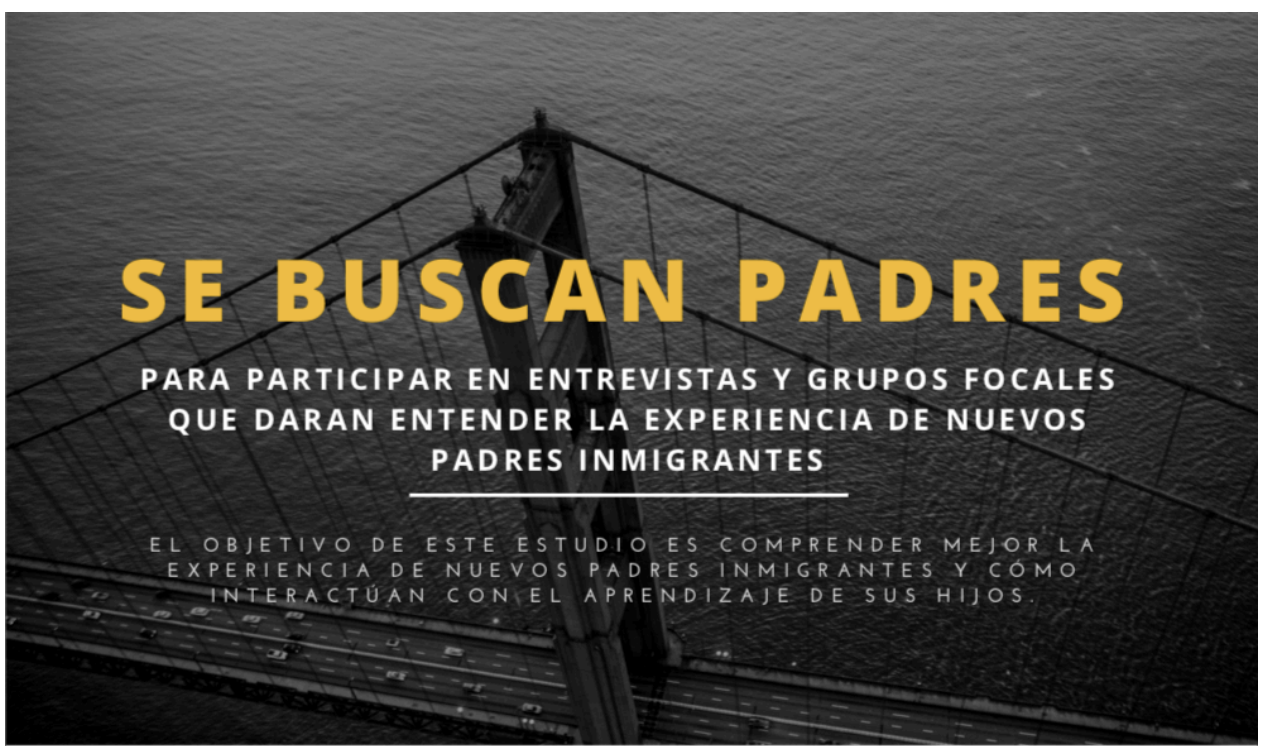

PÓNGASE EN CONTACTO CON NOSOTROS SI ESTÁ INTERESADO, O TIENE CUALQUIER PREGUNTA: ADELINA DUNCAN ALDANA, FAMILY LIAISON-DUNCANALDANAA@SFUSD.EDU

TOdOS LOS PARTICIPANTES SERÁN ELEGIBLES PARA PARTICIPAR EN UNA RIFA PARA RECIBIR UNA TARJETA DE REGALO. 